Florida International University FIU Digital Commons

4-4-1995

\title{
Utilization of needs assessments by decision makers : a comparative analysis of assessment methods
}

Eleanor R. Penn Blyden

Florida International University

DOI: $10.25148 /$ etd.FI14051174

Follow this and additional works at: https://digitalcommons.fiu.edu/etd

Part of the Public Affairs, Public Policy and Public Administration Commons

\section{Recommended Citation}

Blyden, Eleanor R. Penn, "Utilization of needs assessments by decision makers : a comparative analysis of assessment methods" (1995). FIU Electronic Theses and Dissertations. 1715.

https://digitalcommons.fiu.edu/etd/1715 
FLORIDA INTERNATIONAL UNIVERSITY

Miami, Florida

UTILIZATION OF NEEDS ASSESSMENTS BY

DECISION MAKERS: A COMPARATIVE

ANALYSIS OF ASSESSMENT METHODS

A dissertation submitted in partial satisfaction of the requirements for the degree

DOCTOR OF PHILOSOPHY

IN

PUBLIC ADMINISTRATION

by

Eleanor R. Penn Blyden 
To: Dean Mark B. Rosenberg

College of Urban and Public Affairs

This dissertation, written by Eleanor R. Penn Blyden, and entitled Utilization of Needs Assessments by Decision Makers: A Comparative Analysis of Assessment Methods, having been approved in respect to style and intellectual content, is referred to you for judgement.

We have read this dissertation and recommend that it be approved.

\begin{tabular}{l}
\hline Ralph G. Lewis \\
\hline James Carroll \\
\hline Milan J. Dluhy, Major Professor
\end{tabular}

Date of Defense: Tuesday, April 4, 1995

The dissertation of Eleanor R. Penn Blyden is approved:

Dean Mark B. Rosenberg

College of Urban \& Public Affairs

Dr. Richard L. Campbell

Dean of Graduate Studies

Florida International University, 1995 
COPYRIGHT 1995 by Eleanor R. Penn Blyden

All rights reserved 
I dedicate this dissertation to both my mother, Esterline Penn Parrilla, and my husband, Ronald A. Blyden Sr. Without my mother's enduring love, faith, and support, and my husband's patience, understanding, and especially love, the completion of this work would not have been a reality. 
I am indebted to many people for their direct or indirect contributions to the completion of this dissertation. My gratitude goes especially to my dissertation committee chair, Dr. Milan J. Dluhy, whose keen interest, guidance, and support made this achievement a reality. Sincere thanks also go to the other members of my committee Dr. Ralph Lewis, for his invaluable assistance in laying the theoretical foundation for my study and for his insightful comments, and Dr. James Carroll, for his steadfast support and guidance.

I am also also appreciative of Dr. Dolores Brosnan, who became my mentor early in my doctoral studies; Dr. Howard Frank who introduced me to a new world of research; the late Dr. Steve Loveless, whose assistance and friendship I'll always cherish; my colleagues and friends Dr. Dorothy Norris-Tirrell, Ms. Denice Rothman, Dr. Keitha Lawrence, Mrs. Valarie Patterson, and Mr. Walter Dunajick, who provided the inspiration and comradeship to keep me on track; and Mrs. Lorraine Greene, Mrs. Terry Malonry Bini and Ms. Jennifer Davis, who willingly provided assistance and support.

I am enormously indebted to Senator Earle B. Ottley for his unfaltering faith and support; Dr. Harold Lutchman of the University of the Virgin Islands who aroused and guided my interest in pursuing a Ph.D.; former Commissioner of Human 
Services Mrs. Juel T. R. Molloy for providing the inspiration and support for this type of research; Mr. Moleto Smith Jr. for his unfailing assistance, support, and encouragement; Mrs. Marcilline Williams Smith for willingly and unselfishly sharing of her time and computer skills; the Department of Human Services staff, especially Ms. Natalie Thomas, for their assistance and understanding; Dr. Ruth Beagles, Mrs. Marita Wells, Mrs. Marjorie Carabal1o, and Mr. Vernon Finch, for impressing on me what friends are for: and participants in the study for their willing cooperation.

The love and support of my family provided me with the courage to persevere. I am deeply grateful to my mother, Mrs. Esterline Penn Parrilla, my sisters, Mrs. E. Maria Leerdam, Ms. Leona Penn, Ms. Doris Penn, Mrs. Rita Harris, Mrs. Francine PennScipio, and Mrs. Emma Lockhart, and their families; my other relatives, especially my aunt, Mrs. Edris Jackson, and my cousin Mrs. Florence Chinnery and their families, for providing those essential ingredients.

I am immensely grateful to my husband Mr. Ronald "Slimo" Blyden for his unfaltering love, understanding, support, and patience throughout my studies; my children Ms. La Verne C. Blyden and Mr. Ronald A. Blyden Jr., and my grandson, LaMont Joseph for their constant love and faith in me; and to the Almighty God, who stayed with me throughout the process.

Thank you all. 


\begin{abstract}
OF THE DISSERTATION
UTILIZATION OF NEEDS ASSESSMENTS BY DECISION MAKERS:
\end{abstract}

A COMPARATIVE ANALYSIS OF ASSESSMENT METHODS

by

Eleanor R. Penn Blyden

Florida International University, 1995

Professor Milan J. Dluhy, Major Professor

The major purpose of this study was to ascertain how needs assessment findings and methodologies are accepted by public decision makers in the U. S. Virgin Islands. To accomplish this, the following five different needs assessments were executed: (1) population survey; (2) key informants survey; (3) community forum; (4) rates-under-treatment (RUT); and (5) social indicators analysis. The assessments measured unmet needs of older persons regarding transportation, in-home care, and sociorecreation services, and determined which of the five methodologies is most costly, time consuming, and valid. The results of a five-way comparative analysis was presented to public sector decision makers who were surveyed to determine whether they are influenced more by needs assessment findings, or 
by the methodology used, and to ascertain the factors that lead to their acceptance of needs assessment findings and methodologies.

The survey results revealed that acceptance of findings and methodology is influenced by the congruency of the findings with decision makers' goals and objectives, feasibility of the findings, and credibility of the researcher.

The study also found that decision makers are influenced equally by needs assessment findings and methodology; that they prefer population surveys, although they are the most expensive and time consuming of the methodologies; that different types of needs assessments produce different results; and, that needs assessment is an essential program planning tool. Executive decision makers are found to be influenced more by management factors than by legal and political factors, while legislative decision makers are influenced more by legal factors. Decision makers overwhelmingly view their leadership style as democratic.

A typology of the five needs assessments, highlighting their strengths and weaknesses, is offered as a planning guide for public decision makers. 
TABLE OF CONTENTS

CHAPTER

PAGE

I. INTRODUCTION $\ldots \ldots \ldots \ldots \ldots \ldots \ldots \ldots \ldots \ldots \ldots \ldots \ldots \ldots \ldots$

II. LITERATURE REVIEW. .....................

Importance of Needs Assessment............16

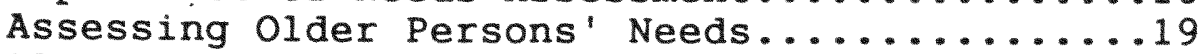

Alternative Needs Assessment Techniques......21

Methodologies Used in Study..............22

Social Science Research and Decision Making...40

III. OBJECTIVES OF THE STUDY

Research Questions.................45

Definition of Needs Assessment...........46

Definition of Other Key Terms..............53

IV. METHODOLOGY

Setting of the study.................... 55

Target Population.................. 57

Methodology of the Population Survey.......660

Methodology of the Key Informants Survey.....80

Methodology of Community Forum............90

Methodology of Rates-under-treatment........99

Methodology of Social Indicators Analysis....110

IV. COMPARATIVE ANALYSIS OF THE FIVE NEEDS

ASSESSMENT TECHNIQUES

Research Question No. $1 \ldots \ldots \ldots \ldots \ldots \ldots 124$

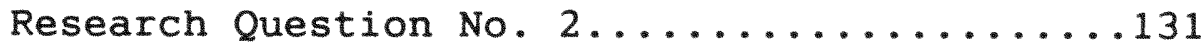

Research Question No. $3 \ldots \ldots \ldots \ldots \ldots \ldots \ldots \ldots \ldots 134$

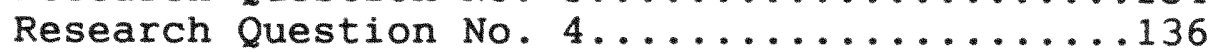

VI. NEEDS ASSESSMENT AND POLICY MAKING IN

THE PUBLIC SECTOR

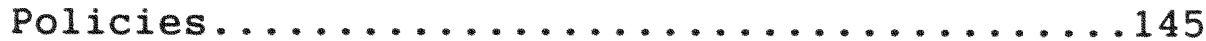

The Nature of Decision Making............146

The Decision Making Process...............151

Linking Needs Assessment to Policy Making....153

Methodology of the Decision Makers Survey....157

Research Question No. $5 \ldots \ldots \ldots \ldots \ldots \ldots \ldots 171$

Research question No. $6 \ldots \ldots \ldots \ldots \ldots \ldots 18 \ldots \ldots \ldots$

Acceptance as a Linking Factor............182 
VII. CONCLUSION

Summary of the Study..................193

Implications for Public Administration

and Policy Research.....................

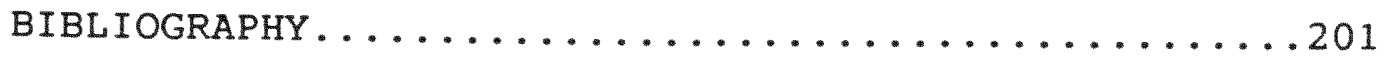

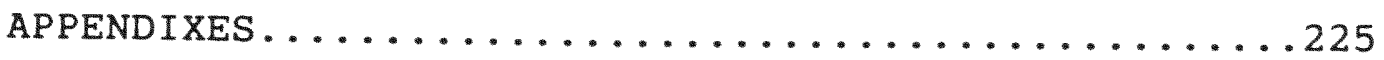


1. 4.1 Ethnic Composition of the U.S. Virgin Islands..................... 56

2. $4.260+$ Population of the U. S. Virgin Islands...58

3. 4.3 Composition of Older Population - U. S. Virgin Islands.................... 59

4. 4.4 Distribution of Older Persons

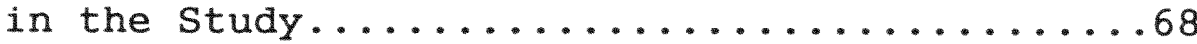

5. 4.5 Select Characteristics of Survey Population...69

6. 4.6 Transportation Characteristics of Older

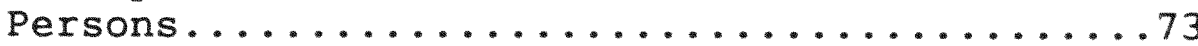

7. 4.7 In-Home Care Characteristics of Older Persons..........................

8. 4.8 Socio-Recreation Characteristics of older Persons.....................

9. 4.9 Comparison of Respondents' Satisfaction that Overall Needs in the Three Areas

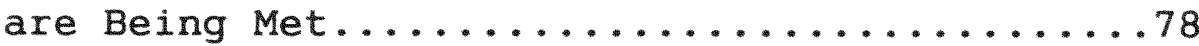

10. 4.10 Characteristics of Key Informants.........86

11. 4.11 Comparison of Older Persons' Satisfaction that Their Overall Needs are Being Met as Perceived by Key Informants...........89

12. 4.12 Characteristics of Attendees at Community Forums................... 96

13. 4.13 Most Serious Problems Facing Elderly........98

14. 4.14 Most Recommended Services for Older People....98

15. 4.15 Use Rate for Transportation, In-Home Care, \& Socio-Recreation Services for Older Persons in the U. S. Virgin Islands........104 
16. 4.16 Ranking of Service Use for Two Consecutive Fiscal Years................105

17. 4.17 Client Population Service Use Trend According to Programs................ 106

18. 4.18 Ranking of Need Areas According to Social Indicators Analysis.............115

19. 4.19 Select Social and Economic Characteristics of the U. S. Virgin Islands..............117

20. 5.1 Ranking of Unmet Needs of Older Persons According to Techniques................. 125

21. 5.2 Most Serious Problems Facing Older Persons: A Comparison of Survey \& Community Forum.....127

22. 5.3 Unmet Needs of Older Persons: A Comparison of Survey, Community Forum, \& Key Informants.129

23. 5.4 Categories of Need Produced by the Five Different Methodologies...............131

24. 5.5 Summary of Cost with Comparative Totals

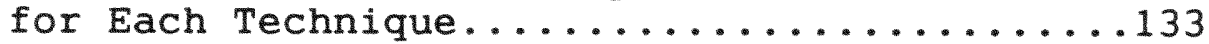

25. 5.6 Summary of Time with Comparative Totals

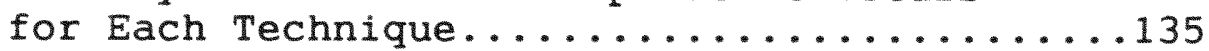

26. 5.7 Ranking of Cost, Time, and Validity Factors..140

27. 6.1 Demography of Decision Makers............. 163

28. 6.2 Job Related Characteristics............ 165

29. 6.3 Increase of the Elderly Population - U. S. Virgin Islands and United States..........169

30. 6.4 Age Distribution of the Elderly PopulationVirgin Islands and United States..........169

31. 6.5 Influence of Needs Assessment Methodology



32. 6.6 Influence of Decision Makers by Findings and Methodology of Needs Assessment........175 
33. 6.7 Factors that Influence Executive and Legislative Decision Makers in Making

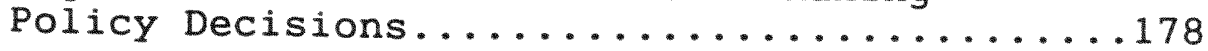

34. 6.8 Decision Makers' Acceptance of Needs Assessment Methodology and Findings........182 


\section{CHAPTER I}

\section{INTRODUCTION}

\section{BACKGROUND OF THE PROBLEM}

\section{Overview}

In public policy making, decisions on what types of service to provide, to whom, when, where, and by whom, are made according to the expressed or implied needs for such services. Decision makers formally, or informally, identify these needs by utilizing one or more of a variety of types of needs assessment. A needs assessment is useful for identifying who the clients are, the services they require, their locations, and their service needs priorities (Morgan \& Hiltner, 1992). It is also instrumental in assisting organizations in the establishment of their goals and objectives. A needs assessment is recognized not only as a critical factor in planning for service delivery, but very often as the initial element that policy makers must consider when making decisions regarding the allocation of resources (Goldsmith et al., 1992).

Techniques for performing needs assessment range from crude and unsophisticated methods, such as approaching persons on the street and inquiring about their needs or problems, to complicated efforts using advanced communication and research technologies (United Way, 1982). Researchers and decision makers in social service planning systems and organizations accept the 
importance of carrying out a needs assessment and using the results as the basis for planning new service programs or for restructuring existing ones. Whether the planning is long-or short-range, needs assessment is an integral step in this process (Morgan \& Hiltner, 1992). With the increasing acceptance of the concept of needs assessment has emerged a parallel growth in the variety and complexity of methodologies for carrying it out.

Even a cursory look at the needs assessment literature reveals that several techniques are used in the applied social science field today (Lareau, 1983; Warheit et a1., 1983; Siegel et a1., 1987; Maddock et al., 1988; Balacki, 1988; Vosburgh et al., 1990; De Villaer, 1990; Martin, 1990; Goldsmith et al.. 1992; Carsjo et al., 1994). (See page 21 for 1 isting of techniques). Operationally, these techniques differ considerably. They vary in cost, time requirement, validity, comprehensiveness, complexity, type of information received, and relative effectiveness (Maddock et al., 1988; Harlow \& Turner, 1993). Conceptually, they collectively offer different information about needs to form a comprehensive assessment or they are administered independently of each other as different and separate types of assessments.

The general consensus of experts in the field is that a combination of at least two techniques (Beaux, 1984; Cagle, 1984; Sonnichsen, 1989; Harlow \& Turner, 1993), but preferably multiple approaches, are necessary to provide a comprehensive needs 
assessment (Dluhy \& Hunt, 1988), while simultaneously minimizing the weaknesses in each technique (Royse \& Drude, 1982; Zautra et al.,1983; Gilmore et al.,1989; Morgan \& Hiltner, 1992).

Once a needs assessment is completed, the exercise can be considered futile if the knowledge acquired is not utilized by decision makers. Consequently, the principal question for researchers in public administration is what factors facilitate the use of needs assessment information by decision makers. This study suggests that a critical element in the utilization of the information is decision makers' acceptance of the methodology used and the results obtained by the needs assessment.

\section{Purpose of the Study}

The purpose of this study is four-fold: 1) to determine which of five needs assessment methodologies used in this study best measure the unmet needs of older persons in the areas of transportation, in-home care, and socio-recreation services; 2) to measure the methodologies in terms of cost and time involved in performing the studies, and the validity of each technique; 3 ) to ascertain how public sector decision makers are influenced by the findings of needs assessment and by the methodology utilized; 4) to ascertain the acceptability of the findings of the five needs assessment methodologies by decision makers; and the major factors that influence them to accept those findings.

The techniques used in the study are as follows: (1) survey of the 60+ population; (2) key informants survey; (3) community 
forum; (4) rates-under-treatment (RUT); and (5) social indicators analysis. These techniques were chosen for this study because each employs a different method of data collection, extracts information from a different segment of the study population, and, most importantly, is recognized throughout the needs assessment literature as useful for extrapolating different types of needs (Morgan \& Hiltner, 1992). These five basic techniques comprise the main elements of the majority of needs assessment techniques in use throughout social research (Maddock et al., 1988).

The population survey is based on the collection of data from a sample or an entire population of a community (Balacki, 1988; Tanur, 1994). Its assumption is that community needs can be projected by communicating with a representative group of people rather than communicating with the entire population directly.

The key informants survey is a technique for collecting information regarding a particular social situation by talking to a selected number of persons in the community who are viewed as "experts" on the subject area. The assumption of this technique is that certain individuals, on the basis of their personal or professional characteristics and experiences, possess knowledge of certain needs in a community.

The community forum technique consists of meetings that are open to all members of the community. These meetings aim at evoking concerns or views on the needs of the community's 
population. The idea of these meetings is to elicit as many concerns as possible on the topic (Balacki, 1988). The assumption is that persons within a general population of a community can express the needs of those who live within the community.

The rates-under-treatment (RUT) approach, also referred to as use analysis (McKillip, 1987) or client utilization technique (Murrell, 1983), analyzes data on current service usage for the purpose of estimating need. In the most basic descriptive sense, these data report numbers and characteristics of people who use the services (Ciarlo, 1992). This technique assumes that the needs of a population can be estimated from a sample of persons who receive care or treatment.

The social indicators analysis is based primarily on inferences of need drawn from descriptive statistics found in public records and reports. These indicators can be used as a baseline for measuring social trends (Martin, 1990). This approach assumes that it is possible to make useful estimates of the needs of a community by analyzing statistics on selected factors that have been found to be correlated highly with persons in need. It further assumes that the inferences are reliable and reflect true need.

In this study, the assessments place special concern on three need areas of the elderly: transportation, in-home care, and socio-recreation services. Transportation is a means of conveyance or travel that helps people to get around (Sheehan, 
1992). It links older persons to community services by allowing for travel to and from service providers and numerous other community activities. Without transportation, virtually no other service for older persons is attainable (Krout, 1994). The result is a lack of social interaction and community involvement for the older population (Gillespie \& Sloan, 1990).

In-home care spans a wide range of support activities designed to assist older persons to live independently in a home environment. These services, which are provided to the elderly in their homes, range from skilled nursing services, to homemaker, home maintenance, and chore services, such as light housekeeping, errands, shopping, meal preparation, laundry services, and a variety of other activities oriented toward daily tasks (Sheehan, 1992; Redford \& Severns, 1994).. These services may be dispensed directly through public programs, or by individual providers or volunteers (Lesemann \& Martin, 1993).

Socio-recreation services refer to activities that may be provided through planned programs that include arts and crafts, games, dancing, concerts, exercise classes, and other special events. Typically, these programs are provided by multiservice senior centers that allow older persons to participate in social activities as well as have access to essential services in the community (Lowry \& Doolin, 1990). The number and variety of activities depend on the service philosophy of the agency's goals and objectives (Cornwell \& Speltz, 1991). 
The reasons for selecting transportation, in-home services, and socio-recreation are five-fold:

1. They are among the major areas of concern referred to in the Iiterature (Lowry, 1985; Schauer, 1994).

2. They collectively facilitate continued independence, an attribute that is strongly valued in American society (Zedlewski, 1989; Cox \& Parsons, 1994), and they also contribute to the physical, emotional, and mental well-being of older adults.

3. They are areas for which public intervention may be attainable through social service programs (Logan \& Spitze, 1994)

4. They have the potential of being measured, to some degree, by a number of different methodologies.

5. The three need areas are interrelated (Sheehan,1992).

There are several other issues faced by today's elderly that were not selected for this study. For example, there is no question that health care is an area of much concern for the elderly (Stoller \& Pollow, 1994). The growing number of elderly, especially in the middle-old and older ranges, the increase in demand for a variety of health care services, the escalating cost for the services, and the questionable quality of such care, are issues of great concern in our society (Cox \& Parsons, 1994). However, to gather data to identify need and to design appropriate service interventions is difficult (Dunkle \& Kart, 1990). 
Older persons are reluctant to admit heal th care need and may even deny using services (Moen, 1978) while many lack the knowledge about the services offered (Silverstone, 1984). Others who have some information may not be able to match need to service, and therefore, may not be inclined to use these services. Because health care covers a wide range of services and resources, and considering the difficulty in assessing the health needs of the elderly, it is unlikely that the unmet needs in this area can be assessed adequately in a multi-dimensional need assessment.

Housing for the elderly is another area of concern. The importance of adequate housing for the older people in our society cannot be overstated. About $95 \%$ of persons nationwide 60 years of age or older live in non-institutional settings (A11, 1994), and their needs are noticeably different from those of other community populations.

Nonetheless, housing need for the elderly is so diverse, that such need must be considered in the context of both hard services and social networks. To analyze housing need effectively, a researcher needs to consider the older persons' household composition, housing tenure, and housing quality. So involved is this type of assessment that theoretical models, such as the Lawton/Nahemow adaptation model, are being used for this purpose. As in the case of health care, the assessment of housing need may not produce adequate results if it is coupled with other major need areas. 
Yet another area that merits research is that of elder abuse. The increase in the number of elderly in our population has created a great potential for abuse of this group of people. So grave has the problem become that elder abuse is thought of as only slightly less common than child abuse (A11, 1994). It is believed that almost four percent of the U. S. elderly are victims of physical, emotional, or financial abuse (01son, 1994).

The issue of elder abuse was not selected, however, because of the invisibility and unreporting of the problem. In emphasizing the problem of elder abuse, Kosberg (1988; 1990) states that the problem is invisible because it takes place out of sight in private homes and is perceived as a family affair. Further, the abused victims very seldom report this problem, and not many professionals who are required to report suspected cases do so. Additionally, elder abuse was not selected for this study because of the methodological difficulties in its assessment, as experienced by Johnson (1986).

The subjects for the study are the older population in the U. S. Virgin Islands. According to the $1990 \mathrm{U}$. S. Census, there are 9,659 persons 60 years of age or older in the Territory. Two hundred persons were randomly selected from the current telephone directory. The desired confidence level was $95 \%$, with a .05 margin of error. The questionnaire was constructed to cover the three need areas of importance for the study and to address the relevant issues. 
Questionnaires were utilized also for the key informants survey and the community forum. For the social indicators and rates-under-treatment techniques, the data were recorded on worksheets. These data were used to answer the first four research questions, and were presented to public decision makers in a one-page summary indicating the outcome of the comparison of the methodologies. This comparative information was used as the base for face-to-face interviews with the decision makers, as they were interviewed concerning the findings and methodologies of needs assessment. Their opinions were sought on the factors that influence their acceptance of needs assessment research. The other two research questions were answered by the decision makers survey. The statistical methodology for the study was essentially that of descriptive statistics.

\section{RATIONALE OF THE STUDY}

On a daily basis, public decision makers throughout the nation affect our lives through the many decisions that they make. One reason they use to justify those decisions is to declare that they acted on the best available information, often citing social science research and surveys to support their claim (Florio, 1993). This claim is reasonable since information production, storage, and use in a variety of disciplines, are mushrooming, while researchers, policy and decision makers, and other users of such information are attempting to keep pace (e.g., Sharratt, 
1989; McMullen, 1990; Overhultz, 1990). As can be heard very often, we are living in the "age of information" (Friedman. 1991).

But to what extent do decision makers use research to formulate public policy? And, what are the forces behind their acceptance or non-acceptance of the research as a base for their decisions? Although acceptance is critical to linking the findings of needs assessment to public policy, the literature search reveals that there is no single study which directly tested the utilization of needs assessment by decision makers. However, there are numerous studies of utilization of other kinds of information by decision makers.

For example, Carol Weiss conducted extensive studies on the utilization of evaluation and other social science research (Weiss, 1987). Weiss and Bucuvalas (1980) demonstrated that decision makers use multiple scientific and political criteria rather than any single criterion to judge the usefulness of evaluation research. They found that research is used based upon how clearly and closely the study's content relates to the decision makers' area of responsibility, whether results match with previous experience, knowledge, and values, and whether the researcher demonstrates the ability to modify those things that can be changed in the program. Freeman, Kiecolt, \& Allen (1982) provided an evaluation report that was used by Congress and health policymakers in developing medical care programs for the poor. 
The data indicated that patients of health maintenance organizations were hospitalized fewer days than patients of the ambulatory clinics of hospitals.

The study of the use of evaluations sponsored by the U. S. Department of Education by Leviton \& Boruch (1983) detected numerous instances in which the results led to important program changes, and Patton (1986), who studied the utilization of federal health evaluations, found that political factors consistently affected whether the research results were used. More recently, Chelimsky (1991) found that social science research provides essential data for the development of public policy.

In Quade (1982), the issues of acceptance and implementation of research were discussed in the context of policy analysis. Quade contends that, in order for policy analysis to help in a practical sense, the problems of acceptance and implementation associated with the real situation need to be taken into account. However, he warns that "we simply do not know how to..." systematically or exhaustively examine acceptance and implementation strategies in bureaucratic organizations because of the political milieu and organizational factors.

This study suggests that utilization of needs assessment findings is directly related to the acceptance by decision makers of the needs assessment research and the credibility of the researcher. It posits that acceptance is a precursor to 
utilization of the knowledge and embraces the challenge to examine the dynamics that influence decision makers' acceptance of needs assessment findings and methodology used to obtain those findings.

It is axiomatic to say that each needs assessment method produces dissimilar data, operates under different assumptions about how needs are assessed, and is utilized for a different purpose. These reasons, coupled with the fact that a multiple technique approach has a greater probability of covering a wide spectrum of need areas and tend to make findings more accurate, influenced the use of five techniques for this study.

This study assumes the limitation of the use of any one needs assessment technique. Its position is that some of the limitations of each technique might be relieved if a battery of assessments is utilized. Another assumption of this study is that the involvement of the decision makers in comparing the findings of the various methodologies would sensitize them to the needs assessment procedures. Consequently, both findings and methodology would be more amenable to acceptance by decision makers, thereby facilitating the linking of assessment results to public policy.

\section{PLAN OF THE STUDY}

This study is reported in seven chapters. Chapter 1 provides an overview, the purpose of the study, and the rationale of the 
study. Chapter 2 consists of a review of literature. This chapter places focus on the importance of needs assessment, especially in relation to older persons. It also provides an historical perspective of past efforts at needs assessment, particularly those involving the methodologies used in this study. A discussion of the relative strengths and weaknesses of each technique takes place and a typology of needs assessment which contains the strengths and weaknesses is presented. Finally, the chapter touches on the topic of social science research and decision making.

Chapter 3 addresses the objectives of the study. The specific research questions are presented, and pertinent key terms and concepts are defined. Chapter 4 presents the methodology and procedures for the five needs assessments. The chapter explains the setting of the study, and places focus on the overall design and procedures, and data analysis for each technique.

Chapter 5 provides a comparative analysis of the five needs assessment studies. In particular, it summarizes the findings from each of the techniques and provides answers for the first four research questions.

Chapter 6 gives a detailed explication of the decision makers study. The focus is placed on the nature of decision making, the use of needs assessment as a decision making tool in the public sector, and the methodology of the decision makers 
survey. Research questions five and six are answered. An acceptance model depicting the major factors that influence decision makers' acceptance of needs assessment findings and methodology is offered for decision makers and researchers. The study is concluded in Chapter 7 where its major findings are reviewed and future implications are explored. 


\section{CHAPTER II}

\section{REVIEW OF LITERATURE}

\section{IMPORTANCE OF NEEDS ASSESSMENT}

As a piyotal component in the process of planning and implementing human service programs, needs assessment is an important tool that serves as a cornerstone for decision making (Harlow \& Turner, 1993). It facilitates service planning, priority setting; allocation of resources, and program evaluation (Morgan \& Hiltner, 1992). The needs assessment process is both scientific and political (United Way of America, 1982; Harlow, 1990); it has the responsibility to assess needs accurately (Sung, 1992) and the mandate to match those needs with services to target unmet need (Harlow \& Turner, 1993). Needs assessment is never an end in itself (Taylor \& Devine, 1993).

Specifically, needs assessment can be utilized by agencies for a wide array of purposes (Sung, 1992). It might be used to gather information required to ensure congruence between services and activities needed by the organization's clientele; to formalize information flow into a communication process to facilitate its use in cyclic planning; to determine suitable goals; to establish two-way communication between the organization and the service area's constituency groups; and to secure data to more accurately identify services needed by the clientele (Nickens et al., 1980). 
Needs assessment is recognized, not only as an important factor in identifying both need and demand (Harlow \& Turner, 1993), but often as the initial step toward the allocation of resources (Goldsmith et al., 1992), and as a foundation for program budgeting. Further, this data gathering exercise serves as an information base for grant applications or budget requests, and is utilized as a tool for reducing costs and providing accountability (Jennings, 1981).

Finally, needs assessment allows for scanning of the service environment. Environmental scanning, which is a critical element in strategic planning (Bryson, 1989; Shortell et a1., 1990). involves identifying the demographics of the target population, the service area's constituency groups, the number of individuals likely to qualify for the services, and the number and types of organizations in the environment that might be providing similar services (Harlow \& Turner, 1993).

In one form or another, needs assessment has been a part of the human services system for more than a century and a half (Kilburg, 1978). But, emphasis on its activities did not come about until the mid-sixties. During this era, federal legislation began to mandate the "assessment of need" as a precondition for grant support, as an ingredient in a planning process, and through the establishment of Title XX of the Social Security Act which required an assessment of service needs for all residents and geographic areas throughout the nation. 
A review of the early exercises under Title XX reveals that in the first year the needs assessment was mandated, only a few states attempted to do it (Benton, 1978). This was due to a combination of factors, including confusion over exact requirements, and lack of time. By the end of the second year, however, several states obtained the staff, money and resources needed to produce valid results.

The rise in interest in, and use of needs assessment during the past two decades, are reflected in legislation that now routinely requires the assessment of health and human service needs for the purpose of planning, developing, and funding service programs. Numerous federal programs required needs assessment in one form or another by the early 1980s (United Way, 1982).

The proliferation of literature in the field (Sung, 1992; Goldsmith et al., 1992; Fenig et al., 1993; Harlow \& Turner, 1993; Ebener, 1993; Donovan et al., 1993; and Korenbrot et a1., 1994 (in health and social services); Quam \& Whitford, 1992; Genthon, 1993; and Leiser, 1993 (in education); Sterngold et al., 1994 (concern for survey issues); Wittmer, 1992 (ethical sensitivity in managerial decision making); Cabrera, 1993 (bilingualism); Chau, 1992 (cultural conflicts); Sallis \& Henggeler, 1980; Lareau, 1983; and warheit et al., 1983); and the rise in both the variety and complexity of methodologies for conducting needs assessment (United Way, 1982; Harlow \& Turner, 1993), also are 
indicators of the continued interest in this needs assessment research tool.

A Girl Scouts of Greater Philadelphia study linking needs assessment to strategic planning for a voluntary organization (Vosburgh et al., 1990), is an indication that the assessment tool continues to survive and expand into new areas. Internationally, the needs assessment technique is said to be "on the verge of establishing itself as a promising development tool, "Butler \& Butler, 1987).

\section{ASSESSING OLDER PERSONS' NEEDS}

As early as 1945, assessments of the needs of older persons were carried out for the purpose of planning and research (Havighurst, 1953). These assessments took place in cities (Barker \& Barker, 1961), counties (USDHEW Office on aging, 1964), clusters of counties (Taves \& Hansen, 1963; Sauer et. al. , 1964), and states (Taves \& Hansen, 1963; Brance, 1977; Schulte, 1978; and Webb, 1984). They increased with regularity since the 1970s, primarily to meet federal planning requirements for entitlement grants, to provide evidence of need when arguing for supplemental federal support, and to provide accountability for delivery of services (Sung, 1992).

In the last decade and a half, needs assessment activity in social services for older persons has mushroomed. So pervasive has this exercise been nationwide that by 1980,34 out of 50 states 
had performed needs assessment of their older population (Young, 1986), and by 1989, according to a survey of the 50 states, fortyseven of the state units had been involved in some type of needs assessment for older persons within the past seven years (Harlow \& Turner, 1993). In several instances, states indicate that needs assessment is the responsibility of the Area Agencies on Aging (AAAs) within the state.

Needs assessment on the elderly continues to be an integral part in social service systems' plans to achieve a variety of diverse goals and objectives. For example, a needs assessment in the form of a survey of 882 members of a rural community was instrumental in evaluating the usefulness of this type of research data as they relate to the development of long-term care services for the elderly population (Iutcovich, 1993). Another examined the specific needs of the elderly in natural disasters and recommends that the elderly be educated and trained in selfprotective behavior and evacuation patterns (Eldar, 1992).

In keeping with a trend to encourage older people to exercise regularly, 8,205 persons between the ages of 68 and 105 were questioned about their exercise habits, in a research project carried out by researchers at the National Institute on Aging in Washington, D.C. The results link exercise in older persons to lower incidence of gastrointestinal hemorrhages, a condition considered to.be a significant health problem in the United States (Muha, 1994). 
Needs assessment on older persons have also been carried out on the national and international levels. Among other purposes, needs assessment has been instrumental in evaluating the effectiveness of hospice care in England (Goddard, 1993); in measuring changes in life satisfaction among very old people in London (Bowling et al., 1993); and for cross national survey evaluating services for the elderly in Europe (Wilderom, $1992)$.

\section{ALTERNATIVE NEEDS ASSESSMENT TECHNIQUES}

Despite the advancement in the state of needs assessment technology and the continued increase in its use, the review of literature reveals that no single approach to assessing needs can be labeled "best." None of the methods is perfect (Morgan \& Hiltner, 1992). Each approach has its inherent strengths and weaknesses.

An in-depth and systematic investigation into the variety of methodologies used for assessing needs reveals at least seventeen approaches. The following is a list as provided by the United way of America (1982):

1. General Population Survey

2. Survey of Subpopulation(s)

3. Survey of Key Informants

4. Survey of Service Providers

5. Survey of Service Recipients 
6. Organized Public Meetings

7. Group-Think

8. Teledemocracy

9. Needs Assessment Week (NAW)

10. Donor Plebiscite

11. Epidemiological Studies

12. Service statistics

13. Social Indicators

14. Projections of EconomicDemographic Data

15. Inventory of Resources

16. Needs Data Identified by Other

Planning Systems

17. Review of Budgets

\section{METHODOLOGIES USED IN STUDY}

The five methodologies used in this study are the ones most frequently used throughout the literature (Nickens et al., 1980; Jennings, 1981; Balacki, 1988; Morgan \& Hiltner, 1992; Harlow \& Turner, 1993). Following is an historical perspective of the methodologies, as well as an exposition of their relative strengths and weaknesses.

\section{Population Survey}

The survey is one of the oldest methods of gathering information, and is among the most important basic research 
methods in the social sciences (Nachmias \& Nachmias, 1992). Face-to-face surveys occurred during ancient times (Gilmore et al., 1989). In other early instances, the survey was utilized by John Howard of England (1726-1790); Frederick Le play (18061882); Dorothy Lynde Dix (1802-1887); and by the English merchant Charles Booth (1840-1916). Following Booth's example of using the interview and participation observer approaches to categorize people, a monumental survey was conducted in the United States during 1909 and 1914 (Polansky, 1971). Much of the urban social research performed during the next decade followed its lead (Baumheier, 1974).

By 1982, a survey of 1,041 cities with population larger than 25,000 revealed that over fifty percent of those cities used surveys during the previous year (Glass, cited in watson, 1991 ). Two years later, a publication appeared as a guide to survey research in underdeveloped countries (Dixon, 1984), where by that time surveys were dominating research for planning and program evaluation. So widespread have surveys now become that an entire text is devoted to the validity of their responses (Wentland \& Smith, 1993).

Of the three types of survey - personal (face-to-face), telephone interview, and mail - the telephone interview has made significant impact on data-gathering. Undergoing serious developments only in the last twenty years (Lavrakas, 1986), survey by telephone has surpassed the more conventional face-to- 
face technique both in frequency of use and in methodological developments (Frey, 1989). This increase in use is attributed in part to the relatively low cost and time required for completion. This type of survey is seen as an efficient method for use in jurisdictions with a well-developed network of telephone subscribers.

The telephone interview also allows the researcher to access persons who are hard to reach because of unusual work shifts, those who reside in dangerous locations, and individuals who resist face-to-face interviews (Fenig et al., 1993). Though the telephone survey has not replaced face-to-face and mail surveys, it can at least be placed on an equal level with other survey methods (Frey, 1989). This type of survey, however, has several drawbacks. It does not have the ability to include those persons without telephones; the time of the interview is limited; and, there is reason to feel that interviewers can be less cooperative because of suspicion of the interviewer or the study.

The personal interview, nonetheless, is reputed to allow great flexibility in the questioning process. It generates a better response rate, allows for a more representative sample of the population, and the face-to-face contact gives ample opportunity to explain the questions, and probe, if necessary. Among the greatest disadvantages of the personal survey are the cost and the time required to administer the interviews (Nachmias \& Nachmias, 1992). 
The mail survey's major advantage is that it costs the least of the surveys - its major direct cost is postage for mailing. In addition, this type of survey reaches a diverse group of people, including those who do not have telephones; it provides the best opportunity for receiving truthful responses; and it gives respondents time to provide thoughtful replies (Gilmore, et al., 1989). Its major problems are its low rate of response, which can cast doubt on the validity of the findings, and the lack of opportunity for interpretation of questions.

Regardless of the survey technique employed, however, it is perceived that the most valid and reliable method of obtaining usable data for a needs assessment, is the general population survey (United Way, 1982). This perception is attributed to the fact that the survey is generalizable to large populations, it can be statistically analyzed, it reflects the respondents' own needs, and it enables diverse community input to play an important role in the political process (Ryan, 1987).

Other strengths of this method are its ability to adapt to available resources, its capacity to address different types of issues or problems, the confidentiality it provides, and its ability to be effectively combined with other methods (Butler \& Butler, 1987). Important elements that contribute to the success of this type of survey are: a well structured, technically sound, bias-free questionnaire, and a random sample that statistically represents the population being studied (United Way, 1982). 
The major limitations are that population surveys are relatively costly and time-consuming. Additionally, there tends to be a large refusal rate, and bias on the part of the construction of the instrument and on the respondents' responses are a real possibility.

The performance of these surveys in the context of programs for older persons is now a common phenomenon. In a nationwide study of needs assessment methodologies used by five types of agencies that plan for older persons, Lareau (1983) found that the survey was the most frequently used data gathering technique.

These surveys make substantial contributions to the awareness of older persons' needs and concerns in a variety of situations. For example, in a 1987 house-to-house survey of 358 elderly citizens in Allegany County, N.Y., the number and composition of the domains comprising the daily lives of the elderly were assessed. The result highlights the impact of dietary and economic deficits on the problems of the elderly (Kowalewski \& Peterson, 1993-1994)

Another survey on the elderly is a 1993 study carried out by the Urban Institute to determine the status of older persons in relation to hunger (Reuters, 1993). Based on the survey, it was estimated that at least 2.5 million elderly experience "food insecurity" over any six-month period.

The urban vs. rural aged comparison is an area that is gaining attention. The belief that older persons living in rural areas in 
the United States are at a health disadvantage when compared with older persons living in metropolitan areas was examined in a survey of 396 persons 65 years or older living in urban and rural areas in Nebraska (Thorson \& Powell, 1992).

Contrary to popular belief, the study concludes that both groups' level of functional ability and health are similar, even though the rural group is significantly older than the urban group. Patterns of health care utilizations and levels of overall satisfaction with health care are similar. The real difference was found in terms of the way each group construed health and health care. Those in the rural group expressed stronger attitude of health independence and self-reliance than did those in the urban sample - the urban group were more likely to avoid seeing a doctor for minor health care items.

Finally, a national survey conducted in 1992 provides a profile of practice that can contribute to elderly care improvement by social workers. The data were collected from a national sample of 118 consultants and full-time nursing home social workers who gave information about the relative importance of the psychological needs of residents and their families, and the frequency of duties either performed or overseen by social workers to meet these needs (Vourlekis et al., 1992).

\section{Key Informants Survey}

Although the key informants survey is now used in applied social research, it began as a method primarily associated with 
anthropology (Agar, 1980). Over time, it has been used in a variety of research settings, including community studies (HummDelgado \& Delgado, 1986; Anderson et al., 1990), health needs (Laffrey, 1989), educational research (Fink, 1985), environmental assessment (Craik \& Appleyard, 1980), and extensively in mental health needs (Siegel et al., 1977; Warheit et al., 1978; Truesdale, 1979; Huebner, 1986; Rasheed, 1986; and Snow, 1987$)$.

Unfortunately, reports of studies in the social services using this technique are scarce, even though this technique is credited with being simple, relatively inexpensive, and politically sensitive. Its limited use has restricted research in the evaluation of the methodological strengths and weaknesses of the technique. This issue was raised by Warheit et al. (1978), and by Huebner (1986), who blame the sketchy references to the relatively low validity and reliability of the technique, and on the low volume of studies published. Huebner points out that only three studies addressed the issue of validity. Two of those studies are Campbell (1955), and Seidler (1974). Reliability was analyzed by Hyman (1967), Seidler (1974), and Young \& Young (1961). No recent studies have been found.

The greatest advantage of the key informant survey is its political sensitivity (United Way, 1982). Needs assessment is a political process, therefore, it is important to ascertain what decision makers are thinking and what's politically possible. 
This technique also encourages input from individuals who otherwise might not participate in this type of session (Butler \& Butler, 1987). Its relatively low cost and its ability to be performed quickly are two other advantages (Morgan \& Hiltner, 1992).

The major disadvantage of this approach is its high probability of class or cultural bias - intended or unintended (Sung, 1992). For example, some relevant community leaders may be overlooked in the process of identifying key informants. This omission can make a significant difference in the results.

Another problem is that some "experts" are likely to exaggerate the scope and gravity of issues close to them and/or may not be familiar with problems that are less visible to them (Jennings, 1981). It is important therefore, that the key informants are in touch with the real problem of the target population and that no relevant segment of the population is overlooked (Sung, 1992). Other difficulties lie in quantifying data, non-generalization to the total population, and potential for extraneous information.

As pointed out by Balacki (1988), key informants studies are appropriate for rural communities where leaders may be in close communication with community problems. It is the consensus of several researchers that this technique is not a promising scientifically rigorous approach to identifying specific community and subpopulations' needs (Warheit et al., 1983). 
However, others are confident that it can play a more critical role than might be expected (Balacki, 1988).

The findings of the minute number of studies performed with the older population indicate that this technique can be an effective tool for identifying service needs for the elderly. Kooperman (1985) and Allen (1986) used the technique effectively for assessing the needs of elderly in a multidimensional approach, and in a rural setting, respectively.

\section{Community Forum}

Like the key informants interview, social indicators and RUT techniques, the community forum method is used extensively in assessing community mental health needs (Warheit et al., 1983 ). These forums, in the form of neighborhood meetings, were first encouraged by OEO-organized Community Action Agencies, and were later inspired by programs such as Model Cities and revenue sharing. They are also a requirement of state units on aging by the Federal Administration on Aging (AoA), (Morgan \& Hiltner, 1992; U.S. Federal Register, 1980). On a state level, community forums are held to gather community input on a variety of issues, such as education (Hart, 1994; Shuman, 1994), welfare benefits (Keating \& Finholm, 1993), and senior citizens nursing homes (Leonard, 1993).

The community forum method has several attractive advantages, especially its community relations enhancement and the potential for community members to express their views on a 
variety of issues (Harlow \& Turner, 1993). In addition, the process is easily planned, it is relatively inexpensive (Morgan \& Hiltner, 1992), and is capable of identifying citizen resources.

Unfortunately, the disadvantages connected to this technique are great. Often-times the participants are not representative of the clientele sought. Very often, the most vocal, articulate, self-serving individuals and special interest groups who set themselves up as representing the population are the ones usually heard from at these forums (Harlow \& Turner, 1993). Further, there is always the probability that expectations as a result of the gathering may be unrealistic.

Rates-Under-Treatment (RUT)

Service utilization in health and social services is a complex process that has been explained in a variety of models in the literature (Anderson, 1968; Reed, 1980; Moore, 1993). The most frequently cited model, adapted by Anderson (1968), conceptualizes utilization of health and social services as an interaction of (1) predisposing factors (demographics, social structure, and beliefs); (2) enabling factors (family and community resources); and (3) level of need as perceived by self and evaluated by others (Moore, 1993). Subsequent empirical studies have demonstrated that the variables contained in the model have interactional effects on service utilization (Coulton \& Frost, 1982; Evashwich et al., 1984). 
A technique to measure the rates of utilization is the ratesunder-treatment, or RUT, needs assessment methodology. Historically, this approach has been used to detect the prevalence of mental disorders and patterns of treatment in communities (Warheit et al., 1977; Bachrach \& Zautra, 1980). The 1933 Mental Hygiene Survey of the Eastern Health District of Baltimore, Maryland, was one of the earliest RUT studies in mental health in the United States.

Cohen \& Fairbank (1938), were successful in isolating distinguishing sociodemographic characteristics that relate to mental health problems and treatment. Almost concurrently, Farris \& Dunham (1939) estimated the prevalence of mental disorders in Chicago using this technique. RUT studies were subsequently conducted by Hollingshead \& Redlich (1958), Malzberg (1944), Leighton et al., (1963), and Langner \& Michael (1963).

Interest in the RUT technique in the area of mental health continues to be high (Bachrach \& Zautra, 1980; Warheit et al.. 1983; Balacki, 1988). The technique is used also for assessing other need areas such as community human service needs (Siegel, 1987 ) and chemical dependency programs (Maddock et al., 1988). The rates-under-treatment method of needs assessment has several strengths. Simplicity, relatively low cost, and easy access to data are among its advantages. Additionally, it is an ideal technique for presenting an overview of the services 
offered by an agency, for determining cost patterns in providing those services, for identifying manpower needs in select occupations (Nickens et al., 1980), and for making projections for expanding services to other areas (Ciarlo, 1992).

This technique is also capable of detecting overlap or gaps in services. For example, an overlap in services can be detected if outreach workers at the Department of Health provide health counselling for seniors who are the recipients of the same type of counselling service from social workers at the Department of Human Services. Likewise, a review of the same records could reveal that a large number of elderly persons suffer from Alzheimer's disease and that there is no type of service provided to assist the elderly and their families to cope with the disease. In an effort to alleviate incidences of overlap or gaps, the RUT methodology can potentially increase communication and coordination between agencies providing the services.

Perhaps the strongest problem associated with using the rates-under-treatment technique is the unavailability of adequate service use records. Some agencies maintain excellent records of their service to clients, while others keep no record at all. Many who can produce records do not gather the type of high quality data from which a meaningful needs analysis can be accomplished (Rossi \& Freeman, 1989).

Further, even when records are kept in a sufficiently systematic and adequate manner, the data gathered in this 
technique can give no clear indication of the unmet needs or the needs of the critical non-service population - such data present only met needs that may or may not serve as measures. For example, it would be a challenge to try to estimate the extent of elderly abuse by reviewing records of those elderly treated for abuse. The interpretation of at least one service use analysis is "that heavy use is an indicator of need, that light use is an indicator of need, and that use is not directly related to need" (McKillip, 1987, p. 58).

The technique was used to measure utilization of services for the elderly by Rabiner (1992), and Wolinsky \& Johnson (1991). In Rabiner's study, the relationship between program participation, utilization of formal in-home services, and client satisfaction in an elderly population was examined. The significant predictors of client satisfaction were age, male, severe activities of daily living ( $A D L$ ) dependency, living alone with no informal support, provision of basic care management services, and utilization of formal in-home services.

The rates-under-treatment technique was also instrumental in assessing the relationship between formal service use and informal help for older persons (Logan \& Spitze, 1994). The study indicates some evidence of family support substituting for formal care, and of the informal network helping link the older person to services. 
Attention is drawn to an analysis of service use patterns for small rural towns, which has implications for problems encountered by the RUT technique (Windley, 1983). Among other things, the study found that some older people travel to other communities for service because of lower prices, more choices, and better service. The consequence of such a situation is that social service planning for the elderly in the community of residence will reflect an underestimation of the actual needs of that population.

An example of such an occurrence is that, if a group of elderly persons living in one municipality travels to another municipality on a regular basis to fulfill the need for socialization, an examination of the utility records of recreation services in the municipality where these elderly persons reside will not reflect the needs of this group of individuals. The consequence of such a situation is that social service planning for the elderly in their community will underestimate the actual unmet needs of that population.

Internationally, the rates-under-treatment technique has been found to be beneficial to some local authorities in England and by city planners in Tokyo, Japan (Little, 1980). More recently, a study conducted in a municipality in mideastern Sweden compared hospital utilization records data to survey responses to questions regarding utilization of health and social services among very old persons (Carsjo et al., 1994). The 
results show no significant difference between what the elderly persons reported and the registered data.

\section{Social Indicators Analysis}

The expression "social indicators" was coined by Raymond A. Bauer in 1966, and it has become a familiar term in reference to quantitative measurement of social phenomena. It has been defined in two distinct ways: the first emphasizes a scientific approach to analyzing and measuring social change; the second is concerned with values and public policy. The valuation or policyoriented approach, as promoted by Bauer, is intended to provide a yardstick to determine where we stand and where we are going with respect to our values and goals, and to ascertain the impact of specific social programs (MacRae, 1985).

This study is concerned with the valuative or normative approach and focuses on public statistics as a means of aiding policy making. It embraces Soderstrom's (1981) definition which refers to social indicators as quantitative measures that describe the condition of a group of individuals or a particular social unit, and can be collected at various points in time.

The most significant source of social indicators is the government: federal, state and local (McKillip, 1987). Most of this information on the federal level is derived from various censuses and surveys; the most notable is the decennial U. S. Census. Information on the state and local levels can be found in client data records and regularly scheduled surveys, and is often 
utilized in conjunction with other data to assess needs (Harlow, $1992)$

The apparent usefulness of indicators to analyze public policy decisions have influenced researchers to apply them in their research methodologies (Horn, 1980). Social indicators analysis has generated much interest in the area of mental health need research (Siegel et al., 1977; Bell et al., 1977; Warheit et a1., 1978; Stewart, 1979; Snider, 1982). It is also being utilized for identifying community needs (Johnson, 1987), subpopulations (Humm-Delgado \& Delgado, 1986), and health care needs for the elderly (Snider, 1982), and to determine the potential indicators of individual welfare (Anand \& Harris, 1994). Another area that proves useful for social indicators is the measurement of sustainable development, diverging the methodology for this area of study from the traditional economicbased indicators (Henderson, 1994).

The roots of the social indicators approach to needs assessment were planted during the 1920s and 1930s by William Ogburn and his colleagues at the University of Chicago as they worked to improve measurement of social change (Rossi \& Gilmartin, 1980). Ogburn was interested in social planning, and in accurately assessing social trends for social planning. This could best be accomplished, he believed, through the establishment of a statistical series that would project the future. 
After Ogburn's appointment as director of research for the Hoover Administration, five reports on the social trends in the United States were issued between 1929 and 1933. In 1933, the committee produced a comprehensive statistical report presenting trends for practically every aspect of American life, under the name of "Recent Social Trends in the United States."

The movement in this direction was slowed down during the 1940 s and 1950 s as researchers directed their attention to macroeconomic data to evaluate economic conditions during and after the depression years (Rossi \& Gilmartin, 1980). During the mid1960s, the movement was revived because of a growing concern for improving statistical information on the noneconomic aspects of social conditions and on the public well-being (MacRae 1985).

Its revival is credited to Raymond A. Bauer's pioneering 1966 publication, entitled "Social Indicators" that called attention to the inadequacy of traditional social analysis tools (Horn, 1980). Because of the apparent usefulness of indicators for social analysis, research in the area focused upon application and methodology, instead of toward the nature of the indicators themselves (Horn, 1980).

A tireless advocate on Capitol Hill for the social indicators movement during the late 1960s and early 1970 s was U. S. Senator Walter F. Mondale (Booth, 1992). This young and energetic freshman fought strongly in 1967 to harness the capacity of the social sciences for advancing the potential of 
government to manage the course of social change. His efforts were hailed by Bertram Gross, a recognized academic force in the social indicators movement as "one of the most significant proposals for governmental improvement yet to be offered in the last half of the 20th century" (Booth, 1992, p. 371).

During the $1970 \mathrm{~s}$, the social indicators movement experienced substantial growth. So fast moving was this approach during the period, that by the end of the 1970 s at least 21 countries, including the U. S., had published national social indicators reports (Rossi \& Gilmartin, 1980). And, spurred by the AoA, thirty-four states had conducted needs assessment studies with older persons using this technique by the late 1970s (Little, 1980).

The interest seemed to slow down somewhat by the early 1980s, although all indications are that attention to its many applications increased during the late 1980s and early 1990s. By 1992, the role of social indicators shared the focus of much attention with environmental indicators after the earth summit in Rio de Janeiro (Henderson, 1994).

The most attractive incentive for using this technique may be that the process is relatively inexpensive. Other strengths are that the data are easily available and easy to access, the information is objective, and there is a built in flexibility in how the data can be used (Goldsmith et al., 1992). 
On theoretical grounds, social indicators analysis has several drawbacks. It is attacked for its heavy reliance on ecological determination since it emphasizes environmental conditions. The fallacies created by this determination make it difficult to generalize from group to individual level findings, and vice versa. Further, the construction of social indicators is said to be clouded with personal and class biases.

The greatest drawback to social indicators analysis that relies primarily on national census data, is perhaps the timeliness of the information. For areas experiencing rapid change, reliance on census data can be risky (McKillip, 1987), since there is a 10-year time lag between censuses.

A typology of these five needs assessment techniques, with some of their relative strengths and weaknesses, is exhibited at the end of this chapter. This typology can potentially be of real managerial significance if it is used as a guide to make decisions regarding planning for social services.

\section{SOCIAL SCIENCE RESEARCH AND DECISION MAKING}

There is a vast amount of literature concerning decision making from a number of perspectives. Areas of interest include conflict and uncertainty (Shafir et al., 1993); social work (Taylor, 1990; Cuzzi et al., 1993); process (Carroll \& Johnson, 1990); and international affairs (Janis \& Mann, 1992). 
During the 1960 s the call went out to social scientists to advise policy makers in the public sector on how to make decisions in regard to designing programs to battle social problems (Florio, 1993). Nonetheless, up to the late 1960s, it was reported that the use of social science information in the policy decision making arena was limited (Nelson et al., 1987).

Responding to these reports, social scientists began to study the utilization of social science knowledge early in the 1970 s. The expectation of the researchers was that there would be a direct link between social science information and policy decisions. It was thought that once policy makers identify a problem, the social science information pertinent to that problem would be used to solve the problem. Evidence of such use was seldom found.

Researchers found that factors, such as time span within which the research was conducted, or the research's conformation to decision makers' expectations, influence the use of such research (Florio, 1993). Carol Weiss (1983) who writes extensively on research utilization by policymakers, constructed a framework describing how research information is used by policy decision makers. She suggests that the use of such information is molded by the ideology and interests of the decision maker.

An observation of the expanding literature that addresses the use of social research reveals that Weiss's framework has been a point of reference for continued research. As the area of 
research expands, discussion on the linking of social research to policy decision making includes the works of Weiss \& Bucuvalas, 1980; Weiss, 1983; Dluhy, 1981, 1988; Martin, 1990; Lester \& Wilds, 1990; Wingens, 1990; Kaufman, 1991; Chelimsky, 1991; Backer, 1991; Frenk, 1992; Florio, 1993).

As tenuous as the link may seem, there is a keen sense underlying the studies that research does in fact influence decision makers' action (Weiss \& Bucuvalas, 1980). The key issue that remains is the determination of the factors that establish that link. 


\section{A TYPOLOGY OF NEEDS ASSESSMENT METHODOLOGIES SOME RELATIVE STRENGTHS AND WEAKNESSES}

APPROACHES TO
NEEDS ASSESSMENT

SURVEY

KEY INFORMANTS

COMMUNITY FORUM
STRENGTHS

* ReLAtively high in RELIABILITY \& VALIDITY

* SAMPLING PROCEDURES

* INDIVIDUALS' OWN NEEDS

* SEVERAL DESIGN ALTERNATIVES

* Politically sensitive

* RELATIVELy Simple to OBTAIN

* COUld enHance COMMUNity RELATIONS

* RELATIVELY INEXPENSIVE

* easily planNed

* POTENTIAL CITIZEN PART ICIPATION

* IDENTIFICATION OF CITIZEN RESOURCES

* Relatively easy ACCESS TO DATA

* relatively low cost

* PROVIDES OVERVIEW OF SERVICES OFFERED

* MAY INCREASE INTER-AGENCY COMMUNICATION
WEARNESSES

* Relatively costly

* TIME CONSUMING

* RESPONDENT BIAS

* Refusal Rates

* HIgH PROBABILITY OF BIAS

* DIFFICULTY IN IDENT IFY ING INFORMANTS

* NON-REPRESENTATIVE

* TESTIMONIES COULD BE SELF-SERVING

* potential for NEGATIVE OUTCOME

* MAY hEIGHTEN EXPECTATIONS UNREALISTICALLY

* NOT HELPFUL FOR UNMET NEEDS OF NON-SERVICE POPULATION

- DEPENDS ON THE ACCESSIBILITY OF RECORDS 
Typology (cont'd)

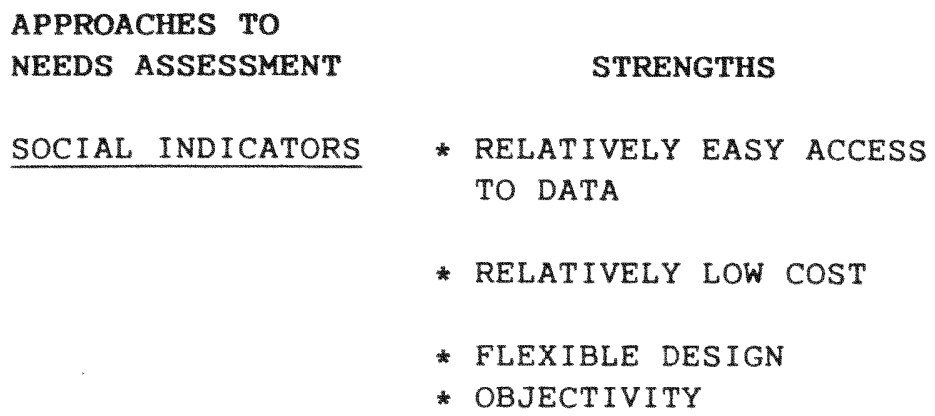




\section{CHAPTER III \\ OBJECTIVES OF THE STUDY}

This chapter addresses the objectives of this study which are reflected in the following six research questions:

\section{RESEARCH QUESTIONS}

1. Which of the following is the highest ranking UNMET NEED of older persons in the U. S. Virgin Islands, and does ranking vary by the type of technique used:
(a) TRANSPORTATION
(b) IN-HOME CARE
(c) SOCIO-RECREATION

2. Which of the five needs assessment techniques is most CostLY to administer?

3. Which of the five needs assessment techniques is most TIME-CONSUMING to administer?

4. Which of the five needs assessment techniques is most VALID?

5. Which of the following two needs assessment factors MOST INFLUENCE how decision makers formulate public policy:

(a) METHODOLOGY of needs assessment, or (b) Substantive FINDINGS of needs assessment 6. Which TECHNIQUE and its FINDINGS do decision makers 
ACCEPT as the most representative of the unmet need of older persons in the Territory, and why?

\section{DEFINITION OF NEEDS ASSESSMENT}

One of the first steps in implementing a needs assessment is the recognition that there is no clear agreement on the two components which constitute the term: (1) "needs," and "assessment." (Royse \& Drude, 1982). The most difficult portion of the term is the word "needs," which seems to have no conceptual boundaries. It is a relative concept that is filled with philosophical, cultural, and emotional characteristics; it has different meanings to different people.

Despite the attempt to place needs into a framework, the concept remains unclear and elusive. Two theoretical concepts of human needs that contribute significantly to an understanding of some of the problems inherent in need identification for needs assessment are worth mentioning. They are advocated by leading theoreticians Eric Erikson and Abraham Maslow.

From a developmental perspective, Erikson (1968) posits, that people go through eight critical stages in their lives. As they move through these stages, various health and "social services" can be identified as responses to the crises inherent in each stage. This concept that human needs vary at different stages of maturation may explain why various human services are organized along the lines of very specific target populations. 
In the construction of his theory of human motivation, Maslow views the worker as having what he calls a "hierarchy of needs," each level of which has to be satisfied before the individual could move to the next level. Beginning with the most fundamental needs, which he labels "physiological needs," (the basic means of survival), Maslow goes next to "safety needs," "belongingness and love needs," "esteem needs," and finally, "self-actualization needs." Most, if not all, human service programs appear to respond to this hierarchy of human needs, even though services may not necessarily be organized in the same order of hierarchy (United Way, 1982).

Webster's dictionary defines "need" as (1) necessity; (2) lack of something required or desired; (3) something required or desired that is lacking; (4) a time or condition when help is required..." In a similar manner, a 1975 U. S. Department of Health, Education and Welfare defines "need" as any identifiable condition which limits a person as an individual or a family member in meeting his or her full potential. Human needs are usually expressed in social, economic or health related terms and are frequently qualitative statements. Needs of individuals may be aggregated to express similar needs in quantified terms. Needs may also be identified in terms of sub-areas of a state. 
Kahn (1969) defines "needs" as

social definitions, representing a view of what an individual or group requires in order to play a role, meet a commitment, participate adequately in a social process, retain an adequate level of energy and productivity -- at a given moment in history.

So vague are the definitions of needs that one analyst, in expressing the frustration shared by many of the planners and researchers regarding the meaning of needs, once concluded:

However common it may be the concept "needs" is more troublesome. A large share of the literature does not even bother to discuss or attempt to define the word. The meaning is assumed to be clear and obvious. After all, we all have needs (Kimmel, 1977).

Despite the vagueness, theorists have been successful in classifying needs according to types. Bradshaw (1977) conceptualized a very useful four-fold classification that is often-times referred to in the literature. They are: (1) normative need - need defined by an expert; (2) felt need - what an actual population feel they need; (3) expressed need - a demand for service; and (4) comparative need - an inferred measure of need determined by examining the characteristics of those 
receiving services and then locating those characteristics in the population (Royce \& Drude, 1982; Balacki, 1988).

Because of the numerous typologies of needs, an operational definition is required each time the word is used in the context of research (Royse \& Drude, 1982). An important distinction has been made between "met needs" and "unmet needs" by some authors (Maddock, 1988; Harlow, 1992). "Met needs" are defined by Maddock as those problems for which services are active and available. These needs are most often characterized by utilization rates. "Unmet needs" are those for which services required to solve the problems are not being received by the segment of the community requiring those services. Unmet needs occur either because the individuals in need of the services do not seek those services or the services that they require are not available.

For the purpose of this study, "needs" is defined as "unmet needs," and will encompass Bradshaw's classification of normative needs, felt needs, expressed needs, and comparative needs. Unmet needs was selected because the thrust of this study is to focus on those needs of older people that are not being met. The use of Bradshaw's classification sheds some light on the concept and allows for the consideration of needs as measured by the different methodologies in this study.

For example, Bradshaw's classification of normative needs is applicable in the key informants study since the experts' perception of need which involves values and judgement, may be 
based on a standard that is not acceptable by the older persons whose needs are being perceived. Normative needs also relate to the community forum where community residents can use certain standards to perceive the needs of a particular segment of the population.

Felt needs involve the simple identification of a problem (Harlow, 1992). These types of needs were the emphasis of community development efforts during the 1920s and 1930s (Wade, 1989) Felt needs can be applied to the population survey and community forum.

Expressed needs can be ascertained from demands made for services, and the translation of those demands into action. For example, requests for in-home care services, and the provision of those services to accommodate the demand. Expressed needs can be seen best in the rates-under-treatment process.

The definition for comparative needs may be useful in the social indicators and rates-under-treatment studies. In the social indicators study, one can look at the characteristics of individuals or groups of individuals in the Census and identify them to be in need of certain services. In rates-under-treatment a comparison can be made between the services provided and the needs of the clientele. Like in other classification of needs, the major measurement problem is that they overlap at different points, as can be gathered from the foregoing analogy.

When the term "assessment" is added, the operational 
definition of needs assessment becomes even more elusive. In a very critical, thought-provoking account of needs assessment, Kimmel (1977), gives prominence to the limitations inherent in the definition, theoretical support, methodologies and uses of needs assessment. Kimmel states that often-times what is called needs assessment is not really needs assessment. Actually, it is an estimate, evaluation, or appraisal of symptoms of the problems and not the problems themselves. The results produced from the "needs assessment" merely describe the problem but neither explain the causes of the problems nor suggest solutions. The "assessment" is non-existent, according to Kimmel.

During the 1970s, when needs assessment literature flourished, several perspectives of needs assessment were developed, especially by researchers for health and human service agencies. Listed below are some representative definitions:

method which enumerates and describes the needs of people living in a community" (Florida Department of Health \& Rehabilitative Services, 1975).

is closely related to goal and objective setting in that needs data provides a measure of demand for services against which service goals and objectives should be set ... Needs assessment is also related to resource allocation in that the 
identified needs become one of the primary considerations upon which to develop...staff recommendations on resource allocations..." (Human Services Institute, 1975).

The process "...includes specific procedures for identifying needs, setting priorities, and relating them to the community education program on a continuing basis" (Bowers \& Associates, 1976).

The process of identifying the incidence, prevalence, and nature of certain conditions within a community or target group. The ultimate purpose is to assess the adequacy of existing services and resources in addressing those conditions. The extent to which those conditions are not adequately addressed denotes a need for new or different services or resources (Minnesota State Planning Agency, 1977).

Other literature tends to give simplistic definitions such as the following:

A need is the difference between the present situation and a more desirable one (Gilmore et al., 1989). 
objectives...are to determine who are the clients, their locations, services they require, and priorities of service needs (Morgan \& Hiltner, 1992).

an essential tool for planning human services (Sung, 1992 ).

an activity designed to identify human needs... a tool that is a cornerstone of a planning and decision making process that leads to prioritization of policies and allocation of resources (Harlow \& Turner, 1993).

Of the several perspectives offered by researchers, the one that best suits the purpose of this study is proposed by stewart (1979), and adopted by Royse \& Drude (1982). The operational definition for "needs assessment" in this study, then, is the range of different techniques, separately and collectively, by which the needs of older persons for specific services, may be identified and prioritized.

\section{DEFINITION OF OTHER KEY TERMS}

A number of other terms are of special importance for the study. They are defined below in the context of the study. 
Acceptance. Approval by decision makers of the needs assessment technique, and the findings, or knowledge obtained by the studies.

Cost. The amount of money it takes to perform the studies.

Decision makers. Individuals who are in a position to make, and often implement, important decisions regarding public policy and public actions for older persons. Decision-makers include politicians, social service heads, health care administrators, educators, and others.

Findings. Conclusion reached by the five needs assessment studies. The words "findings" and "results" are used interchangeably.

Influence. The power to produce effects or impact on the minds of the decision makers.

Methodology. The process by which each needs assessment is prepared. It is used interchangeably with "technique," and "method."

older Persons. Persons who are 60 years of age or older. Also referred to as "elderly" and "senior citizens."

Time. The length of period during which the studies are performed.

Valid. The ability of the results of the studies to come to the best available approximation to the truth of the research questions. 


\section{CHAPTER IV}

\section{METHODOLOGY}

SETTING OF THE STUDY

The setting of the study is the U. S. Virgin Islands. Consisting of three main islands - st. Croix, st. Thomas, and st. John - and about 65 small islets and cays, these islands are situated approximately 1,400 miles southeast of New York City, 1,075 miles east-southeast of Miami and 1,035 miles northeast of the Panama Canal. St. Croix lies completely within the Caribbean, while St. Thomas and St. John are flanked by the Caribbean Sea on the south and the Atlantic Ocean on the north. The square mileage of the largest island of St. Croix is approximately $84, \mathrm{st}$. Thomas, 32, and St. John, 20. Three miles separate St. Thomas and St. John, and St. Croix is 40 miles south of St. Thomas.

Like individual members of a family, each island has a distinct personality and a special past. St. Thomas is the capitol, and is cosmopolitan in nature; St. Croix is industrial; St. John is rural.

The islands' natural attributes, combined with the investment security of a U. S. territory, and various federal and local business tax incentives, have contributed to the development of tourism as the major local economic activity. A major employer is the territorial government, with its jobs representing approximately one-third of total employment. 
Because of a history of immigration from other Caribbean islands, the ethnic composition of the territory is very diverse. This diversity is enumerated in Table 4.1 .

\author{
Table 4.1
}

ETHNIC COMPOSITION OF

THE U. S. VIRGIN ISLANDS

Virgin Islands born

39,705

39

Born in other West Indian islands

29,525

29

From U. S. mainland

13,235

13

Puerto Rican born

11,199

11

Came from other areas,

$$
\text { primarily Europe \& Latin America }
$$

8,145

8

U. S. Citizens

69,230

68

Racial Composition

Black

78,003

77

White

13,775

14

Hispanic

14,708

14

Other

10,031

10

Source: U.S. 1990 Census 
The median age is 28.2 years; there are 3.14 persons per each household (U. S. 1990 Census). Labor force participation in 1993 was 52.7\%; and per capita income was $\$ 11,052$ in 1989 (Dept. of Economic Development \& Agriculture).

\section{TARGET POPULATION}

The 1990 Census fixed the Territory's population at 101,809. St. Croix has 50,139 residents, St. Thomas, 48,166, and St. John, 3,504. Of the 101,809 persons in the Territory's population, 9.659 (9.49\%), are 60 years of age or older. Table 4.2 on the following page gives a breakdown of the U. S. Virgin Islands 60 years and older population by island and age categories. The composition of this older population according to sex, marital status, race and those below the poverty level, is illustrated in Table 4.3 .

The study covers the the older persons community in a territory comprising of three major islands geographically, unicameral executive, legislative and judicial governments, which is comprised of two districts -- District of St. Thomas-St. John, and District of St. Croix.

All of the assessment techniques involved in this study were conducted within the same context, on the same population, and during the same time frame. Because each technique is different, information regarding the type and source of data, measurement instrument, design and procedures, and analysis of data for each 
technique will be outlined separately in the remainder of this chapter.

Table 4.2

60+ POPULATION OF THE

U. S. VIRGIN ISLANDS

(By island and age category)

\begin{tabular}{|c|c|c|c|c|}
\hline ISLAND & $\begin{array}{l}60 \text { to } 64 \\
\text { years }\end{array}$ & $\begin{array}{l}65 \text { years } \\
\text { and over }\end{array}$ & $\begin{array}{l}75 \text { years } \\
\text { and over }\end{array}$ & $\begin{array}{l}85 \text { years } \\
\text { and over }\end{array}$ \\
\hline St. Croix & 1,537 & 3,021 & 978 & 174 \\
\hline St. Thomas & 1,550 & 3,245 & 1,150 & 239 \\
\hline St. John & 93 & 213 & 68 & 5 \\
\hline TOTAL & 3,180 & 6,479 & 2,196 & 418 \\
\hline
\end{tabular}


Table 4.3

COMPOSITION OF OLDER POPULATION

U. S. VIRGIN ISLANDS

Sex:

Males

4.404

45.6

Females

5,255

54.4

Marital Status:

$\begin{array}{lrr}\text { Married } & 5,081 & 52.6 \\ \text { Single } & 1,062 & 11.0 \\ \text { Widowed } & 2,083 & 21.6 \\ \text { Divorced } & 952 & 9.9\end{array}$

Race :

Black

7,076

73.3

White

1,801

18.6

Other

782

8.1

Below poverty level

1,956

20.3 


\section{METHODOLOGY OF THE POPULATION SURVEY}

\section{Sampling}

The telephone survey is the data gathering methodology used in this technique. A random sample of 200 individuals was selected from the population of persons 60 years of age and older. The sampling frame for the survey was the telephone directory.

A problem found with using telephone directories is that a portion of the eligible population without telephones or with unlisted numbers is excluded (Frey, 1989). However, omitting those without telephones was not necessarily a serious sampling problem in this study because of the high percentage of Virgin Islands households with telephones. There are 32,020 occupied households in the territory, and 42,890 separate residential telephones, according to the Department of Economic Development and Agriculture data, and data obtained from the V. I. Telephone Corporation. These statistics compare favorably with those nationwide. According to Frey (1989), 97\% of the nation's households have telephones. A recent study on older Oregonians reveals that nearly $98 \%$ of this population have telephones in their households (Neal, 1993).

Another problem in using the telephone directory for surveys is the omission of unlisted numbers and new listings from the directories. The trend toward unlisted numbers has produced estimates nationwide ranging from 16-30\% (Lavrakas, 1986) for some jurisdictions in the United States. 
Use of the directory in this study however, did not pose the threats brought on by unlisted telephone numbers. Although the percentage of unlisted telephone numbers was not obtained from the telephone agency, the consensus is that this figure does not exceed $10 \%$. The telephone directory then, accounts for a representative coverage of the territorial population.

Additionally, previous studies demonstrate that generally, people with unlisted telephone numbers are the younger population, live in urban areas, and move frequently (Lavrakas, 1986). The population in this study is older, live in small cities, and move infrequently. The 1990 Census indicates that approximately $60 \%$ of the Virgin Islands population reside in urban areas; and, according to this survey, $75 \%$ of the older population have resided in the Territory for 21 years or more. This corresponds with Knapp's (1993) theory that most older persons are not likely to move frequently.

Although surveys that use the telephone directory clearly can omit unlisted telephones (Stoller \& Pollow, 1994), the efficiency of using the mechanism in this case outweighs the problems associated with its use.

\section{Survey Instrument}

The measuring instrument was the questionnaire. A version of a questionnaire which was used successfully by Florida International University's Southeast Florida Center on Aging in 1988 to conduct a needs assessment for the Opa Locka area of Dade 
County, Florida, was modified to meet the objectives of this study. It is not assumed that because a questionnaire was used previously, it is guaranteed that the questions are good or appropriate for another survey. However, the use of this established instrument as a base assisted in curbing questionnaire biases, and thereby enhancing the validity of the study. Modification of this instrument took into consideration the purpose of the study, the kinds of variables that were being measured, and how the data were to be analyzed.

The questionnaire is 10 pages long; the interviews approximated 30 minutes in duration. In addition to gathering demographic data on older persons in the territory, the questionnaire solicited information relevant to transportation, in-home care, and socio-recreation needs of older persons.

Eight questions measured need for each of the three service areas (e.g., "Do you have trouble getting to places you need to go?", What kind of in-home care are you receiving?", and "Do you belong to any clubs or organizations such as church groups, senior citizens' groups, fraternal groups, or the like?").

Two questions sought information about other problems facing older persons and asked for recommendations for additional services. There were no open-ended questions primarily because of the desire for the respondents to understand the questions and give precise responses, and to facilitate statistical analysis. The questionnaire appears in Appendix E. 


\section{Interviewer Selection}

To keep bias in administering the questionnaire at a minimum, reduce estimates error, and increase the credibility of the samples, four interviewers were carefully selected and trained for the task. Care was taken to choose interviewers who asserted confidence that the respondents would want to cooperate, and who exhibited the ability to foster good personal interaction.

Reasonably good reading and writing skills, maturity, and the ability to work flexible hours during the interviewing process, were serious considerations in selecting the interviewers. Interviewers also were given a sense of the way that the interviewing fitted into the total research process to encourage commitment to the quality of the research. Specifically, the four interviewers were given a one-day training session as a group. They were explicitly explained the objectives of the research and the role that they play in achieving those objectives. Emphasis was placed on the high standards set for the interviewing exercise.

To ensure the interviewers' acquaintance with the interview instrument, they were required to read aloud each item, and were given a full explanation of the purpose of the question, and the possibility of encountering certain problems with the responses. They were encouraged to question any of the items on the questionnaire and to simulate interview situations with each 
other and with the trainer. Finally, the procedure for coding of the responses and analyzing the data was discussed.

The interviewers were instructed to play primary roles in enlisting the cooperation of the respondents, asking and recording questions properly and in a standardized manner, and ensuring that answers met the questions' objectives.

\section{Design and Procedure}

The population survey is designed to solicit descriptive data. Typically, it is concerned with assessing attitudes, perceptions, conditions, demographic information, and procedures, and permits the investigation of a variety of problems. In this study, the design facilitates the measurement of the three service need areas assessed by the study -transportation, in-home care, and socio-recreational services.

Transportation needs were measured by the following variables: availability of transportation in the homes of older persons in the survey; how these older persons get around when they leave their homes or apartments; how much trouble they experience getting to places where they need to go such as the doctor's office or to shop; whether they know about and/or have used special transportation services; and how satisfied they are with such services.

In-home care needs were measured by whether older persons can perform activities essential to daily living such as preparing meals, performing light household chores, taking 
medication, shopping, and taking care of their personal hygiene activities; and, if they need help, how much. These services were also measured by the kind of help they are receiving, and from whom, their familiarity with in-home care services provided by human service agencies, whether they have used such services, and how satisfied they are with these services. The household makeup was also taken into consideration.

Socio-recreation needs were measured by the frequency of telephone interaction and time spent away from the home. Membership in clubs or organizations such as church groups, senior citizen groups, fraternal groups, etc., and the frequency of their getting-together with relatives, friends or neighbors were also used as measures.

The assessment strategy was to report percentage of respondents expressing each specific need, and the satisfaction level of respondents with services provided in each area. Also, an indication of the most pressing needs of people 60 years of age and older was sought.

The procedure used in this survey is as follows: The size of the population was identified and a sample interval number was determined by dividing the population size by the sample of 200 . A number with the same amount of digits in the population size was randomly selected from a table of random numbers.

The next step was to proceed through the telephone Iisting, taking every number that represented the sample interval number. 
Every 15th number was selected for calling. It took approximately 10 - 15 calls before an interview was effected. When a selection turned out to be a non-residential number, or if no 60 or older respondent resided at the household, that number was eliminated and the count, continued from the original residential listing. This procedure was followed until the desired sample size was achieved.

For those households with two or more persons age 60 or older, one was selected randomly. To avoid the high refusal rate often experienced by surveys of this age group, persons in households who could have served as "key informants" were asked to be interviewed for older persons in the household who wanted to participate but were physically incapable of responding. Two households fitted into this situation, and the two persons interviewed answered all the objective measures for the would-be respondents.

In order to detect working problems and to ensure that the final questionnaire was as close to perfection as possible, the instrument was pretested with 12 respondents. As a result of the pretest, several problems were cited. Two questions were identified as difficult for respondents to understand, and another question which asked for one answer was capable of getting more than one response. These questions were adjusted before the survey was conducted. The pretest also gave a clear indication of the length of time it would take for each interview and the limits 
of the respondents' ability and willingness to answer the questions.

Analysis of Data

After the interviews were completed, the questionnaires were formatted, a coding system was designed, the responses were coded for computer analysis, and the data were analyzed utilizing the Integrated Micro Processing System (IMPS) computer program. Data were gathered and analyzed according to districts - (1) St. Thomas-St. John District, and (2) St. Croix District -- and on a territory-wide basis. One hundred and five persons were interviewed from the St. Thomas-St. John District, and 95 from the St. Croix District, making a total of 200 interviewees territorywide. This proportion is indicative of the breakdown of the territorial older population.

The analysis is reported according to total territory-wide figures since the tendency is for the two districts to give similar results. Only in instances of great discrepancy is there a separation in reporting results.

Table 4.4 gives a distribution of the 200 persons interviewed, according to age in relation to others in the household. Table 4.5 , which begins on the following page, shows select characteristics of the survey population. 
Table 4.4

DISTRIBUTION OF OLDER PERSONS

IN THE STUDY

\begin{tabular}{lcc}
\hline Characteristics & Amount & of Respondents \\
\hline Oldest woman in household & 75 & 37.5 \\
Oldest man in household & 65 & 32.5 \\
Youngest woman in household & 38 & 19.0 \\
Youngest man in the household & 22 & 11.0 \\
\cline { 2 - 2 } & 200 & 100 \\
\hline
\end{tabular}

In testing for the first variable, transportation, $67 \%$ of the respondents indicate that they are familiar with the Territory's special transportation service, the Senior Citizens Activities Transportation (SCAT) program. Within the last year, this service was used by $11.2 \%$ of the respondents. Those who used it are very satisfied $(60 \%)$, or somewhat satisfied (26.7\%). The $60 \%$ satisfaction level is skewed by the high satisfaction expressed by older persons in St. Thomas-St. John District $(88.9 \%)$ as opposed to $16.7 \%$ for St. Croix District. 
Table 4.5

SELECT CHARACTERISTICS OF

SURVEY POPULATION

Characteristics

Age of respondents:

$60-64$

$65-69$

$70-74$

$75-79$

$80-84$

$85-89$

90 or more

Race/cultural background:

Black, non-Hispanic

White, non-Hispanic

Oriental

Hispanic

Native American

Other

Sex:

Male

Female
Amount

$\div$ of Respondents
33

57

40

41

20

7

2

133

29

5

30

2

1

80

120
40.0

16.5

28.5

20.0

20.5

10.0

3.5

1. 0

66.5

14.5

2.5

15.0

1.0

0.5

60.0

(cont'd) 
Select characteristics (cont'd)

Characteristics

Marital Status:

Married

Separated

Divorced

Wi dowed

Never married
99

9

19

52

19
49.5

4.5

9.5

26.0

9.5

Residence in territory:

Over 30 years

110

55.0

21 to 30 years

40

20.0

11 to 20 years

32

16.0

12

6.0

1 to 5 years

1

0.5

Household size:

One person

$18 \cdot 5$

Two persons

75

37.5

Three persons

46

23.0

Four persons

23

11

8
11.5

5.5

4.0

$\left(\operatorname{cont}^{\prime} \mathrm{d}\right)$ 
Select characteristics (cont'd)

Characteristics

Amount $\quad \frac{\circ}{5}$ of respondents

Household income:

Over $\$ 20,000$

49

24.5

$\$ 10,001$ to $\$ 20,000$

54

27.0

$\$ 5,000$ to $\$ 10,000$

40

20.0

Under $\$ 5,000$

42

21.0

No response

15

7.5

Sources of income:

Social Security

167

83.5

Other pensions

76

38.0

Employed

45

22.5

Assistance from children

33

16.5

Other sources

65

32.5

The reason for the low satisfaction level in St. Croix is that public transportation system in St. Croix, at the time of the survey, was non-existent. Persons who did not have private transportation relied on family members, friends, and taxis or mini van taxi services. The satisfaction level for this service is compared to satisfaction level for in-home care and sociorecreation services in Table 4.9 , following discussion of the two other variables. 
An analysis of the transportation needs reveals that, overall, transportation is not a major area of unmet need among older persons in the Territory. Fifty three percent of the respondents indicate that they own a car, more than sixty-eight percent live in households with at least one vehicle; seventyfive percent have no trouble getting to places they need to go even though more than half do not drive.

older persons in the Territory get around very well by themselves. Forty-eight percent drive themselves to visit friends and relatives, and more than forty-four percent go to entertainment activities. Half of them shop on their own, go to the doctors'/dentists' offices, and make miscellaneous trips to places such as the bank and church. These statistics are detailed in Table 4.6 on the following page.

The second key variable analyzed in the study is in-home care services. These services are deemed critical for persons who need assistance to continue to live independently (Gillespie \& Sloan, 1990). On the surface, it appears that older persons in the Territory can take care of themselves in their homes. More than ninety-six percent eat without help, bath and dress themselves, administer medication, get in and out of bed on their own, and take care of their own personal appearance. More than 86 percent prepare their meals, manage their money or pay bills, and walk up and down stairs by themselves. Table 4.7 details these statistics. 


\section{Table 4.6}

TRANSPORTATION CHARACTERISTICS

OF OLDER PERSONS

\begin{tabular}{lrc}
\hline & Amount & $\begin{array}{c}\text { \% of } \\
\text { Activities }\end{array}$ \\
& 106 & 53.0 \\
Own a car & 63 & 31.5 \\
No vehicle in household & 108 & 54.0 \\
One vehicle in household & 23 & 11.5 \\
Two vehicles in household & 6 & 3.0 \\
Three or more vehicles in household & 100 & 50.0 \\
Drive self to shop, bank, church. & 96 & 48.0 \\
Drive self to friend/relative & 89 & 44.5 \\
Drive self to entertainment & 149 & 74.5 \\
Don't have trouble getting around & & \\
\hline
\end{tabular}

Less than ten percent receive help because of health problems, disability, or longterm illnesses, and that help is predominantly in assisting with heavy chores. This result compares favorably with the national research findings which indicate that three quarters of persons 65 to 75 years of age living away from institutions consider themselves in good health. Just $10 \%$ need help with everyday activities (Knapp, 1993). 
Table 4.7

IN-HOME CARE CHARACTERISTICS

OF OLDER PERSONS

\begin{tabular}{|c|c|c|}
\hline Activities & Amount & $\begin{array}{l}\frac{\%}{\circ} \text { of } \\
\text { respondents }\end{array}$ \\
\hline Eat w/o help & 193 & 96.5 \\
\hline Bathe w/o help & 192 & 96.0 \\
\hline Take medication $\mathrm{w} / \mathrm{o}$ help & 190 & 95.0 \\
\hline Get in/out of bed w/o help & 194 & 97.0 \\
\hline Take care of own appearance & 187 & 93.5 \\
\hline Prepare meals w/o help & 172 & 86.0 \\
\hline Manage own money & 173 & 86.5 \\
\hline
\end{tabular}

A large percentage of this group who receive help are assisted with shopping and are aided in food preparation. The major sources of help are other relatives. Little help is provided by friend/neighbor, and community agencies. Volunteers provide a small percent of this type of assistance. In case they should become ill, less than half of the older persons expect that their children or spouses will most likely provide help. 
More than half of the respondents are familiar with the Territory's Homemaker Services Program. However, only six percent have actually used such services within the last year. Overall, the majority of those who receive the service are somewhat satisfied.

The third variable, socio-recreation, appears to be an area with which the respondents are satisfied. At least once a week almost half of the respondents visit with their neighbors. More than half visit with relatives and friends, and attend church. Almost half leave their homes every day, and more than eighty percent are frequently conversing with families/friends on the telephone -- at least once a day. Table 4.8 details these statistics.

Three fourths of the Territory's elderly are familiar with senior citizens centers. In many communities, including the U. S. Virgin Islands, these centers have become the focus of a variety of programs and services for older people (Gillespie \& Sloan, 1990). Although in the Territory the involvement of elderly in the senior center program is limited because of financial constraints, about one-tenth of them participate in that program. Almost seventy percent of those who participate are satisfied with the service. This finding is supported by the Oregon study where over three-fourths of the elderly reported satisfaction with their current amount of social involvement and participate in a wide array of social activities (Neal, 1993). 


$$
\begin{gathered}
\text { Table } 4.8 \\
\text { SOCIO-RECREATION CHARACTERISTICS } \\
\text { OF OLDER PERSONS }
\end{gathered}
$$

$$
\text { 응 of }
$$

Activities

\section{respondents}

Visit with neighbors:

At least once a week

At least once a month

Less than once a week

Never

Visit with friends/relatives:

At least once a week

At least once a month

Less than once a week

Never

Attend Church/religious services:

At least once a week

At least once a month

Less than once a week
85

40

49

24

42.5

20.0

24.5

12.

103

51.5

49

24.5

34

17.0

13

6.5

119

59.5

36

18.0

33

(cont'd) 
Table 4.8 (cont'd)

음 of

Characteristics

Amount

respondents

Frequency of leaving home:

$\begin{array}{lcc}\text { Every day } & 99 & 49.5 \\ \text { Two or three times a week } & 63 & 31.5 \\ \text { Once a week } & 26 & 13.0 \\ \text { Almost never } & 11 & 5.5\end{array}$

Frequency of telephone conversation:
At least once a day
164
82.0
At least once a week
28
14.0
Less than once a week
4
2.0
Never
3
1.5

As in the case of many variables within a data set, several of those in this study are highly correlated. This is the case with the older persons transportation situation and their ability to perform major personal functions without help. Of the persons interviewed, more than half drive without help. They therefore, are in a good position to perform several tasks on their own. 
In the ranking of the three variables as unmet needs, the respondents pointed to transportation as the highest ranking unmet need, and socio-recreation as the lowest. (See Table 5.1 for comparison with the other needs assessment techniques.)

Table 4.9 Compares the level of satisfaction with transportation, in-home care and socio-recreation. The level of satisfaction categories used are: very satisfied (V.S.): somewhat satisfied (S.S.); somewhat dissatisfied (S.D.); and very dissatisfied (V.D.). It should be noted that the older persons ranked from the highest unmet need to the lowest unmet need from categories of services with which they are satisfied, although the level of satisfaction with each differs.

Table 4.9

COMPARISON OF RESPONDENTS' SATISFACTION THAT ONERALL

NEEDS IN THE THREE AREAS ARE BEING MET
Need Variable
V.S.
(옹)
S.S.
(옹)
S.D.
(웅)
V.D.
(응)

$\begin{array}{lllllllll}\text { Transportation } & 41 & 20.5 & 110 & 55.0 & 31 & 15.5 & 18 & 9.0 \\ \text { In-Home Care } & 75 & 37.5 & 93 & 46.5 & 26 & 13.0 & 6 & 3.0 \\ \text { Socio-Recreation } & 64 & 32.0 & 107 & 53.5 & 25 & 12.5 & 3 & 1.5\end{array}$


Analyzing the data with a focus on age reveals that the satisfaction level peaks at the 65-69 age bracket. Of the 57 respondents who fall within this age range, $77 \%$ are either "very satisfied" or "somewhat satisfied" that their transportation needs are being met; $86 \%$ are either "very satisfied" or "somewhat satisfied" that their in-home care needs are being met, and $86 \%$ or more are also "very satisfied" or "somewhat satisfied" about their socio-recreation situation.

In summary, the survey was successful in determining that transportation is the highest ranking unmet need of the three areas tested. Additionally, it was instrumental in bringing into focus the several other challenges that older Virgin Islanders face. For example, the most serious problem facing them, according to one fourth of the respondents, is their physical health. Financial problems follow with a distant thirteen percent, and inadequate health care/medical aid comes next.

Other problems cited which make up about twenty percent of the responses, are high insurance rates, inadequate housing, crime against older people, and other societal problems. Another twenty percent of the respondents think there are no serious problems confronting them. The top recommendations for more social services are better health care/medical care, respite care, and medical insurance.

Many of the respondents expressed their pleasure in being a part of the interview process and feel that they contributed 
tremendously to a worthwhile effort. The interview process itself afforded older Virgin Islanders the opportunity to talk to persons about issues that ordinarily, they would not discuss.

Finally, the study demonstrates the viability of a telephone survey as a method for assessing needs of older persons.

\section{METHODOLOGY OF KEY INFORMANTS SURVEY}

\section{Sampling}

For the key informant survey, face-to-face interviews were held with a total of 25 key informants who were selected according to the following criteria, taken from Jennings (1981):

* That the individual resides in the community and plays an important role in the delivery of social services or the formation of social policy relating to older persons.

* That the individual is responsible for knowledge of the needs of older persons for social services.

* That the individual is in the position to have direct contact with the community of older persons.

* That the individual is in the position to legislate policies pertaining to older persons

* That the individual is in a position to formulate policies that affect social services for older persons. 
* That the individual is in a position to implement the findings of the study.

The list was prepared to reflect a wide cross-section of government, private, and non-profit organizations, community leaders, and other persons, who by virtue of their position in the community, have the responsibility or stature to speak about the selected need areas of older persons. The individuals were identified by their elected office, appointed position, or membership on advisory or planning organizations or other community-oriented groups. Unlike the population survey, this sample of interviewees is of the non-probability type - the informants were not chosen randomly.

The study utilized more informants than the 10 to 15 usually utilized in key informant surveys (McKillip, 1987), because of the insular nature of the community. Some informants responded to the questions with the St. Thomas-St. John District in mind, others gave their opinion for St. Croix District, and still others represented both districts, or the Territory as a whole. The number of informants chosen gives adequate representation for the two districts.

Four legislators who head Senate standing committees responsible for government operations comprising the areas of health and human services are included in the listing. Eleven persons who head up executive branch agencies or programs that offer services to older persons, comprise a proportionately large 
portion of the sample surveyed. The remaining ten informants comprise leaders of private, non-profit and community organizations that deal with programs involving the provision of services to a clientele which includes older persons. A list of the key informants, by title and the organization with which they are affiliated, appears in Appendix A.

Survey Instrument

Like the population survey, the measuring instrument is a questionnaire. Instruments used in previous studies, including Fink, (1985), and Ormentrout et al., (1976) were utilized as a base and were modified to incorporate questions that would produce the results sought by this study. The questionnaire contains twenty nine questions, several of which comprise subsections. It is relatively non-technical, and utilizes both fixed alternative questions seeking specific responses, and open-ended questions which facilitate the interviewer's ability to tap into the respondents' perception. These open-ended questions were designed to encourage the respondents to express his/her feelings, beliefs, or perspectives regarding the issues of the study, and allow the interviewer to probe the respondents when necessary.

The first portion of the questionnaire focuses on demographic information in order to describe the population, then questions addressing the respondent's views on the three need areas, transportation, in-home care and socio-recreation 
services were asked. The questions are identical for each need area. The final two questions seek to gather information regarding the respondent's perception of the most serious problem facing older persons and recommendations for possible expansion of social services in the Territory. The questionnaire appears in Appendix F.

\section{Interviewer Selection}

All interviews were performed personally. Limiting the interviewing to myself, particularly because of my integral involvement with the research project, avoided interviewer biases that sometimes accompany surveys that utilize several interviewers, especially if interviewer training is not adequate. The different interviewers generally convey dissimilar personalities to the interviewees and therefore risk the chance of eliciting different responses. A sole interviewer also eliminates the need for monitoring of the interviewing and data collection.

\section{Design and Procedure}

Like the population survey, the key informants survey is designed as a primary data analysis. The design allows for the production of descriptive data that is useful for analysis. This study gathered the opinion of key informants about the selected needs of older persons in the Territory.

To refine the instrument, a pretest was administered to five individuals. Each informant was interviewed following the format 
of the survey instrument and was asked the same questions. The interviews took place at times arranged between the informants and the interviewer. First, telephone calls were placed to make a formal introduction, outline the purpose of the study, solicit assistance, and set up an appointment for a face-to-face interview. The interviews were then administered, placing extensive effort on person-to-person communication.

Only on three occasions did the interviewer fail to meet face-to-face with the informant. These instances occurred because of difficulty in coordinating interviewing time with respondents on the island of St. Croix. Telephone interviews were substituted for these three informants. This combination of telephone calls and person-to-person approach was used because it is known to get a relatively high response rate and it minimizes the cost of the survey (Fink, 1985). The call paves the way for better communication between the interviewer and informant. As a result of this procedure in the study, significant rapport was established and the interviewees were very receptive. There were no refusals; the response rate was 100 percent.

The average duration of the interviews was 35 minutes, and they were performed during work hours, 8:00 a.m. to 5:00 p.m., Mondays through Fridays, primarily in the mornings.

\section{Analysis of Data}

Upon completion of the interviews, the questionnaires were formatted, coded, and analyzed, utilizing the sPSS computer 
statistical program. Each person interviewed were measured equally, although they represent different types of organizations that provide a diverse group of services for older persons. Results are presented in three sections.

The first section contains descriptive data. Demographic and related characteristics of the respondents are reported. Secondly, the information regarding the three need areas are reported. In the third section, a discussion is presented regarding the informants' perception of the most serious problems facing older persons, and their recommendations for change in delivery of social services for this population.

Most of the key informants are females, between the ages of 45 and 54, and are Black. Almost half are married, and forty percent have graduate degrees.

Forty eight percent of the informants are affiliated with organizations that represent both St. Thomas-St. John and St. Croix Districts. About two thirds represent St. Thomas-St. John District only and one third, St. Croix. Public organizations make up most of the sample, and non-profits comprise the remainder. Forty four percent of the public organizations are in the executive branch. Supervisors or directors of social service programs or agencies account for approximately half of the respondents, and more than half of the respondents worked for the organization for ten years or less. Approximately one half operate in an upper management level capacity. 
The informants' characteristics are reported in Table 4.10 .

$$
\text { Table } 4.10
$$

CHARACTERISTICS OF KEY INFORMANTS

응 of

Characteristics respondents

Sex:

Female

Male

Ages:

$35-44$

$45-54$

$55-64$

Over 64

Race :

Black

White

Other

Marital Status:

Single

6

11

8

80

20

5

20

4

16

17

68

3

12

1

4

22

88

2

8

1

4

Married

Divorced 
Table 4.10 (cont'd)

$\%$ of

Characteristics
Amount respondents

Education:

High School graduate

Attended college

College graduate

Attended graduate school

Graduate degree
2

7

5

1

10

12

5

Representing St.Croix only

Representing St.Thomas-St.John only

Representing public organizations

Representing non-profits

Executive branch representation

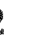

20

4

40

Representing St.Thomas-St.John

and St. Croix districts

2

48

8

20

15

32

60

10

40

11

44

More than half, or $60 \%$ of the organizations provide a combination of services including transportation, in-home care, 
socio-recreation services, housing, education, and employment. Several perform advocacy roles for the older population.

According to the informants, older persons need transportation to run errands, attend social events, and visit the doctor's office. Fifty three percent of the respondents feel that these needs are unmet. Their perception is that older people need in-home care for reasons such as companionship, for performing household chores and administering health services, and for assisting in personal hygiene activities. Fifty five percent perceive these needs are being met.

Informants believe that the reason older persons should become involved in social activities is for companionship, and to remain physically and mentally stimulated. According to $46 \%$ of them, these needs are not being met. Table 4.11 illustrates the key informants' perception of how older people feel about their needs being met.

In an effort to determine how needs are being met, the informants were asked to rank the three need areas. The highest ranking unmet need is in-home care, and the lowest ranking is socio-recreation. (See Table 5.1 for comparison with the two other techniques).

The informants perceive that the most serious problem for older persons in the District of St. Thomas-St. John, is loneliness (16\%). For the District of St. Croix, access to medical services $(20 \%)$, is the most serious problem. 
Table 4.11

COMPARISON OF OLDER PERSONS' SATISFACTION THAT

THEIR OVERAL NEEDS ARE BEING MET

AS PERCEIVED BY KEY INFORMANTS

\begin{tabular}{lrrrrrrrrr}
\hline NEED VARIABLE & V.S. & $\left(\frac{\%}{6}\right)$ & S.S. & $(\%)$ & S.D. & $(\%)$ & V.D. $(\%)$ \\
\hline Transportation & 12 & 48 & 11 & 44 & 12 & 48 & 2 & 8 \\
In-Home Care & 0 & 0 & 5 & 20 & 20 & 80 & 4 & 16 \\
Socio-Recreation & 2 & 8 & 12 & 48 & 14 & 56 & 2 & 8 \\
\hline
\end{tabular}

Other serious problems in the Territory are thought to be elderly abuse (abuse especially by relatives), housing, fear of crimes, neglect, and lack of the opportunity for physical exercise for older persons.

If the Territory were to offer more social services for older persons, $14 \%$ of the informants would want to see in-home care services expanded. Another $40 \%$ gave a variety of other choices, including day respite care; outreach services to keep in touch with the older community; an elderly hotline; spa for the elderly; reference manual for seniors; a central telephone service that provides information to seniors; expansion of pharmaceutical program; and adopt-a-grandparent service. 
In summary, the key informants study demonstrates that the informants' perception of the elderly's lowest unmet need -socio-recreation -- corresponds with what is indicated by the elderly themselves, though the groups differ on the highest and lowest unmet need. Both groups agree that the need for sociorecreation services is the greatest of the three service areas.

\section{METHODOLOGY OF COMMUNITY FORUM}

Type and Source of Data

Anyone living or working in a community potentially is a source of information on the sociological aspects of that community. Either directly, indirectly, or through personal experience, observation or study, community residents form impressions about the human service needs in a social area (Siegel, 1987).

The community forum is an approach to data collection that captures those impressions within a short span of time. It focuses on the democratic tradition of "let the people speak." The goal of this needs assessment technique is to identify and assess varied needs of those in the service area. It relies on views expressed by the general public to accomplish that goal.

Application patterns for the community forum are similar to that of the key informants approach in that both methods are based on input from individual perceptions (Nickens, 1980). However, 
the community forum widens the circle of respondents to include persons from within the general population.

The views of the Virgin Islands community were solicited at five (5) public meetings to which all residents were invited to present testimony on the older population's needs.

Transportation, in-home care and socio-recreation were targeted. The responses were utilized to further identify problems relating to needs of the Territory's older persons.

\section{Design and Procedure}

The format of the meetings was designed to structure the sessions around the topics to be discussed. This was accomplished by the preparation of a short, one-page questionnaire directed toward eliciting information about the subject of the study. Although it was important to have a basic questionnaire to facilitate a systematic retrieval of information, it was recognized also that latitude had to be provided to encourage spontaneity and candor on the part of the participants. (See Exhibit $G$ for the questionnaire).

Following the establishment of the questionnaire's purpose, the designing of the format and the preparation of the instrument took place. The relevant data regarding each need area to be discussed were assembled. A small cadre of community persons were identified to help publicize and plan the forum.

Next, a comprehensive program of publicity was undertaken through the mass media, including $10 \mathrm{cal}$ newspapers; radio and 
television. Posters and flyers were prepared and distributed, and person-to-person contacts were made with the news media. Announcements included purpose of meetings, sponsor, place, date, and time. Telephone calls were made to over 85 select individuals and organizations urging attendance and offering assistance to facilitate their attendance.

In making arrangements for the forums, special emphasis was placed on holding the meetings in places that are geographically accessible to all segments of the community and at dates convenient for the citizens to attend. This has been emphasized as a necessary ingredient to allow for, and encourage maximum attendance (Humm-Delgado, 1986).

Five meetings were held - two on the island of St. Thomas, two on St. Croix, and one on St. John. These meetings were kept in strategically located positions to allow for easy accessibility of interested community groups, organizations, and individuals. They were scheduled for early evenings, on week-days, and were held several days apart on each island.

The forums were held on the dates and places outlined below:

1. Monday, November 15, 1993

Aldershville Multi-Purpose Center

Frederiksted, St. Croix, V.I.

2. Tuesday, November 16,1993

Lutheran Senior Center 
Christiansted, St. Croix, V.I.

3. Wednesday, November 17,1993

Department of Human Services Multi-Purpose Center St. John, V.I.

4. Tuesday, November 30,1993

Legislature's Conference Room

St. Thomas, V.I.

5. Wednesday, December 1, 1993

Anna's Retreat Senior Center

St. Thomas, V.I.

The forums were held under the auspices of the Department of Human Services, with the cooperation of the Legislature of the Virgin Islands' Standing Committee on Youth and Human Services. The moderators were the Deputy Commissioner of Program Development and Evaluation, and the Special Assistant to the Commissioner of Human Services. The latter has the skills and experience in holding these types of community forums. The average duration of the meetings was eighty minutes.

Analysis of Data

Despite the wide publicity, the forums attracted a low turnout - an average of ten persons per meeting for a total of 52 persons. A low turnout in forums such as these is not uncommon. As Gilmore (1989) indicates, even though these forums usually have the potential to attract a wide cross-section of a community, in reality, this rarely occurs. 
The attendees in this study, though small in number, can be considered representative of the community. They include senators, public and private sector administrators, senior citizens service providers, seniors (representing themselves), AARP representatives, friends and relatives of older people, and the media. Most of the attendees represented themselves; others represented groups or organizations.

The sparse turnout can be attributed to several factors, which include the following:

1. The topic is one of low priority for the community it is not perceived as a big problem area.

2. Some persons who have concerns about the topic may have been unwiling and/or unable to air concerns in a forum such as this.

3. People are apathetic toward issues unless these issues develop into crisis proportions.

4. For public hearings, community forums, and other related gatherings, there is a trend in the Virgin Islands, not unlike many other places, toward a low turnout. A subsequent article in the August 17. 1994 issue of the Daily News, headed, "Town Meeting' More A Corner Gathering, but Ideas Flow," indicates that less than a dozen persons showed up at a wel1-publicized meeting for a topic that is of great interest to the community. 
An analysis of the demographic data from the forums indicates that females comprised more than fifty percent, and Blacks made up eighty-two percent of the attendees. The older population represented the highest attendance. This high percentage of the older population in attendance came about because of the elderly's interest and their ability to arrange individually and in small groups to attend the forums. More than eighty percent of the attendees represented their own views. The characteristics of the attendees appear in Table 4.12 on the following page.

On a scale from $1-5$ with 1 representing "not at all effective," and 5, "very effective," the majority of the respondents ( $44 \%$ ) feel that the overall service delivery to the elderly is moderate to very effective for socio-recreation, effective for in-home care, and not at all effective for transportation. Like the population survey, the attendees at the community forums indicated that the highest unmet need is transportation, and the lowest unmet need is socio-recreation. A contributing factor to the similarity between these two outcomes is believed to be the high percentage of older persons in attendance at the community forums.

The most common reason for the attendees' interest in being present at the meetings is the the overall concern about services for the elderly. Others pointed out that they are interested in the specific areas of transportation, in-home care, and socio- 
recreation services. Additional interests are crime, outreach programs to isolated elderly, and homes for the elderly.

Table 4.12

CHARACTERISTICS OF ATTENDEES AT

COMUUNITY FORUMS

\begin{tabular}{|c|c|c|}
\hline Characteristics & \multirow[t]{2}{*}{ Amount } & \multirow[t]{2}{*}{$\begin{array}{c}\frac{\circ}{\circ} \text { of } \\
\text { attendees }\end{array}$} \\
\hline Sex: & & \\
\hline Female & 29 & 56 \\
\hline Male & 23 & 44 \\
\hline \multicolumn{3}{|l|}{ Race/Ethnic background: } \\
\hline Black & 42 & 81 \\
\hline White & 4 & 8 \\
\hline Other & 6 & 11 \\
\hline \multicolumn{3}{|l|}{ Age: } \\
\hline 65 years and older & 22 & 42 \\
\hline $55-64$ & 10 & 19 \\
\hline $45-54$ & 8 & 16 \\
\hline $35-44$ & 9 & 18 \\
\hline $25-34$ & 3 & 05 \\
\hline
\end{tabular}


The most serious problem facing older persons in the Territory is transportation. In-home care is the second, and crime toward the elderly and health/medical care share the third spot. Other responses are loneliness, lack of adequate housing for the elderly, elder abuse, and financial problems.

The expansion of transportation services is highly recommended should the Territory plan to offer more social services for older people. The second recommendation is in-home care services, followed by protection against crime and an exercise program for the elderly. Repeated demands were made for exercise oriented programs. Tables 4.13 and 4.14 which appear on the following page, give a detailed breakdown of the results. Finally, the attendees were asked to indicate their satisfaction with the forum on a scale from $1-5$, with 1 representing "not at all satisfied," and 5, "very satisfied." Most of the attendees were moderately to very satisfied with the forum.

In summary, it should be noted that the community forum's ranking of unmet need is identical to that of the population survey. Although it can be concluded that a contributing factor to this outcome is that more than forty percent of the forum were older persons, the indication is that the community has an awareness of the needs of the elderly population. 
Table 4.13

MOST SERIOUS PROBLEM FACING ELDERLY

응 of

Services

Amount

respondents

\begin{tabular}{lcc}
\hline Transportation & 16 & 30 \\
In-home care & 9 & 18 \\
Crime toward the elderly & 7 & 14 \\
Health/medical care & 7 & 14 \\
Loneliness & 6 & 11 \\
\hline
\end{tabular}

Table 4.14

MOST RECOMMENDED SERUICES FOR OLDER PEOPLE

음 of

Services

Amount

respondents

Expansion of transportation

18

35

Expansion of in-home care

14

27

Exercise program

6

12

Protection against crime

6

12 


\section{METHODOLOGY OF RATES-UNDER-TREATMENT (RUT)}

\section{Data Required}

Rates-under-treatment, or RUT, is basically a technique of "calculating a utilization" rate. That rate is calculated using data representing use of service by agency clients.

These data can be obtained from public records, private practice records, or health agencies (Maddock et al.,1988). They can be utilized for identifying and describing the clientele of a specific program; for making comparisons with rates of service from an earlier period to indicate trends; and for making comparisons among similar programs and with other kinds of service delivery systems.

For example, a RUT needs assessment for a Public Administration Department of a university could look at the following data:

1. Population in $1000 \mathrm{~s}$

2. Number of public sector agencies

3. Number of public sector employees

4. Number and type of vacancies in public sector agencies These data can be utilized as the base for identifying public administration activities in the community and the potential for students in the Public Administration program.

Data required and were sought for this study include:

1. Socio-demographic characteristics of clients; e.g., age, race, sex, marital status 
ethnicity, education, occupation, \& income

2. Record of actual use of transportation, in-home care services and socio-recreational services

3. Frequency and duration of the services

4. Household characteristics

(See Appendix C for data collection form).

\section{Design and Procedure}

Several agencies that provide services to the elderly were contacted to gather data. These include the Departments of Human Services, Health, Education, and Public Works, V. I. Housing Authority, and senior citizens centers.

To legitimate the study, and maximize accessibility of the data, a rapport was established with the persons in authority to lay the foundation to access the required data. The study was discussed in some detail with the personnel whose input was needed. They were assured of the importance of the study, and were made aware of the critical role they play in the study's success. The need for and usefulness of the data were discussed. To ensure simplicity and accommodate comparability, a worksheet was prepared for each client.

Two workers were utilized to gather the information from the various agencies. Data were gathered from the following programs :

- Homemakers Services

- Home Health Care Services 
- Socio-Recreation Services

- Senior Citizens Activities Transportation

Service (SCAT)

In recording and compiling the data, several limitations were encountered. First, most of the records do not include socio-demographic documentation of any consequence. For example, the public transportation data could not be utilized since the number of older persons riding the buses is not isolated from the general population. Although it is recognized that the older population generally has different characteristics (e.g., mobility), than the general population, and that they ride the buses at a reduced rate, no estimate of their ridership could be made with any degree of accuracy. Consequently, it was not possible to gather information for public transportation, even though it plays a key role in the mobility of older persons in the Territory.

Second, the confidentiality of certain health care records require special permission from each client (e.g., home health care), before detailed information from the records could be disclosed. In this situation, the only information that was obtained from the Department of Health, is the number of clients served within a particular period of time.

Third, the information gathered covers only those receiving services from the formal system and could not identify those who may need services but are not being served. 
In summary, the information retrieved is limited and therefore, could not be utilized adequately to make the RUT approach a consequential endeavor to adequately report service use and infer need. However, the data collected, which are limited to number of clients served for specific service periods, and select demographic information, were used to calculate the use rate, or rate of utilization, for each category of service, and to determine service use trends for a five-year period. Analysis of Data

Basic to the rates-under-treatment process are the rates of services provided (McKillip, 1987). Rates can be calculated for any subgroup and program factor that can be definable. The process can be applied at various degrees of sophistication. A sophisticated method that analyzes historical data through statistical equations such as logistic regression analysis, can be implemented (Logan \& Spitze, 1994). However, identifying predictors and inferring relationships to agency programming through the computation of a use rate is one process that would provide generally acceptable data for policy making. Use rate, or rate of utilization, is calculated as follows:

(use rate $($ per 1000$)=$

\# of persons served/\# of eligibles x 1000

Specifically, rates like these are ideal tools for comparative analysis. If the comparison indicates underuse of the services, barriers to use may be examined and programs can be 
adjusted to more effectively link services to need. The use rate process was chosen for this study primarily because of the limited available data base. Also, the straightforward and simple nature of this method facilitates explanation of results to decision makers.

The use rate for the areas of transportation, in-home care and socio-recreation was calculated by first determining the number of people served, dividing that number of individuals by the number of eligibilities, then multiplying the fraction by the base. The number of eligibles in this study is 9,659 , which is the amount of persons who are 60 years and older, and represents the older population in the Territory who participate in the social service programs for the elderly.

Analysis of the available information resulted in the findings that, of the three variables -- transportation, in-home care and socio-recreation -- in-home care services has the lowest use rate, and socio-recreation has the highest use rate. The use rate analysis, and the ranking of service use for two consecutive fiscal years are demonstrated in Tables 4.15 and 4.16, respectively. The use rate is calculated based on a $60+$ population of 9,659. Table 4.17 shows the service use trend for the most recent five year period -- FY 1990 to FY 1994. 


$$
\begin{aligned}
& \text { Table } 4.15 \\
& \text { USE RATE FOR }
\end{aligned}
$$

TRANSPORTATION, IN-HOME CARE, \& SOCIO-RECREATION SERVICES

FOR OLDER PERSONS IN THE U.S. VIRGIN ISLANDS

$$
\text { POPULATION SERVED }
$$

$\begin{array}{ccc} & \text { In-Home } & \text { Socio- } \\ \text { Transportation } & \text { Care } & \text { Recreation } \\ \text { Services } & \text { Services } & \text { Services }\end{array}$

SERVICE

AGENCY

$\begin{array}{cccccc}\text { FY } & \text { FY } & \text { FY } & \text { FY } & \text { FY } & \text { FY } \\ 1993 & 1994 & 1993 & 1994 & 1993 & 1994\end{array}$

HUMAN SERVICES DEPT.
Number served
525
567
314
$296 \quad 572$
627

HEALTH DEPT.

Number served

TOTAL SERVED

USE RATE n.a.

n.a.

150

145

n.a.

n.a.

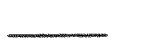

525

567

464

441

572

627 
Table 4.16

RANKING OF SERVICE USE

FOR TWO CONSECUTIVE FISCAL YEARS

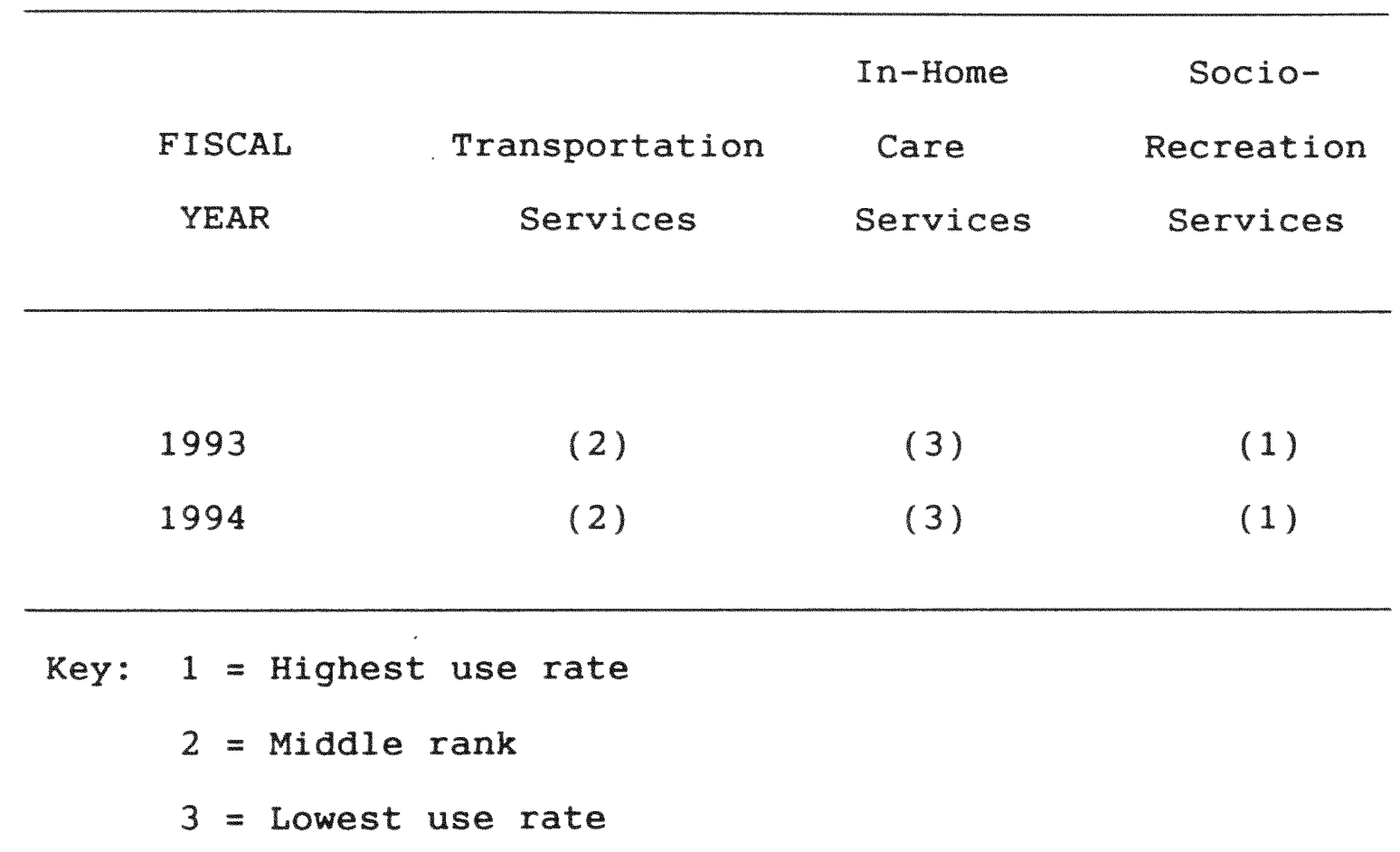


Table 4.17

CLIENT POPULATION

SERVICE USE TREND

ACCORDING TO PROGRAMS

\begin{tabular}{|c|c|c|c|c|c|}
\hline PROGRAMS & 1990 & 1991 & 1992 & 1993 & 1994 \\
\hline HOMEMAKER SERVICES & 174 & 205 & 324 & 314 & 296 \\
\hline HOME HEALTH CARE SERVICES & n.a. & n.a. & n.a. & 150 & 145 \\
\hline SOCIO-RECREATION SERVICES & 662 & 696 & 625 & 572 & 627 \\
\hline SENIOR CITIZENS ACTIVITIES & & & & & \\
\hline TRANSPORTATION SERVICES & 610 & 685 & 605 & 525 & 567 \\
\hline
\end{tabular}

Code: n.a.= data for these years are not available.

The demand for in-home care services nationwide, is attributed to the simultaneous aging of family members along with their frail relatives, and the decreasing pool of women caregivers (Monk \& Cox, 1991). Impacting also, on this service are the 1987 changes in hospital discharge policies which require 
that hospitals discharge patients during an early stage of convalescence (Special Committee on Aging, 1986, cited in Monk \& Cox, 1991).

In the Territory, the major portion of formal in-home care is provided through the Homemaker Services program. In fiscal year 1994, this program served 296 older persons. As can be observed from the service use trend in Table 4.17 , the number of clientele in this program increased steadily between 1990 and 1992, but the clientele decreased continually for the following two years. According to a 1994 Budget Report of the Department of Human Services, the agency that provides the major in-home care services to the elderly, this declining number of clients is attributed to budget cuts and the difficulty in recruiting inhome care workers.

Like in the other two areas of service in this study, the analysis for in-home care takes into consideration only that care provided by the social services agencies. This is significant, especially in the case of in-home care services, because the sentiment is that service providers in the formal system are not best suited for providing in-home care (Logan \& Spitze, 1994).

Some researchers have found that properly trained personnel can provide significant relief and solace to chronically ill persons and their families (Benjamin, 1993). Nonetheless, there is no question that the predominant source of care for older persons is the informal care given by family, and to a lesser 
extent, by friends (Chappell, 1990; Olson, 1994). According to 0lson, $80 \%$ of all long-term care in the United States is provided by families.

Given these sentiments, the possibility is that there is a sizeable amount of in-home care being provided by family members and friends in the Territory. It is believed also, that in-home care is being given by private providers and paid for by the clients themselves or their families. As was reported by The Urban Institute (Summer 1994 report), home care for the disabled elderly is being used as a complementary form of long-term care rather than a substitute for it, and increasingly, the elderly are paying for home care themselves.

The socio-recreation programs provided by the Department of Human Services served 627 seniors in the Territory during fiscal year 1994, approximately $86 \%$ of whom are clients of multipurpose senior centers. This figure is an increase of approximately $10 \%$ over 1993, following a decrease between fiscal years 1992 and 1993.

It is no surprise that socio-recreation activities through the senior centers is experiencing a high rate of demand and participation. These centers are a forum for sociability, and attract those elderly who are usually active in other social associations within the community (Krout, 1987; Ferraro \& Cobb, 1987). This finding supports past research which found that social interaction is the most significant predictor of whether 
or not a person attends a senior center in the past year (Logan, 1994).

The transportation of senior citizens in the Territory is linked to the senior center activities, and provides the opportunity for older persons to participate in the senior center activity programs, and in other special activities sponsored by the Department of Human Services. The service was provided to 567 individuals during FY 1994. This is a slight increase over a 525 figure for the previous fiscal year. The drop in figures from fiscal year 1992 to 1994 reflects a freeze on admission by the government because of limited resources. The freeze was lifted during fiscal year 1994.

The analysis of the rates-under-treatment technique reveals that, service use records did not provide adequate information to determine which of the three need areas are the highest or lowest unmet. The records indicate that only a small portion of the older population is being served, and there is no indication of how many elderly in the remainder of the population are in need of the services.

This finding is supported by previous research findings which conclude that most formal services for older persons are used by only a minority of that population in a community (Logan \& Spitze, 1994). 


\section{METHODOLOGY OF THE SOCIAL INDICATORS ANALYSIS}

\section{Data Required}

Social indicators analysis, or social area analysis, as labeled by Ciarlo et al. (1992), is a needs assessment technique that is helpful in assessing the need level of a community, establishing general priorities, measuring program input, and documenting change over time. It accomplishes these tasks by endeavoring to compare relative needs of the community by area and population groups.

The first step in deciding on the appropriate data for this study was the examination of some factors that have widespread use in past studies as indicators of social and personal problems encountered by older persons. Those usually focused upon are:

1. Characteristics of the population - age, sex, marital status

2. Housing characteristics

- housing tenure

- household size

- relationship of household members

3. Education

4. Income

5. Health or functional ability levels

The next step was to determine what factors could be selected as indicators to infer needs of the older population for transportation, in-home care, and socio-recreation services. 
The extent to which reliable data were available to provide measurements of the need areas was examined. The result was the determination that the major source of information for the study would be the U. S. Census. This decision was made because census data are readily available, and they are the most reliable statistics on the study population if the timing of the study is close to the census year, and/or there has not been significant change in the population between the census year and the time of the study. Based on observed trends, the assumption of this study is that the demographic composition in the Territory has not changed significantly between 1990 and 1994.

The age bracket used as the focus of this analysis is the 65 years and older population because this is the age range for which the major portion of the information is reported. To supplement the census data and facilitate the ranking of the variables, service use as well as waiting lists for services were utilized.

\section{Unit of Analysis}

The choice of a unit for analysis for a study such as this carries with it extremely important consequences. For example, if one chooses to analyze Census tracts, the large size and the heterogeneous nature of the tracts tend to obscure the relevance of certain types of data (warheit et al., 1977). Conversely, the use of a much smaller unit of analysis, such as block groupings, can result in thin data and unwieldly number of blocks. 
The unit for analysis chosen for this study is the "Territory". This decision was made since the Territory as a whole is a relatively small area. Additionally, although the Territory is divided into two districts for administrative purposes, there is only a slight variation between the two districts in regards to social and demographic data. Moreover, the Territory as a unit for analysis provides an excellent base for longitudinal studies since economic and social analyses are typically territory-based.

\section{Design and Procedure}

A statistical technique that can be used in social indicators analysis is discriminant analysis. This technique has the ability to classify individuals or objects into groups with some degree of accuracy. It has been used in a variety of disciplines, including health, and education (Dillon \& Goldsmith, 1984).

Factor analysis is a statistical technique more commonly used. The utility of this method is that it takes variables and reduces them into a smaller number of indicators which express that which is common among the original variables (Dillon \& Goldsmith, 1984). This technique is based on the assumption that if a large number of variables are intercorrelated, the interrelationships may be due to the occurrence of one or more underlying factors. The variables which have a high correlation with a particular underlying factor should be srongly related to 
each other. This correlation between a certain item and a factor is represented by a factor loading. It is assumed that the items with the highest "loadings" are the best indicators for those factors.

The factor analysis approach has been used for human services planning since the late 1960s. A criticism of this approach is that, if the related variables do not make sense conceptually, the analysis is of little value to the researcher and decision maker. Both the discriminate analysis and factor analysis were used in a social indicators analysis to assess the needs of alcohol-related services in Los Angeles, California. The study resulted in overall need index scores reflecting relative need for services in each of the planning areas.

Indicators of need can also be ascertained by other simplier methods. One such method is by the selection of indicators that have already been tested through other studies as valid indicators of need for specific communities, and the ranking of those indicators for each of the variables being analyzed.

This method was selected for the study because of its simplicity and its ability to produce acceptable results for decision makers. As with the use of discriminant analysis and factor analysis, selection of the appropriate data for analysis is critical for producing sound results.

Data were gathered from the following 1980 and $1990 \mathrm{~V}$. I. Census reports: 
1. Census of Population - General Population Statistics

2. Census of Population \& Housing - Social, Economic, and Housing Characteristics

3. Census of Population - Social \& Economic

Characteristics

After carefully reviewing the pertinent literature, the following six (6) social indicators were selected:

1. Characteristics of the population - age, sex, marital status

2. Housing characteristics

- household size

- relationship of household members

3. Income

4. Transportation

5. Education

6. Service use statistics

These indicators were chosen because they are the basic characteristics of the elderly that impact on needs in a variety of situations. Their relationship to the need variables of this study is explained in the following analysis of data.

Analysis of Data

From the census data, it was possible to predict needs through the ranking process, and to analyze trends. The three need variables were ranked on each of the indicators according to the analysis of variables that are believed to infer need in the 
tested areas. As can be observed from Table 4.18 the highest unmet need is for transportation services, and the lowest is for sociorecreation services. Typically, in social indicators analysis, a degree of subjectivity in selection of the variables and in the ranking process occurs. This analysis is no exception.

Table 4.18

RANKING OF NEED AREAS

ACCORDING TO SOCIAL INDICATORS ANALYSIS

$\begin{array}{ccc}\text { Transportation } & \text { In-Home } & \text { Socio-Recreation } \\ \text { Services } & \text { Services } & \text { Services }\end{array}$

RANKING OF

NEED AREAS

3

2

1

Key: 1 = Lowest ranking unmet need

2 = Middle ranking

3 = Highest ranking unmet need

A review of the level of and trends in the social characteristics of the Virgin Islands population indicates that between the 1980 and $1990 \mathrm{U}$. S. census periods, the 65 years and 
older population increased almost forty-five percent (44.8\%). (See Table 4.19). This cohort of older persons now comprises $6.37 \%$ of a total Virgin Islands population that has a median age of 28.2 years. With the increase in the number of the elderly came an increase in their inability to take care of themselves, and a decrease in their mobility.

Limited mobility has implications for the three need areas, but particularly, it poses a transportation problem for these individuals. Another factor that serves to compound the situation is the large percentage of occupied housing units with one vehicle or no vehicle in the household. Although the amount of units with no vehicle has decreased between 1980 and $1990,26.8$ percent of the units remain without a vehicle. And, another $43.7 \%$ of the housing units are equipped with only one vehicle for each unit.

An assumption is that, even with a vehicle in the unit, many of the older members of the household do not drive. They must rely on others for means of transportation, especially family members or friends to access community affairs, and special and other activities in their lives. Very often these non-driving elderly remain at home rather than ask a relative or friend to drive them, because they perceive themselves as being a burden on others.

The sitution is compounded for older persons who depend on transportation to enable them access to health and other facilities. It is especially difficult for the disabled, the more 
Table 4.19

SEIECT SOCIAL AND ECONOMIC CHARACTERISTICS

OF THE U. S. VIRGIN ISLANDS POPULATION

CHARACTERIST ICS

1980

1990

OF OF CHANGE

POPULATION CHARACTERISTICS

Total population

Male

Female

$65+$ population

Male 65+

Female 65+

With mobility limitation

With self-care limitation

$\begin{array}{rrr}96,569 & 101,809 & 5.4 \\ 46,204 & 49,210 & 6.5 \\ 50,365 & 52,599 & 4.4 \\ 4,475 & 6,479 & 44.8 \\ 1,981 & 2,841 & 43.4 \\ 2,494 & 3,638 & 45.9 \\ 605 & 829 & 37.0 \\ \star & 641 & \text { n.a. }\end{array}$

HOUSING CHARACTERISTICS

Total families

Total households

Persons 65+ in households

Householders $65+$

Householders 65+ living alone

Persons living in group quarters

Persons $65 \pm$ in group quarters

In institutions

In other group quarters

Median age

INCOME AND POVERTY CHARACTERISTICS

20

20,855
28,329
4,373
2,307
1,291

620

102

97

5

22.5
23,012

32,020

6,312

4,165

1,644

1,321

167

130

37

28.2

10.3

13.0

44.3

80.5

27.3

113.1

63.7

34.0

6.4

25.3
59,310

38,082

4,254

$\$ 11,914$

$\$ 11,090$

$\$ 10,173$

446

5,893
70,323

41,769

9,440

$\$ 24,036$

$\$ 22,050$

18.6

9.7

121.9

101.8

98.9

$\$ 12,848 \quad 26.3$

$\begin{array}{ll}313 & -29.8\end{array}$

$5.349 \quad-9.2$

(cont'd) 
Table 4.19 (cont'd)

\begin{tabular}{|c|c|c|c|c|}
\hline CHARACTERISTICS & 1980 & 1990 & OF & CHANG \\
\hline $\begin{array}{l}\text { Persons with income below } \\
\text { poverty level } \\
\text { Persons } 65+\text { with income below } \\
\text { poverty level }\end{array}$ & $\begin{array}{r}31,958 \\
1,528\end{array}$ & 27,334 & & $\begin{array}{r}-14.5 \\
28.0\end{array}$ \\
\hline TRANSPORTATION CHARACTERISTICS & & & & \\
\hline $\begin{array}{l}\text { Occupied housing units } \\
\text { Units with no vehicle } \\
\text { Units with } 1 \text { vehicle } \\
\text { Units with } 2 \text { or more vehicles }\end{array}$ & $\begin{array}{r}28,329 \\
9,787 \\
13,379 \\
5,163\end{array}$ & $\begin{array}{r}32,020 \\
8,581 \\
13,993 \\
9,446\end{array}$ & & $\begin{array}{r}13.0 \\
-12.3 \\
4.6 \\
83.0\end{array}$ \\
\hline $\begin{array}{l}\text { EDUCATION CHARACTERISTICS (FOR } 65+ \\
\text { Less than } 5 \text { th grade } \\
5 \text { th to } 8 \text { th grade } \\
9 \text { th to } 12 \text { th grade } \\
\text { Some college or associate degree } \\
\text { Bachelor's degree or higher }\end{array}$ & $\begin{array}{r}\text { POPULAT } \\
499 \\
1,873 \\
612 \\
301 \\
515\end{array}$ & $\begin{array}{r}747 \\
2,486 \\
2,020 \\
540 \\
686\end{array}$ & & $\begin{array}{r}49.7 \\
32.7 \\
230.0 \\
79.4 \\
33.2\end{array}$ \\
\hline
\end{tabular}

Sources: U. S. Census 1980

U. S. Census 1990 
than $25 \%$ of older persons who live alone, and the females, who represent more than 56\% of the elderly population in the Territory. Older persons who live alone comprise one of the most vulnerable and impoverished portion of the population. Nationwide, this group constitutes 30.5\% of America (Aging America, 1991). Elderly females on the national level comprise $68 \%$ of those elderly.

The need for transportation appears to be more pronounced because of the apparent need for older Virgin Islanders who are not disabled, to seek modes other than the private automobile; more especially, public transportation. Further, the limitation of public transportation in the Territory presents a barrier to transportation for those who must use the service. The bus routes do not accommodate the older persons' need to be picked up and dispatched in close proximity to their residences. This is evident, especially in St. Croix, where a large number of housing units are located at a distance from the main arteries of the towns. For a large percentage of older Virgin Islanders, therefore, the public bus service can only minimally meet their need for transportation.

Taxi service is not a viable alternative for many older Virgin Islanders, and especially for the more than $30 \%$ whose income fall below the poverty level. This figure almost triples the national rate of poverty for the elderly, which was $11.4 \%$ in 1989. For these individuals, the high taxi rate is an added 
hindrance to adequate transportation. The data indicate that these individuals have difficulty going places because of the lack of affordable transportation services.

The educational level of Virgin Islands elderly increased substantially between 1980 and 1990. The trend indicates that the elderly with 9 th to 12 th grade education increased more than any other category. This growth in the level of education translates to approximately $20 \%$, of this population with at least a 12 th grade education. This compares to a national figure of $24.8 \%$ of elderly persons who had at least a 12 th grade education in 1990.

Generally, the better educated the population, the betteroff they tend to be economically (U.S. Dept. of Commerce, 1993). However, elderly Virgin Islanders did not experience a corresponding improvement in their economic status. There was a 28 increase in the amount of individuals in this group who were below the poverty level in 1990, even though the population, in general, experienced a decrease in persons below the poverty level for the same period.

The fact that more than one-third of the elderly population have an 8 th grade or less education, helps to explain the poverty status of this population, and infers that these elderly would have difficulty in meeting their needs, especially that of transportation. The aforementioned obstacles and barriers to the use of transportation services have created a strong need in the 
older population for the expansion and/or modification of transportation services in the Territory.

Limited mobility for an increasing number of older residents in the Territory impacts also on the ability of these individuals to take care of themselves at home. Even more significant is the almost ten percent $(9.9 \%)$ of older residents territory-wide who indicate self-care limitations for the 1990 Census. These persons are identified as having a self-care limitation for six or more months, and that limitation poses a difficulty in taking care of their own personal needs, such as bathing, dressing, or getting around inside the home.

Another indicator of need for in-home care is the median household income for older persons. In a total population with a median household income of $\$ 22,050$, the median income for elderly living alone was $\$ 12,848$ at the time of the census. Further, more than thirty percent (30.2\%), or 1,956 individuals in the older population, reported family income below the poverty level. This places almost two thousand older persons at potential risk for reduced ability to provide their own health and other in-home care because of financial constraints.

When one reviews the limited in-home care offered by social service agencies in the Territory in fiscal year 1994 (service use of 45.7 out of every 1,000 eligibles), and the waiting list for institutionalization ( 28 persons) and Homemaker Services (23), the need for in-home care becomes more evident. 
The need for socio-recreation services does not appear to be as critical as those of transportation services and in-home care for the elderly. A review of socio-recreation activities in the Department of Human Services indicates the presence of a program that accommodates a large percentage of elderly who have expressed the desire to participate in such activities. As indicated in the rates-under-treatment study, 627 individuals, or $6.6 \%$ of those persons 60 years of age or older enjoyed these services during fiscal year 1994. Besides the assumption that the elderly are attracted to senior centers because of the socialization these places offer, their attendance is enhanced by the transportation provided to and from the centers.

In summary, the increasing population and the high percentage of growth for older persons in the Territory may indicate need for an expansion of services for the elderly in the three areas. However, a careful analysis of social indicators leads to the projection that transportation is the most critical of the three, with in-home care ranking closely behind. According to the indicators, there does not appear to be a critical need for socio-recreation activities at this time. The findings of the social indicators analysis regarding the highest and lowest unmet needs, are congruent with the findings of the population survey and the community forum.

A comparative analysis of the five needs assessment techniques is offered in Chapter 5. 


\section{CHAPTER V}

\section{COMPARATIVE ANALYSIS}

\section{OF THE FIVE NEEDS ASSESSMENT TECHNIQUES}

Needs assessment comes in a wide variety of forms, from simple and unsophisticated approaches to more complex and technical research efforts. There is no single approach, no best method, no one combination of methods that can be declared "best." One point can be soundly declared, however, is that a single approach will not meet even the most basic requirements of a generalized needs assessment (United Way, 1982). However, any approach or combination of approaches to be used will depend primarily on the type of data required by the decision maker. The decision maker and the researcher are the ones to decide.

Collectively, the five techniques used in this study provide a wide range of information, all of which can impact on decision making in regard to planning and allocating resources for social services for the elderly. They provide the mechanism for the community, together with public officials, to make informed and comprehensive decisions about a rapidly growing and significant segment of our community. Individually, each needs assessment technique provides valuable and varied data that decision makers can apply to specific needs of their agencies.

Collectively, and individually, the five techniques of this study provides answers to the first four of this study's six 
research questions. A comparative analysis of the techniques and responses to research questions $1-4$, are presented in this chapter.

RESEARCH QUESTION NO. 1. Which of the following is the highest ranking UNMET NEED of older persons in the U. S. Virgin Islands; and, does ranking vary by the type of technique used?

\section{a. Transportation \\ b. In-Home Care \\ c. Socio-Recreation}

The response to Research Question No. 1 is found in Table 5.1 on the following page, which illustrates the ranking of unmet needs of older persons according to the five methodologies and the three need variables. As can be observed, the ranking does not vary to any great extent by the type of technique used.

The survey findings point to a decision by the older population that their highest unmet need is transportation, and their lowest, is socio-recreation. This determination is strengthened by the opinion of the community at large, as represented by the community forum and by the predictions made from the social indicators analysis. The result is that three of the five techniques validate each other's conclusion by producing major findings. similar to each other. 
Table 5.1

RANKING OF UNMET NEEDS OF

OLDER PERSONS ACCORDING TO TECHNIQUES

\begin{tabular}{|c|c|c|c|c|c|}
\hline . & & KEY & COM. & & SOCIAL \\
\hline NEED VARIABLES & SURVEY & INF. & FORUM & RUT & IND. \\
\hline \multicolumn{6}{|l|}{ Highest Unmet Need: } \\
\hline Transportation & 1 & & 1 & n.a. & 1 \\
\hline In-home care & & 1 & & n.a. & \\
\hline Socio-recreation & & & & n.a. & \\
\hline \multicolumn{6}{|l|}{ Lowest Unmet Need: } \\
\hline Transportation & & & & n.a. & \\
\hline In-home care & & & & n.a. & \\
\hline Socio-recreation & 2 & 2 & 2 & $\mathrm{n} \cdot \mathrm{a}$. & 2 \\
\hline
\end{tabular}

Key: 1 = Highest ranking unmet need

2 = Lowest ranking unmet need

n.a. = not applicable--technique does not measure unmet need.

The findings obtained by the survey and community forum confirm a study by Gundry and Heberlein (1984) which hypothesized a difference but showed no statistically significant difference, between the findings obtained from the meeting and a survey of the 
public. It opposes the argument that opinions expressed by selfselected individuals/groups who attend community forums are significantly different from those obtained from sample surveys.

A major contributing factor for the similarity between the findings of the survey and those of the community forum is believed to be the high percentage of older persons who attended the forums. The 65-74 year old individuals made up $40 \%$ of the participants, and another 19\% were in the 55-64 age range.

The two methodologies differ, however, on the question regarding the most serious problem facing older people. The overwhelming response in the survey is physical health, while the community forum evokes transportation as the most serious problem. Table 5.2 lists the major problems faced by older persons for both methodologies.

The age factor contributes to this difference. Fifty-five percent of the survey population are 70 years of age or older, and another 28.5\% fall within the 65-69 age bracket. A large percentage of the $40 \%$ at the forum who are 65-74, are below 70 years of age.

Almost one fourth of the respondents in the survey, and more than one third of the community forum attendees cited other serious problems. Those problems include loneliness, lack of adequate housing, and crimes and abuse against older people. 
Table 5.2

MOST SERIOUS PROBLEMS FACING OLDER PERSONS

A COMPARISON OF SURVEY \& COMMUNITY FORUM

\begin{tabular}{|c|c|c|c|c|}
\hline \multirow{2}{*}{ PROBLEM } & \multicolumn{2}{|l|}{ SURVEY } & \multicolumn{2}{|c|}{ COMMUNITY FORUM } \\
\hline & Respondents & $\frac{\circ}{2}$ & Respondents & $\frac{\%}{0}$ \\
\hline Physical health & 46 & 23.0 & - & - \\
\hline Medical care & 25 & 12.5 & 7 & 14.0 \\
\hline Financial & 27 & 13.5 & - & - \\
\hline Transportation & 8 & 4.0 & 16 & 30.0 \\
\hline In-home care & 7 & 3.5 & 9 & 18.0 \\
\hline other & 49 & 24.5 & 20 & 38.0 \\
\hline None & 38 & 19.0 & - & - \\
\hline TOTAL & 200 & 100.0 & 52 & 100.0 \\
\hline
\end{tabular}

The social indicators analysis infers that transportation is the highest unmet need, primarily because of the limited mobility of more than $12 \%$ of the $65+$ population, the more than $25 \%$ who live alone, the limitation of public transportation in the Territory, and the more than $30 \%$ whose income falls below the poverty level. 
Decision makers who wish to formulate policy based on these needs assessments would get a different direction from the key informant findings. Unlike the population survey, the community forum, and the social indicators analysis, this technique finds that in-home-care is the highest unmet need for older persons in the U. S. Virgin Islands.

The key informants survey attempted to solicit information from persons in the community who might have a broad impression of the needs of older persons in the Virgin Islands. Approximately half of those informants perceive that older persons' needs for in-home care, transportation, and socio-recreation are unmet, but that the need for in-home care is the greatest. Table 5.3 gives a breakdown of the unmet needs of older persons according to the respondents in the survey, community forum, and key informants.

As can be observed from the analysis of the 5-dimensional comparison in Table 5.1, only four of the techniques measure "unmet" need. The fifth, rates-under-treatment, measures "met" need only, since the process is restricted to service use data and does not take into account those persons whose needs are not being met. The four techniques produced the same findings for the lowest unmet need. These findings strengthen the previously mentioned finding of similarity in the population survey, community forum, and social indicators analysis. 
Table 5.3

UNMET NEEDS OF OLDER PERSONS

A COMPARISON OF SURVEY, COMMUNITY FORUM

AND KEY INFORMANTS

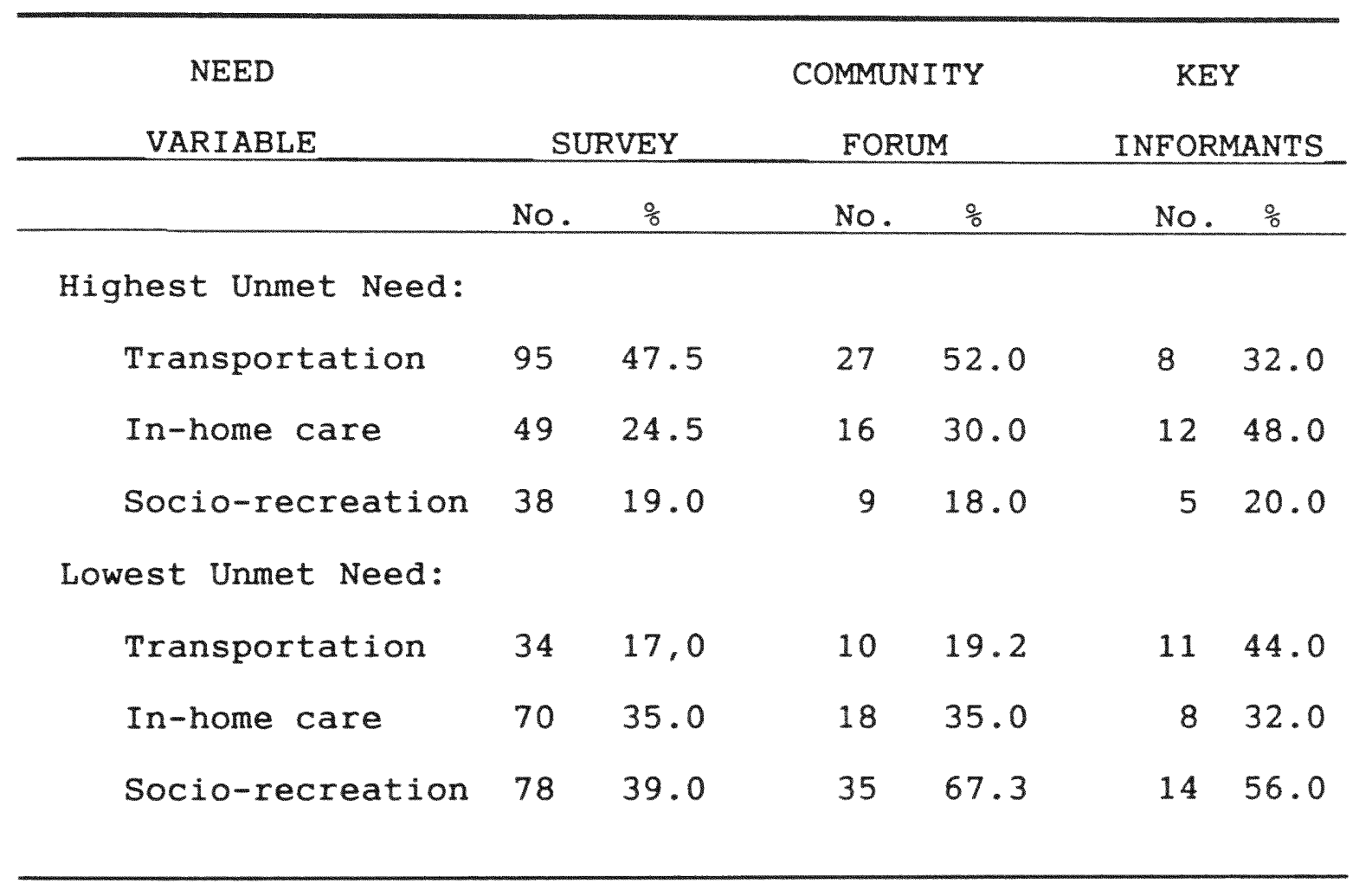

It cannot be construed from these findings, however, that the methodologies produced the same unmet needs. One has to look beyond these findings to the theoretical base of need before the meaning of these results can be determined. Each of the need assessment techniques approached the assessment of older persons' needs from different perspectives. Because of these differences in perspective, measuring the concept of need is 
inconsistent across the methodologies. This inconsistency resulted in the assessment of different types of needs and the composition of different findings. The critical difference in the findings is attributed to the categorization of needs according to how those needs are determined.

Four conceptual categories of need were identified by Jonathan Bradshaw (1977), in his attempt to guide planning for social services according to the type of need that must be met. Felt need represents a simple identification of a problem by asking a certain population whether they desire a particular service.

As is shown in Table 5.4, the population survey generated felt need. The key informants approach brought to the comparison only normative need, or the type of need that is gathered from those who are believed to be knowledgeable about the needs of the community studied. Both felt need and normative need were provided by the community forum which identified need based on the opinions of individuals at the meetings who desire the services, and others who perceive need according to their expert judgment.

Expressed need and comparative need are the results of the rates-under-treatment technique. In this methodology, the needs considered are those expressed by the clients action by use of the services, which can be compared to those not receiving the services. The social indicators analysis used indicators to look 
at trends, predict need, and make comparison with other jurisdictions.

Table 5.4

CATEGORIES OF NEED PRODUCED BY

THE FIVE DIFFERENT METHODOLOGIES

\begin{tabular}{ccccc}
\hline & KEY & COMMUNITY & & SOCIAL \\
SURVEY & INFORMANTS & FORUM & RUT & INDICATORS \\
\hline Felt & Normative & Normative & Expressed & Comparative \\
need & need & need & need & need \\
& & $\&$ & Comparative & \\
& & Felt & need &
\end{tabular}

The next section continues the analysis of these five techniques by comparing the cost, time, and validity of each and, in the process, answering research questions nos. 2,3 , and 4 .

RESEARCH QUESTION NO. 2

Which of the five needs assessment techniques is most COSTLY to administer?

The most costly of the five techniques is the population survey. The social indicators study is the least costly. Second, 
third and fourth highest in cost are the key informant, ratesunder-treatment, and community forum, respectively.

The costs involved in implementing a telephone survey is usually listed as the methodology's major disadvantage. This type of survey is reported to be the most costly of the methodologies (Maddock et al., 1988; Balacki, 1988; \& Freeman, 1989 ).

The telephone survey is reported to be the most costly of the methodologies for assessing needs (Maddock et al., 1988; Balacki, 1988; Rossi \& Freeman, 1989). Cost is usually listed as the survey's major disadvantage. This study upholds that view. Table 5.5 compares the costs for the five studies.

There are certain key elements that comprise the cost of a telephone survey. The most significant are the (1) sample size, (2) geographic dispersion of sample, and (3) interview or questionnaire length. The larger the sample size, the more hours are spent in interviews. Although there comes a point when the marginal costs of adding to the sample size begin to decline, the survey costs are generally still high.

In a telephone survey with a dispersed sample, telephone charges can be very high, therefore, the more accessible the population, the lower the sampling costs. According to one account, the average cost per telephone interview is approximately $\$ 10-\$ 15$ (Frey, 1989). 
Table 5.5

SUMUARY OF COST WITH COMPARATIVE

TOTALS FOR EACH TECHNIQUE

\begin{tabular}{|c|c|c|c|c|c|}
\hline & SURVEY & K.I. & $C \cdot F$. & RUT & S.I. \\
\hline \multicolumn{6}{|l|}{ COST } \\
\hline \multicolumn{6}{|l|}{ Professional } \\
\hline Services & $\$ 1,800$ & $\$ 1,250$ & $\$ 500$ & $\$ 250$ & $\$ 250$ \\
\hline Personnel & 900 & $-0-$ & 75 & 720 & $-0-$ \\
\hline Training & 30 & $-0-$ & $-0-$ & $-0-$ & $-0-$ \\
\hline Supplies/Materials & 95 & 20 & 10 & 10 & 10 \\
\hline Printing/Xerox & 150 & 30 & 10 & 10 & $-0-$ \\
\hline Travel & $-0-$ & 300 & 210 & 80 & 5 \\
\hline Data Processing & 150 & 40 & 10 & 5 & 5 \\
\hline Miscellaneous & 50 & 10 & 5 & 10 & 5 \\
\hline TOTAL COST & $\$ 3,175$ & $\$ 1,650$ & $\$ 820$ & $\$ 1,085$ & $\$ 275$ \\
\hline
\end{tabular}

Interview or questionnaire length and complexity impact significantly on costs. The more open-ended questions on a questionnaire, the more expensive it is to administer. That is because unstructured items add to the cost of interviewing, coding, and analysis. Additionally, telephone surveys carry a certain amount of labor, supervisory, and professional service 
costs, and costs associated with printing of the questionnaires.

Although the telephone survey is the most costly in this study, two major factors contributed to the cost being substantially lower than the average cost in this study. They are:

1. No additional telephone charges for the calls. All calls were territorial, and fell under the same area code as the interviewers'.

2. There were no open-ended questions.

The key informant approach ranks the second highest in terms of cost. Major factors in making this technique's cost lower than the population survey are the differences in the length of the key informant questionnaire, and the sample size. Critical costs in the key informant survey are the length of time for each interview, inter-island travel, and data analysis.

RESEARCH QUESTION NO. 3.

Which of the five needs assessment techniques is most TIME-CONSUMING to administer?

Cost and time go together in the undertaking of needs assessment. Surveys are known to be the most time consuming of needs assessment techniques (McKi11ip, 1987; Frey, 1989). The time that it takes for a telephone interview research varies 
according to the length of the interview, the number of interviewees, and the number of recalls made. As is indicated in Table 5.6, the survey in this study is the most time-consuming. It required almost 320 hours to be accomplished.

Table 5.6

SUMMARY OF TIME WTTH COMPARATIVE TOTALS

FOR EACH TECHNIQUE

\begin{tabular}{|c|c|c|c|c|c|}
\hline & SURVEY & K.I. & $C \cdot F$. & RUT & S.I. \\
\hline TIME (in hours) & & & & & \\
\hline Professional Services & 104 & 80 & 40 & 40 & 40 \\
\hline Personnel & 200 & $-0-$ & $-0-$ & 80 & $-0-$ \\
\hline Training & 6 & $-0-$ & $-0-$ & $-0-$ & $-0-$ \\
\hline Supplies/Materials & $-0-$ & $-0-$ & $-0-$ & $-0-$ & $-0-$ \\
\hline Printing/Xerox & 2 & 1 & $-0-$ & 1 & 1 \\
\hline Trave1 & $-0-$ & 10 & 8 & 8 & 2 \\
\hline Data Processing & 2 & 1 & 2 & 2 & 2 \\
\hline Miscellaneous & 5 & 3 & 2 & 3 & 2 \\
\hline TOTAL TIME & 319 & 95 & 62 & 144 & 47 \\
\hline
\end{tabular}

The second ranking methodology in terms of time is the ratesunder-treatment technique. A major advantage of this technique 
is that it capitalizes upon availability of existing data that offers relatively easy access (United Way, 1982; Balacki, 1988). However, in cases where data may not be readily available because of poor record keeping, bulky filing systems, and the lack of centralization of agencies that perform the services, time and costs are likely to escalate (Balacki, 1988).

As a result of encounters with some of these barriers, this approach was more time-consuming than, for example, the key informants survey. Other factors that lengthened the time are the limitation on personnel to collect the records that were available, and coordination with agencies to access their records.

Like with the cost factor, the social indicators technique is the least time consuming. The time spent for this technique was limited to the time required to locate, review, and analyze the data.

RESEARCH QUESTION NO. 4.

Which of the five needs assessment techniques is most VALID?

When one talks about validity, the concern is whether a measurement of a phenomenon successfully measures that phenomenon (Brewers \& Hunter, 1989). For example, does voter turnout measure political involvement? Validity then, refers to the accuracy of a measure. The validity of any measure is 
difficult to prove in a definitive way, particularly because the procedures for judging measurement are complicated and they do not follow obviously from most definitions.

Validity is a problem in all needs assessment data sources. The basic problem relates to the degree of consistency between a "need" and its operational definition and measurement, since there are several possible meanings for the word "need" (Kaufman, 1987).

There are two levels of concern with validity: (1) the conceptual definition of need should be represented adequately by the operational definition; and (2) the operational definition should be measurable. Given the multifaceted, multidimensional nature of the concept of need, none of the data sources used by any one of the various techniques can provide a really valid indicator of need. Therefore, the researcher and decision maker should look at the data collected from all of the sources as a symbol of only a portion of the conceptual dimensions of need. Further, they should be aware that any attempt to deal with the data as a complete definition will result in an inappropriate use of the data.

Validity can be classified under two basic categories. Internal validity refers to the cause and effect relationship between variables, for a particular sample of persons, the time covered by the study, and the social setting. External validity relates to the generalizability of the results to other studies 
involving different measures of the same variables and using different social settings, samples, populations and time periods (Brewer \& Hunter, 1989). This study is concerned with comparing the level of internal validity in the five needs assessment techniques by making comparisons across the procedures.

One of the major research procedures for controlling threats of internal validity is through the process of randomization (Nachmias \& Nachmias, 1992). This process is accomplished by selecting a sample of the study population through random assignment by using a table of random digits or any other method that assures equal probability of assignment.

Randomization serves two purposes. The first is that it facilitates the selection of samples that represent a known population within limits of sampling error; the second is that it permits the selection of samples that are comparable to each other within known limits of sampling error (Cook \& Campbe11, 1979). As the only methodology in this study that used randomization, the population survey generated information that is more internally valid than the other methodologies.

Randomization allowed for all members of the elderly population in the Virgin Islands who are reachable through household telephones to be given an equal chance of being selected for the sample. It permitted statistically valid inferences to be made about the incidence of service needs. None of the other techniques offered these conditions. 
Another factor taken into consideration in the validity of the population survey is the ratio of telephones to households. Until recently, the greatest criticism of these surveys had to do with the unavailability of a complete listing of those who were assigned phone numbers (Frey, 1989). However, the high percentage of households with telephones in the Territory eliminated that concern in this study.

Because of these two major advantages, the population survey is ranked the highest for validity. A comparison of cost, time, and validity appears in Table 5.7 .

The key informants interview is selected as second for the criterion of validity. Although several researchers contend that the findings may not represent the actual needs of the community at large (Maddock et al., 1988; Rossi \& Freeman, 1989), the theory is that in small intimate communities such as the U. S. Virgin Islands, the leaders may be closer in touch with community problems and can therefore target the needs of a particular group (Balacki, 1988).

Other factors that lead to the validity of this technique are that the key informants survey was performed face-to-face with practically all of the informants, and the interviews were implemented by the same person. A pre-test was performed, and the informants were carefully selected to represent all of the services for which needs were being assessed. 
Table 5.7

RANKING OF

COST, TIME, AND VALIDITY FACTORS

\begin{tabular}{|c|c|c|c|c|c|}
\hline & & $\mathrm{KEY}$ & COMMUI & & \\
\hline FACTORS & SURVEY & INFORMANT & FORUM & RUT & INDICATORS \\
\hline costs & 1 & 2 & 4 & 3 & 5 \\
\hline TIME & 1 & 3 & 4 & 2 & 5 \\
\hline VALIDITY & 1 & 2 & 3 & 5 & 4 \\
\hline
\end{tabular}

Key: $1=\mathrm{High}$

2 = 2nd highest

3 = Medium

$4=$ Next to lowest

5 = Low

The community forum ranks third; social indicators, fourth; and rates-under-treatment, fifth for validity in regards to measuring unmet need. Even with the most extensive record keeping and recording system, the rates-under-treatment research method uses data that reflect demands, and therefore, measures only "met needs." The implementation of this technique presented an excellent opportunity for an overview of services provided by social service agencies, and the usage of those services by older 
persons. However, a meaningful assessment could not be made because of the unavailability of extensive records.

In summary, what transpired was the soliciting of input from the subject population, experts in the community, and the community at large concerning their views or perception of unmet needs of the older population in the Territory. A study of how the services are used, and the demographics and other social indicators of the population as provided by the decennial census, serve to verify, or at least assist in substantiating the subjective information collected from the three different segments of the community. The use of these five techniques for analyzing needs strengthens this study.

The fact that some of the methodologies are ranked lower in internal validity than others does not infer that any of them is incapable of answering the research questions. Rather, it infers that there may be some ambiguity as to the truth or falsity of the findings.

This needs assessment exercise suggests that each of the techniques is characterized by various strengths and weaknesses. Decision makers should select a particular method based on the type of information needed, and the goals and objectives of the planning process.

The population survey is particularly effective in documenting the needs felt by those who are targeted for the services. It is instrumental in assessing their needs and in 
obtaining a first-hand account of the effectiveness of the existing programs and the accessibility of the services. If the service agency has available resources, such as money, time and personnel, and requires detailed information about the potential clients' own needs, the population survey can be the preferred method.

The key informant approach may be preferred if the agency wishes to systematically elicit the opinion of "experts" in the field of study, and to sensitize those individuals to the needs of the target population. It must be realized that the information gathered by this technique reflects a standard of adequacy set by experts whose standards may not reflect the actual needs of the target population.

The community forum, whose cost and time consumption surpass only the social indicators technique, is ideal for soliciting community opinion about the service needs and their involvement in facilitating the planning process and strengthening community networks. However, decision makers must give careful consideration to the possibility of collecting unrepresentative data.

For a good overview of the services currently rendered within the target area to be used as a base for modifying or expanding services, the rates-under-treatment technique may be preferred by decision makers. However, this methodology addresses met needs only, as reflected by the actual use of 
services. It does not take into account the larger population that may be in need of the services and are not receiving those services. An added problem experienced with this methodology is the often-times unavailability of adequate data for extensive analysis.

The social indicators methodology is the least costly and time consuming of the techniques. It is flexible and adaptable to infer needs in a variety of areas, and can provide data on the actual social conditions of older people, by demographic groups or as individuals. The major problems decision makers would find with this approach are that it gives an indirect measure of need and can potentially involve class and personal bias in the selection of social indicators.

Each of the techniques comes with a different perspective to assessing needs. None of them, by itself, is capable of comprehensively identifying needs of a target population. The use of multiple approaches to combine perspectives on needs, is therefore highly recommended, although it should not be viewed as a panacea. With such a rapidy increasing and diverse group as the elderly, the use of several techniques may be even essential.

The absence of assessing needs before developing or redesigning human programs can result in inefficient allocation of resources, the continuation of ineffective programs, and inadequate planning for future needs. Their presence can have the opposite effects. 
Once the needs assessment data are produced, they must be channeled into the overall decision making environment of government and utilized for a variety of purposes by different levels of management. If there is success in this transition, the linking of needs assessment and decision making would be realized. 


\section{CHAPTER VI}

\section{NEEDS ASSESSMENT AND POLICY MARING \\ IN THE PUBLIC SECTOR}

This chapter addresses the issues involved in linking needs assessment to decision making. It explains the nature of decision making and the decision making process, and presents factors that link needs assessment to decision making. The major segment of the chapter focuses on the decision making survey methodology and its findings.

\section{POLICIES}

Policies are general statements or understandings which guide or channel managerial decision making and supervise the activities of employees (Weinbach, 1990). In this definition, the word "general" suggests that policies set broad parameters for decision making. Their primary purpose is to define an area within which a decision is to be made and guarantee that that decision will conform with and contribute to an objective.

The phrase "statements or understandings" implies that policies are communicated in a variety of ways (Weinbach, 1990). They may be written or unwritten, spoken or unspoken (Megginson et al. 1991; Taylor \& Devine, 1993). Policies are also communicated verbally in formal and informal settings, and can be initiated by peers, superordinates, or subordinates of 
the organization. Very often policies are simply implied by the actions of others, usually superordinates who are observed exhibiting certain patterns of behavior and decision making over time (Weinbach, 1990). The phrase "guide or channel managerial decision making" infers that policies are an attempt to shape the thoughts and actions of others.

Although policies serve as a guide for decision making, critical decision making is a prerequisite for the formulation or modification of policies. In this chapter, the concept of decision making is expressed as the forerunner for policy formulation.

\section{THE NATURE OF DECISION MAKING}

As a starting point in understanding decision making, it is necessary to explore its meaning, as well as the process involved in making decisions. A decision is defined as the act of making up one's mind or reaching a conclusion. In the management literature, decisions are broadly classified into two categories: (1) programmed decisions, i.e., routine and competitive; and (2) unprogrammed decisions, i.e., those that occur infrequently and require a separate response time (Megginson et a1., 1991; Koontz \& Weihrich, 1990).

Griffin (1990) defines decision making as the act of choosing one alternative from among a set of alternatives. Similarly, Daft (1992) defines it as the process of identifying 
and solving problems. A more specific definition comes from Megginson et al., (1991), who posit that decision making is the conscious selection of a course of action from among available alternatives to produce a desired result. Emphasis is placed on key aspects, namely, the words "conscious," "available," and "desired results."

The most relevant definition for application to this study is one offered by Gordon (1982). According to Gordon, a decision is:

$$
\begin{aligned}
& \text { "making a choice to alter some existing } \\
& \text { condition, choosing one course of action } \\
& \text { in preference to other possible courses } \\
& \text { of action, expending some amount of organi- } \\
& \text { zational or individual resources to implement } \\
& \text { the decision, and acting with the expecta- } \\
& \text { tion of gaining something desirable" (p. 235). }
\end{aligned}
$$

This definition is pertinent to this study because the study examines decision making in the public sector, and Gordon's meaning suggests that decision making is the result of a complex social process that generally extends over a considerable period of time. Decision making in the public sector meets this description. As defined by Gordon, it is a way of life for public administrators.

Over time, decision making has been described from a variety of theoretical perspectives. The most common portrayal 
is that of the rational or classical model (March, 1994). This model assumes that decision makers are logical and rational and that they choose from among alternatives and make decisions directed toward the best interests of the organization. It is prescriptive and tells how managers should make decisions according to professional points of view (Jun, 1990).

This approach is derived from models of decision making developed in traditional economic theories, such as the economic theory first projected by Adam Smith in his book An Inquiry into the Nature and Causes of the Wealth of Nations, in 1776. A Scottish political economist, Smith established the classical school of management and became the founder of liberal economics (Wren, 1994). The value system from this theory -- competitiveness and emphasis on rationality -provided a rationale for the operation of the business firm in society and influenced entrepreneurial behavior. The economic theory of the firm emerged from a broader, more inclusive macroeconomic theory in which the business manager's role was one of adaptation to market forces (Kast \& Rosenzweig, 1985). This approach emerged as a means of guiding decision making based on the observation that managers approached organizational decisions in an unsystematic and arbitrary manner.

The second decision making perspective is the bounded rationality or administrative model. This perspective is based 
on Herbert A. Simon's views that logic and rationality are not invariably characteristics of the decision making process. Instead of prescribing how decisions should be made, this model describes how decisions often are made because of time pressure and other factors, such as the political, economical, and social elements in the decision making environment (Jun, 1990).

Simon's model claims that managers are constrained by bounded rationality; have incomplete and imperfect information; and tend to satisfice when making decisions (Simon, 1976). An important aspect of the "bounded rationality" model suggests that decision makers are 1 imited by incomplete information and knowledge, their personal values, and unconscious reflexes, skills, and habits. "Satisficing" suggests that decision makers do not conduct an exhaustive search for the best possible alternative. Rather, they consider only a few choices and look at them sequentially rather than simultaneously. Once they identify an alternative that meets some minimum standard of sufficiency, they discontinue their search.

Recently, the bounded rationality perspective has become amply integrated into conventional theories of rational choice, resulting in the general acceptability of this viewpoint. It has come to dominate most theories of individual decision making and has been applied to decision making in 
political, educational, and military contexts (March, 1994). This perspective is often associated with the intuitive decision making process in which decisions are made based on experience and judgment, rather than on sequential logic or explicit reasoning (Daft, 1992).

A third decision making perspective is the vigilant problem solving approach offered by Janis (1989). This approach focuses upon making successful decisions by eliminating symptoms of defective decision making before implementing policy changes. In proposing this perspective. Janis takes into consideration, and attempts to pull together, the different approaches to research on policy making offered by a wide array of fields.

Vigilant problem solving assumes that a quality decision making procedure is one of the major determinants of a successful outcome; that top level decision makers are capable of implementing procedures necessary for high-quality decision making; that decision makers resort to "quick-and-easy" decision making for unimportant issues, and that, even when the issue is important, decision makers' thinking, in many instances, can be dominated by constraints to successful decisions which can lead to decisions based on simplistic reasons. 


\section{THE DECISION MAKING PROCESS}

The decision making process has attracted much attention during recent years. The search for influence over decisions, access to decision makers, and accountability of decision makers, attest to the importance attached to the process.

The rational approach process, as described by Megginson et al. (1991), consists of the following steps:

1. The recognition that there is a problem to solve or an opportunity to seize.

2. The development of alternative courses of action.

3. The evaluation of advantages and disadvantages of each alternative.

4. The selection and implementation of the preferred al ternative.

5. The evaluation of the results of the decision and the reinitiation of the process if the decision does not work.

The bounded rationality process begins much like the rational process, in that there is the recognition of a situation, a condition, or a "problem" to be corrected, or that there is a potential for future problems. However, as strategies begin to develop, they are shaped by the knowledge and technology in existence, the availability of resources (financial and others); and the political feasibility of the 
strategies. Inevitably, the question shifts from "what should be done" to "what can be done" (Maroney, 1991).

The vigilant problem solving process, like bounded rationality, begins with the formulation of the problem. From the beginning, a vigilant problem-solving strategy to deal with threats and opportunities is put into place as decision makers are required to ask and answer key questions that emphasize critical evaluation feedback.

Regardless of the direction taken, alert decision makers are aware of the significance of that first step in the decision making process. They know the importance of properly defining and understanding the situation (Megginson et al., 1991).

The significance of this first step is embraced by the Kepner-Tregoe decision making model, which indicates that defining the real problem is critical for making an intelligent, valid decision about a solution (Kepner \& Tregoe, 1985). This model, which over the last two decades has been taught to managers in some of the largest organizations in the world, distinguishes between problem analysis (getting to the cause of the problem), and decision making (deciding what to do about it). It maintains that, only after the problem is defined, and the situation well understood, is the decision maker prepared to proceed to the next step on the decision making process. 
A well known tool for defining problems and paving the way for comprehending the magnitude of the situation and effectively making decisions and formulating policy, especially in the area of social services is the needs assessment (Harlow \& Turner, 1993).

\section{LINKING NEEDS ASSESSMENT TO POLICY MAKING}

The collection and analysis of information which occurs in a needs assessment is only the beginning. What determines the usefulness of this data gathering exercise, no matter how credible the data may be, is how the knowledge acquired from the raw data is utilized to formulate policy and impact the social services delivery system (Neuber et al., 1980).

Linking this research knowledge to policy formulation is by no means a straightforward undertaking, according to Dluhy (1981; 1988). Quinn and Mueller (1991) agree. They believe that the biggest problem in managing research today is getting research findings effectively transferred into action. Moving this knowledge from the world of the researcher and into the realm of public policy and the decision making process is dependent on other inherent and fundamental factors besides the knowledge itself. These factors are relevant to applied research in general, but will be directed in this study to needs assessment research, in particular. 


\section{Factors that Affect Linking Needs}

\section{Assessment to Policy Making}

Inherent in the political system are factors that substantially influence whether the findings of a needs assessment would be linked to public policy decision making. Several of these factors offered in the literature are:

\section{Differences in Work Culture}

There are fundamental differences in work cultures between researchers and decision makers who use the research information to make policy decisions. On the one hand, researchers tend to view the decision making process as messy. difficult to understand, and irrational. They desire a more systematic process, and especially more time to perform their tasks (Verdier, 1984; Frenk, 1992). Very often they are preoccupied with standards and norms for doing the research, and show little concern for completing the study in a timely manner so that the decision makers can utilize the findings (Dluhy, 1981; 1988).

On the other hand, policy makers tend to become frustrated with researchers' tendency to spend a great deal of time on analysis and not enough time on producing strategies. Policy makers operate in such a dynamic system -- characterized by short time frames, busy days and continual political pressures -- that they are forced into what Charles Lindblom (1959) calls incremental decision making. 
Lindblom contends that public policy makers arrive at decisions by going through a series of limited successive comparisons. They operate within a relatively narrow range of alternatives rather than a comprehensive one and use the status quo as a key point of reference to arrive at decisions. These policy makers focus on short-term needs and on solving problems with short-term solutions.

\section{Timing}

To compound the situation, researchers are often mandated by proposal requests to complete research within a tight turn around time. Research completed within this kind of unrealistic time frame generally does not produce the high quality results that decision makers require to effectively intervene in the problem area. And, in instances where the researcher fails to produce results within the decision makers's time frame, the tendency is for the decision maker to select choices from other alternatives and move on to the next issue (Dluhy, 1981; 1988). Dluhy points out that removing the time constraints from public decision makers' environment is a difficult, if not impossible, task. Among some of the more significant reasons he cites are the crises-oriented decision making process, the unstability of the larger social and economic environment, and the large size of government and of its wide scope of responsibilities. 


\section{Feasibility of Alternatives.}

The feasibility of the alternatives given by the findings is especially important. Conflicting interests, such as cost, values and beliefs, political support or opposition, and the needs assessment finding itself must be balanced by the decision maker in order for him to arrive at a feasible alternative (Dluhy, 1981; 1988). Feasibility of findings is often not a major concern for the researcher. Decision makers, however, must be aware that if implementation of the research findings is not feasible, those findings have little chance of being utilized.

\section{Funding}

The availability of funding influences the use of needs assessment information by policy makers. Research presented during a time of funding shortage is likely to have very little or no impact on resource allocation or policy making decisions. On the other hand, where funding is available, utilization of the information is likely to occur (Nagel, 1991).

It is the assumption of this research that the underlying and most critical factor that contributes to linking needs assessment to decision making is the acceptance of the findings of the needs assessment and the methodology used to obtain those findings. If the decision maker who formulates the policy does not accept what the researcher presents, implementation of the findings will not be possible. 
An elite survey of decision makers in the public sector of the Virgin Islands was instrumental in investigating this issue. In the remainder of this chapter the methodology of the elite survey is presented.

\section{METHODOLOGY OF THE DECISION MAKER SURVEY}

\section{Sampling}

A sampling procedure not unlike the key informants survey was used to select the decision makers for this survey. The study bordered on the concept of a task force, except that the interviews contributed individually, rather than collectively, to the purpose of the study. Like members of a task force, the respondents in this study have an expertise in the area of concern -- decision making for policy formulation. They were selected because they serve as key personnel who constantly make decisions and choices about what is to be done, who is to do it, and when, where, and sometimes, how it will be done within the public sector.

Forty three individuals were selected from the larger population of decision makers in the public and non-profit organizations in the Territory. These individuals were selected from the pool of decision makers based on their level of management, type of position, decision making experience, tenure, and type of service the agency provides. Those selected from the legislative branch represented senators and 
chief staff persons who are presently, or have been in the most critical positions in that branch of government for making decisions regarding issues of social concerns and finance.

They include the President of the V. I. Legislature, chairperson of the Finance Committee, chairpersons of other standing committees closely connected with social service issues, and other legislators and staff persons. The same rationale was used to select the executive branch decision makers, who were represented by cabinet level officials, top management officials, and middle management individuals.

Also included in the sample are leaders of three nonprofit organizations. These individuals were selected because of their involvement in the provision of services to a broad cross-section of the community.

To increase the representativenes of the sample, an attempt was made to obtain a sample that reflects the general population of public decision makers on the basis of gender. The sample reflects a top and middle management public decision making population that is at least $80 \%$ female. (A) listing of the decision makers is found in Appendix D).

Thirty-two percent of the decision makers in this survey were interviewed for the key informant survey which was included in the comparative analysis presented to decision makers. Since these individuals played a double role, the assumption is made that the possibility exists for the 
occurrence of a spurious relationship. Certainly, their responses for this question could have been influenced by their knowledge that they participated in the key informants study. Inclusion of a certain percentage of this group was unavoidable, since the "expert" key informants involved in provision of services to the elderly are also key decision makers in the public sector.

Survey Instrument

Survey questionnaires are a common means of gathering information on a variety of issues. When used appropriately, questionnaires have the advantage of being both quantitative and democratic while at the same time offering a relatively painless and low-cost way of getting information (Zemke \& Kramlinger, 1982). The questionnaire is the appropriate instrument for this decision makers' study because it facilitates the interview process.

The search for a questionnaire format appropriate for this study was futile. Consequently, an instrument was formulated, based upon the review of the literature, and the goals of the study. The result of this effort was a 5-page instrument involving 23 questions, several of which comprise multiple subsections.

Objective fixed alternative and open-ended questions were utilized to allow for specific and direct objective responses to facilitate coding and analysis, and to afford the 
researcher the flexibility needed to probe the interviewees for details and clarification of their responses. Several of the fixed alternative objective questions were followed by questions that permitted expansion or explanation of responses.

The survey instrument was divided into three sections. The first section solicited demographic information. The other sections placed emphasis on management style, perception of the elderly's constituency, and the status of social programs for older persons. The survey culminated with questions pertaining to the use of needs assessment and the influence of various factors inherent in needs assessment on decision makers' activities.

To validate the instrument, two individuals -- the Special Assistant to the Commissioner of Human Services in charge of program development, and a research analyst at a nonprofit, federally funded organization assisted in constructing the questionnaire.

\section{$\underline{\text { Procedure }}$}

Five individuals were interviewed in a pre-test implemented in an attempt to reduce validity and reliability problems. Several glitches were discovered, and modifications were made. The pre-test indicated a high interest by decision makers in the study. 
The initial step in the interviewing procedure was to solicit the respondents' cooperation in providing the desired information. To facilitate that process, telephone contacts with the respondents were made to explain the nature of the study and to attempt to induce their interest. The respondents were told why and how they were chosen. They were made aware of the importance of the study to public policy studies.

After the scheduling of appointments, I administered the 43 interviews personally according to the respondents' time schedule. The decision makers were interviewed, face-toface, in their places of employment between 8:00 a.m. to 5:00 p.m., Mondays through Fridays, primarily in the mornings, during a four-week period. The interviews were of the nonscheduled-structured form, and proceeded on the basis of an interview guide. The interviewing time was approximately 45 minutes.

The personal, face-to-face interviewing method was used for several reasons. Inherent in this type of survey is a high response rate (Nachmias \& Nachmias, 1992), since a personal interview can capture respondents who are unwilling to take the time out on their own to respond to a mail questionnaire, and those who have difficulty reading, writing, or understanding the question content. This rate of response can lead to greater scientific validity of the data because the higher the rate of response, the more representative the 
sample (Nachmias \& Nachmias, 1992). Further, utilizing this method facilitated flexibility in the questioning process, controlled the interview situation, and allowed the respondents the liberty to express themselves.

The format of the questionnaire was followed, though informally, and caution was taken to avoid influencing the opinion of the respondents. Because previous studies have shown that even a slight modification in how the questions are presented can change the response (Nachmias \& Nachmias, 1992), questions were asked exactly as stated in the questionnaire, and in the same order. The respondents were allowed to elaborate on their responses to allow for a full insight into their views.

The terms in the questionnaire that might have been unfamiliar to the respondents were fully explained. This type of caution is extremely important in a study such as this which solicits views from a set of individuals in the public sector who are involved in varied decision making situations. During the interviews, care was taken to interact pleasantly and enthusiastically with the respondents. Realizing that nonverbal cues are important in face-to-face interviews, the personal reactions, specific emotions, and other non-verbal expressions displayed by the respondents during the interviewing sessions were especially observed. The questionnaire appears in Appendix $\mathrm{H}$. 
Findings and Analysis of Data

Upon completion of the interviews, the questionnaires were numbered and formatted. A coding system was devised and the questionnaires were coded in preparation for computer analysis. The SPSS statistical computer software was utilized for the analysis. Data are reported on a territory-wide basis, since most of the respondents represent organizations with territorial responsibilities. Tables 6.1 and 6.2 show demographic and job characteristics of the decision makers.

Table 6.1

DEMOGRAPHY OF DECISION MAKERS

Characteristics

Frequency

$\frac{\circ}{\partial}$ of respondents

Sex:

Male

15

34.9

Female

28

65.1

Age:

25 - 34 years

4

9.3

$35-44$ years

8

18.6

45 - 54 years

22

51.2

55 - 64 years

8

18.6

(cont'd) 
Table 6.1 (cont'd)

Race/ethnic background:

White

Black

Other

Marital status:

Single

Married

Divorced

widowed

Educational background:

High school graduate

2

Attended college

College graduate

Attended graduate school

Graduate degree
2

38

2

5

27

9

2

11.6

62.8

20.9

4.7
4. 7

88.4

4.7 
Table 6.2

JOB RELATED CHARACTERISTICS

Frequency $\quad \%$ of respondents

District represented:

Both districts

St. Thomas/St. John only

St. Croix only

Type of organization:

Public

Non-profit

Branch of government:

Executive

33

76.7

7

2

40

93.0

3

$$
7.0
$$

16.3

4.7

Legislative

Length of time with organization:

Under 1 year

1 - 5 years

6 - 10 years

11 - 15 years

16 years or more

Level of management:

Upper

Middle

Lower
8

5

11

10

3

14

74.4

18.6

政 
As an important part of management, leadership plays a substantial role in decision making. Based on the use of authority, leadership styles can be classified as autocratic, democratic (or participative), and laissez-faire (Koontz \& Wiehrich, 1990).

Because of the importance of management style to decision making, the respondents were asked to discuss how they make decisions. A strong tendency toward a democratic style of management was projected from these discussions. This is not surprising since the central message carried throughout the literature is that the democratic style of management is the preferred one (Mcclellan \& Burnham, 1995), although autocratic and laissez-faire leadership have been found to be most effective in some situations (Van Fleet \& Yukl, 1986). However, it is difficult to get an accurate indication of how people make management decisions by talking directly to those individuals about their decision making style. Research findings dictate that observations of decision makers' behavior are better indicators than direct questions about how they behave.

Driver et al. (1990), who offer a variation of decisional styles for executive and business success, demonstrate that most people, including executives and legislative decision makers, are partially blind to how they behave. Further, they 
say, most individuals misperceive parts of their decision making behavior even though these parts may be obvious to others who work with and have the opportunity to observe the actions of these individuals.

In another study conducted by Yetton \& Crawford (1992), which reassessed participative decision making, decision makers who were offered training oriented toward a participative management style, were asked directly about their leadership style as a follow-up to the training. The overwhelming response was that they see themselves as participative style managers. Their response presented a major inconsistency between what they espoused as their leadership style and their actual style as indicated by their daily actions.

The decision makers in this study were asked a select group of questions to ascertain the respondents' perception of the elderly constituency in the Territory and the elderly's entitlement to social services. These questions were intended to acclimate the respondents to the elderly in preparation for the questions that followed regarding acceptance of findings of the five needs assessment studies.

Almost three-fourths of the decision makers feel that the elderly population is a significant constituency - in numbers as well as in political strength. Forty-seven percent believe 
that the elderly effectively lobby for social services. Respondents also indicate that the lobbying effort of the elderly is not as effective as it could be.

Their view regarding the growth in numbers of the elderly population is supported by reports of growth of the 65 years of age and older population in the Virgin Islands, from 4,475 in 1980 to 6,479 in 1990 , or a $44.78 \%$ increase in one decade. During this period, the percentage increase was even greater than on the national level. Comparisons of the older persons in the U.S. Virgin Islands and on the national level are made in Tables 6.3 and 6.4 . on the following page.

The decision makers' claim that the elderly are politically strong is supported by the American Association of Retired Persons' (AARP) recent nation-wide lobbying efforts for inclusion of long-term care in the national health care plan (Associated Press, 1993).

Sixty-seven percent of the decision makers affirm that the Territory has a legal mandate to provide social services, such as transportation, in-home care, and socio-recreation activities, to the elderly. However, only one-third agree that the legal mandate is adequate to meet the demands by the elderly for services. 
Table 6.3

INCREASE OF THE ELDERLY POPULATION (\%)

U. S. VIRGIN ISLANDS AND UNITED STATES

1980 pop. 1990 pop. $\quad$ o change

$\begin{array}{lccc}\text { U. S. V. I. } & 4,475 & 6,479 & 44.78 \\ \text { United States } & 222,943(\mathrm{~m}) & 246,106(\mathrm{~m}) & 10.39\end{array}$

Sources: U.S. Census \& Aging America - Trends and Projections.

Table 6.4

AGE DISTRIBUTION OF THE ELDERLY POPULATION

UIRGIN ISLANDS AND UNITED STATES

U. S. Virgin Islands

Year Tot.Pop. 65+Pop. $865+$ Tot.Pop. 65+Pop. $865+$

\begin{tabular}{lllllll}
\hline 1980 & 96,569 & 4,475 & 4.63 & $222,943(\mathrm{~m})$ & $24,524(\mathrm{~m})$ & 11.0 \\
1990 & 101,809 & 6,479 & 6.36 & $246,106(\mathrm{~m})$ & $29,041(\mathrm{~m})$ & 11.8
\end{tabular}

Source: U. S. Census \& Aging America - Trends and Projections 
By a narrow margin of $49 \%$ to $51 \%$, respondents indicate that the Territory does not offer enough programs to meet the needs of the elderly in the areas of social services. The closeness between the "yes" and "no" responses attests to a wide range of differences in how public sector decision makers perceive the provision of services for the elderly. It also demonstrates that a large percentage of decision makers are not satisfied that the needs of the elderly in the Territory are being met.

Regarding needs assessment, an overwhelming $83.7 \%$ responded in the affirmative when asked: "Does the use of needs assessment influence the way that you make a policy decision?" The overwhelming response was "yes." The consensus is that decision makers welcome needs assessment as an essential element in planning for human services delivery. They regard it as a process that assists in integrating services and identifying potential problem areas at critical times. Needs assessment, according to the decision makers, serve as a guide to program design, development, implementation, and evaluation. This view is supported by Siegel et al., (1987); Maddock et al., (1988); and Sung (1992), among others.

The consensus of those who responded negatively is that needs assessment is a routine and meaningless exercise, and it is difficult to implement. These decision makers cite lack of 
uniformity in the approaches, failure to integrate findings into the goals and objectives of the programs, and the persistent gap between researchers' perspective and the perspectives of the program directors.

Harlow \& Turner (1993), contend that the mixed reaction to needs assessment is due to the lack of understanding of the actual purpose and potential uses for the information produced by the needs assessment.

The decision makers were asked a series of questions to investigate Research Question No. 5, which is as follows:

RESEARCH QUESTION NO. 5.

Which of the following two needs assessment factors MOST influence how decision makers formulate public policy?

(a) METHODOLOGY of needs assessment, or

(b) Substantive FINDINGS of needs assessment

The response to this question begins with the assumption that the findings of the methodology are consistent with the various needs for research information. Those decision makers who indicate that they are influenced by needs assessment were asked directly: "What influence do the following methods of needs assessment have on the way that you make a policy decision? 
1. Population survey

2. Key informant survey

3. Community forum

4, Rates-under-treatment

5. Social indicators

The responses project the population survey as the most influential and the key informants as the least influential. Table 6.5 displays these responses.

Table 6.5

INFLUENCE OF NEEDS ASSESSMENT METHODOLOGY

ON DECISION MAKERS

(by percentage of responses)

\begin{tabular}{lccc}
\hline & $\begin{array}{c}\text { Very } \\
\text { Methodology }\end{array}$ & $\begin{array}{c}\text { Some } \\
\text { influential } \\
\text { influence }\end{array}$ & $\begin{array}{c}\text { Not at all } \\
\text { influential }\end{array}$ \\
\hline Population survey & 53.5 & 27.9 & 11.6 \\
Key informant survey & 7.0 & 41.9 & 51.2 \\
Community forum & 30.2 & 55.8 & 7.0 \\
Rates-under-treatment & 41.9 & 34.9 & 14.0 \\
Social indicators & 27.9 & 48.8 & 16.3 \\
\hline
\end{tabular}


There is no significant difference between executive and legislative decision makers' views on this issue. The concensus on both sides is that the population survey serves as a check on what the residents in a defined population want. By going to the source of the problem area for input on need, decision makers believe that program planners could formulate a cohesive overview of the needs of the population. It is their firm belief that the respondents in a population survey are in a far better position than anyone else to identify their own needs. This view is supported widely in the survey and needs assessment Iiterature (Sung, 1992).

Further, decision makers believe that the legitimacy of the survey is enhanced by the probability sampling process used in the method, and that its high cost and time are offset by the credibility and legitimacy of its findings. This view also is supported widely in the survey and needs assessment literature, most recently by Sung (1992).

Despite the fact that a representative number of the decision makers were interviewed as key informants, they are not influenced to any great extent by the key informant technique of needs assessment. They believe that collectively, key informants' perception of the needs of any defined community is not necessarily a true reflection of those needs. 
There is no doubt in the decision makers' minds that the key informants technique has the potential to contribute important insight and support for decision making. However, they emphasize, it should be used only as a starting point and must be followed with a direct assessment of the target population, and/or other types of assessments. Harlow \& Turner (1993), who revisited needs assessment in 1993, support this opinion.

The decision makers recognize the limitation of any one of the needs assessment methodologies. Consequently, they emphasize the importance of utilizing multiple methodologies, investigating multiple research questions, and extracting data from multiple research constituencies to define needs. The use of multiple approaches, according to decision makers, allows for gleaning of the most useful or most likely to be true information for use as a base for decision making. They believe that each technique is capable of supplementing the other in providing a comprehensive understanding of what the existing policies have achieved and what types of policy changes are needed. They see this approach as the most practical means to grasp what is worth knowing from a variety of perspectives.

To answer research question \# 5 directly, the decision makers were asked to select the one category that best finishes 
the question: "When making a policy decision, I am more influenced by:

1. Findings than method

2. Method than findings

3. Both findings and method equally

4. None

5. No opinion/no response/don't know"

As can be observed from Table 6.6 , almost seventy percent of decision makers take into consideration both the findings of a needs assessment and the method used to generate those findings.

Table 6.6

THE INFLUENCE OF DECISION MAKERS BY FINDINGS

AND METHODOLOGY OF NEEDS ASSESSMENT

(by amount \& percentage of responses)

Amount

of responses

Findings than method

8

18.6

Method than findings

4

9.3

Both findings \& method equally 30

69.8 
Decision makers' awareness of how each methodology is implemented, and the type of needs it generates, allows them to focus on the methodology as an important clue to ascertain from which perspective the findings are derived.

Findings are equally important, because decision makers view the results as critical for determining the direction their programs must take to fulfill the service population's needs. The findings dictate the setting of priorities in relation to the agency's goals and objectives.

Decision makers prefer that their goals and objectives are taken into consideration at the inception of the needs assessment process. As they expressed, having an input from the inception of the process will most likely have a stronger influence on whether or not they accept the findings and methodology. Contributing to the process, then rejecting that process and its results is counterproductive, they suggest.

In the majority of the agencies represented by the decision makers, there is a high degree of collaboration between researchers and decision makers. This collaboration exists because needs assessments are usually carried out from within the agencies, or by individuals that are knowledgeable about the agencies' needs. 
There is no significant difference between the executive and legislative decision makers' choice regarding the influence of methodology vs. findings. Seventy-two percent of the decision makers from the executive branch are influenced equally by findings and methodology, compared to $62.5 \%$ from the legislative branch.

In an attempt to categorize select factors that influence decision makers' formulation of policy decisions, the respondents were asked whether they are influenced more by political, legal, or management factors. A comparison between decision makers from both branches of government reveals that executive decision makers are influenced more by management factors, as expressed by more than $65 \%$ of the respondents. Seventy five percent of the legislative decision makers chose legal factors as the most influential. A breakdown of the information, according to branch of government, appears in Table 6.7. Executive decision makers admit that, although management factors influence them the greatest, other factors, such as personal knowledge; personal feelings; experience; legal, social, and political forces; intuition; and funding infiltrate the decision making process. The degree to which each of these factors is present depends on the nature of the decision to be made and the condition under which implementation is to take place. 
Table 6.7

FACTORS THAT INFLUENCE EXECUTIVE AND LEGISLATIVE DECISION MAKERS IN MAKING POLICY DECISIONS

(by percentage of responses)

\begin{tabular}{lccc}
\hline & Legal & Political & Management \\
Decision Makers & Factors & Factors & Factors \\
\hline Legislative & 75.0 & 12.5 & 12.5 \\
Executive & 31.3 & 3.2 & 65.6 \\
\hline
\end{tabular}

If you should ask any political scientist to name the major influences on a legislative decision maker, the response will probably involve constituent demands, party leaders, campaign contributions, lobbyists, committee colleagues, and the local news media. According to Angle (1993) and the decision makers in this survey, all of these would be perfectly good responses.

The legislative decision makers indicate that they tend to put managerial functions on the back seat. They concentrate on how to deal with interest groups, the press, and other legislators, and ultimately, how to enact laws to satisfy their constituents' demands. They emphasize that the legal 
aspect of decision making is a 'given' in their role of formulating public policy to solve societal problems.

An explanation for this behavior lies in the differences in the executive and legislative management cultures. These differences were found by Gerald Gabris (1992), who used strategic planning to expand cooperative decision making between elected and appointed government officials; by Judith Ross (1993), who looked at decision making in social work; and by Richard Nathan (1993), who explains the management challenge of implementing workfare, in his book, Turning Promises into Performance.

Because public executives have to respond so frequently and extensively to dynamic and fast changing conditions, they develop a management culture that emphasizes several core values that define their role expectations (Gabris, 1992). Implicit in this culture are certain professional management values that are oriented toward emphasizing high quality, and objective analysis of policy issues. In this culture, it is expected that the executive decision makers must resolve and mitigate the inevitable political demands from the external environment without sacrificing those professional management values.

The executive decision makers, collectively, tend to be mission-oriented, although many of them are appointed 
officials, accountable to the politicians who select them. They are expected to follow the rational decision-making model, acting according to a unified set of preferences which guide their action (Ross, 1993).

A study comparing the behavior of executives in community service organizations with executive behavior in social welfare, education, and business from an international perspective, found that executives are preoccupied with routine administrative tasks (Schmid et al., 1991), a trait that characterizes the executive's influence by management factors.

Legislative decision makers, on the other hand, operate under different conditions within an elected-official culture (Gabris, 1992). They are not inclined to become involved in long-term planning. Rather, they focus on immediate issues and goals, which they feel can be accomplished with a minimum of analysis. Legislative decision makers believe that any problem can be solved right away.

There is an indication however, that this cultural gap in decision making between executive and legislative decision makers may be closing. A 2-year study of 16 state legislatures and 900 legislators, conducted by Lillian Woo, (Holmstrom, 1993) indicates that legislative decision makers are becoming younger, more professional, issue-oriented, and self- 
selecting. Their professionalism or careerism, according to Fiorina (1994), was encouraged by the postwar good government reforms.

There is a wide range of literature on legislative professionalism (Fiorina, 1994; Lupia \& McCubbins, 1994; Berkman, 1993; Squire, 1992; and Hedlund, 1984). This literature puts legislative professionalism in a favorable light and view it as a means of strengthening the decision making powers of legislators.

The last research question of this study speaks to the issue of acceptance of needs assessment findings and the methodology used to provide those results.

RESEARCH QUESTION NO. 6.

Which TECHNIQUE and its FINDINGS do decision makers ACCEPT as the most representative of the unmet needs of older persons in the Territory, and why?

To answer this question, findings of the needs assessment studies of the elderly were presented to the decision makers and discussed in detail.

The survey and its findings were overwhelmingly selected as most representative of the unmet needs of older persons in the Territory. The second selection was the community forum, with the key informants, social indicators, and rates-under- 
treatment and their findings following in that order. Table 6.8 shows decision makers' acceptance of needs assessment methodology and findings.

Table 6.8

DECISION MAKERS' ACCEPTANCE OF NEEDS ASSESSMENT

METHODOLOGY AND FINDINGS

(By percentage of response)

Methodology

HighestLowest

1

2

3

4

5

Population survey....46.5

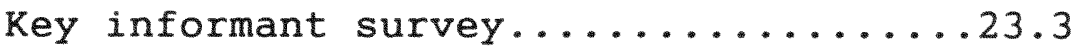

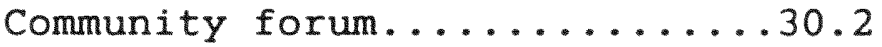

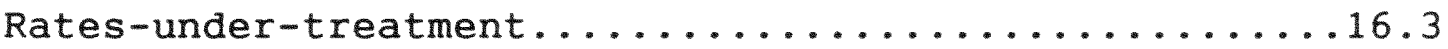

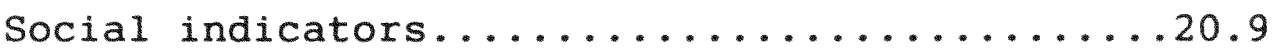

\section{ACCEPTANCE AS A LINKING FACTOR}

Acceptance of the population survey and its findings as the first choice facilitates the linking of those findings to public decision making directed toward social services for older persons in the Virgin Islands. However, regardless of 
the choice of methodology or findings, decision makers undergo a decision process that involves the influence of several factors. These factors, as determined by this study, fall into three (3) major categories:

1. Congruency of the research findings with the decision makers goals and objectives.

2. Feasibility of alternatives.

3. Credibility of the research team.

These factors are incorporated into a model of acceptance which is presented in Figure 6.1 on the following page. This model illustrates the process of accepting needs assessment research as depicted by the decision makers in this study. The model begins where the findings of the needs assessment are being made available to the decision maker. The decision maker then is influenced by several factors in the process of making a decision based on the data acquired from the researcher.

Acceptance of the methodology and findings is contingent on how the conditions of the factors are met. Finally, acceptance facilitates the linking of needs assessment research to policy making. A discussion of the linking factors will reveal that they form the umbrella for a variety of conditions, several of which overlap with other conditions within another factor. Consequently, the factors are not mutually exclusive. 


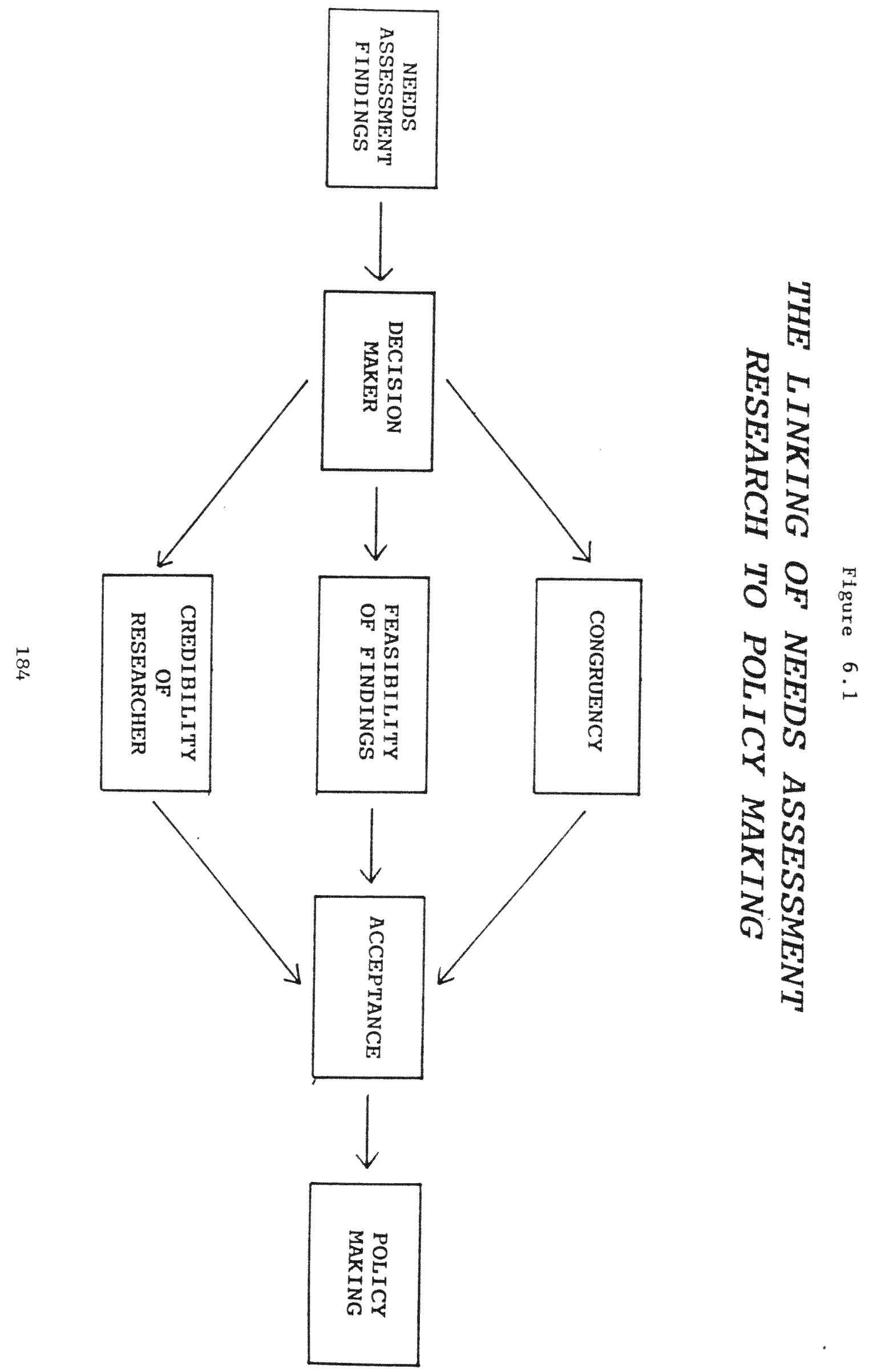




\section{Congruence of the research findings with}

\section{the decision makers' goals}

Both executive and legislative decision makers surveyed recognize the importance of having parallel goals between the researcher and themselves. Consequently, they indicate that the degree to which the findings correspond, or are congruent with, the decision makers' requirements to meet his or her goal is a major factor in their acceptance of those findings. Thus, the decision makers feel that if the researcher establishes a dialogue with them to collaborate on the goals to be achieved, congruency is most likely to be achieved. The result is that chances of acceptance of the research findings will be enhanced. The stronger their perception of being a stakeholder in the process, the more likely their support of the findings.

Morgan (1984) who wrote about administrative decision making tools, and Lipton (1992) who writes extensively on utilization of evaluation research by decision makers, agree. Lipton suggests that the earlier the dialogue is established, the better the chances for utilization of the research.

Nagel (1991) takes congruency even further by extending it to societal and group goals, as well as to the decision makers' goals. He contends that policy is oriented toward societal goals and that if a conflict should exist between 
these societal and the researcher's goals, and the research is guided toward societal goals, then the policy is unlikely to be implemented. However, he says that, if there is congruency between the interest groups, or political parties, and the decision maker's goals, the findings are more inclined to be accepted, or at least more likely to influence policy making.

If the needs assessment produces supporting evidence for the policy maker's pre-existing policy preferences, says Hobbs (1987), the influences toward acceptance increases. As he puts it, an effective needs assessment should produce evidence that takes on a forensic quality. If the data produced are to contribute to accomplishing the intended goal, they must be perceived by policy makers as a well-organized research that intends to prove a case.

A researcher who presents a well organized report tends to reduce the skepticism that decision makers hold regarding whether the analytical information has the propensity to effectively address the problem. This skepticism, according to Averch (1987), makes it difficult for decision makers to sort out the general good or reasonable research findings from the larger spectrum of bad ones that they encounter. If the researcher can convince the decision maker that the needs assessment findings are relevant to the problem to be solved, 
acceptance is more likely. This theme was echoed by executive and legislative decision makers throughout the survey.

Feasibility of the findings

Both executive and legislative decision makers expressed strongly that the feasibility of the needs assessment findings is especially important for their acceptance of the findings. One of the issues that is considered in analyzing the feasibility of findings is the cost involved in achieving results. This is especially true for the executive decision makers. They project the view that findings which seem to be cost-effective, are more likely to influence acceptance than those that seem less efficient. This view corresponds with that of Nagel (1991), who states that policy makers like to save money, even though they may differ on what to do with the money saved.

Differences in values, beliefs, and perceptions between researchers and decision makers are obstacles to the acceptance of research (Frenk, 1992). Decision makers acknowledge that there are value cleavages between themselves and the researcher. They are respectful of researchers' values and beliefs; however, their opinion is that researchers should operate more within the value frame of the decision makers. Decision makers, they claim, are accountable for fulfilling goals and objectives.

Acceptance is threatened also, by differences in perception of the relevance of the research, and of expectations of the final 
results. Kaufman (1991) notes that decision makers relate perceptions to knowledge and they substitute missing information with guesses, knowingly or unknowingly.

Possibly the over-encompassing element that determines the acceptance of needs assessment findings for the delivery of social services is the politics within the environment of public organizations. The issue of politics is nothing new. Aristotle once remarked that politics "is not only an architectonic science but antedates and transcends al1 other sciences" (Odegard, 1973, p. 3). In the public policy arena, politics permeates decision making to the extent that the environment within which public decisions are made is commonly referred to as a political system.

Complex, dynamic, and often confusing, this system forms a difficult environment within which decision makers must operate. Caputo (1974) explains in his model of the political system that policy decisions are enacted by the political system as a result of the interplay of needs, demands, and loyalties with the people, institutions, and other elements which impact on the system.

In discussing the political nature of decision making in the context of evaluation, Patton (1986) explains several factors that render social research inherently political. These factors include the values, perspectives, and politics of those persons involved; the use of categories and classification systems which 
directly affect the nature of data collected; the empirical data used to present probabilities and patterns, and the value-laden interpretation of the data. Included in the factors, also, are the decisions and actions as a result of multiple factors and influences; the involvement of decision making organizations that must strike a balance between rational and political forces; and the powerful role that information plays in the decision making process.

The general consensus of the decision makers surveyed is that decisions are very often pre-determined by the constellation of interests that surrounds a policy issue. Those interests are made up of the stakeholders in the policy who include individuals. groups, or organizations that are affected by the policy issue.

One of the most compelling political factor that affects the acceptance of research is whether the results are convenient and favorable to the officials' view. This point was lamented by Lipton (1992), who comments that the political reality of public organizations determines what is right and proper in the utilization of research information. Executive and legislative decision makers agree that the wider the differences on issues of feasibility, the less likely is the acceptance of needs assessment findings. 


\section{Credibility of the researcher}

It is generally agreed among the respondents to the survey that needs assessments are complex. Therefore, they expressed, the more credible the researcher, the more comfortable the decision maker feels about the findings and methodology, and the better the chances of acceptance. Researchers are concerned about the researcher's reputation, skills, and technical competency in the design used to assess the needs or problems. Instrument design, effective data collection procedures, an adequate sample design, and meaningful data analysis, are preconditions for a high rate of acceptance of the findings.

Executive and legislative decision makers do not place the same level of importance on the credibility of the researcher. Executive decision makers are more inclined to look at the researcher's competence in carrying out the research than do legislative decision makers. The rationale for this difference may lie in the indirect manner that information is channeled to legislative decision makers. As the information is passed on to the legislators through their professional staffs or other sources, a filtering and condensing process occurs. This results in a distance between the researcher and the legislative decision maker. Conversely, executive decision makers are generally in closer proximity to the researcher as they interact with each other, often, throughout the research process. 
Further, executive decision makers usually are the implementors of the research results and are responsible for the programs' outcome. It seems logical, then that they would be more vigilant in monitoring the credibility of researchers from whom they get direction for program changes.

The three factors enumerated above and illustrated in the acceptance model constitute the frame of reference by which decision makers accept needs assessment findings and methodologies. Competence of the researcher is less important for accepting findings when those findings are congruent with decision makers' prior knowledge than if the findings are unexpected or even counter-intuitive. Congruency, together with feasibility of the findings, constitutes an acceptance test for the needs assessment findings.

In summary, this chapter analyzed the linking of needs assessment to decision making. This analysis was accomplished through a survey of 43 decision makers in the public sector of the U. S. Virgin Islands. The decision makers were receptive to being interviewed.

The analysis reveals that none of the observed personal characteristics of the decisionmakers (e.g., age, sex, race, marital status, education, length of time on job) affects their judgment, although this is very impressionistic. The majority of decision makers are in agreement about the three major factors 
that contribute to acceptance of research; however, executive decision makers indicate a higher level of concern for the researcher's credibility and for feasibility of findings than their legislative counterparts. Decision makers from both branches of government look at congruency of findings as a critical factor in the acceptance of research and utilization of the findings. 


\section{CHAPTER VII}

\section{CONCLUSION}

This chapter concludes with the summary of the study, and implications for public administration and public policy. Also, a future research agenda is suggested.

\section{SUMMARY OF THE STUDY}

This study examined the major factors that influence acceptance by executive and legislative decision makers of needs assessment methodologies and findings. It's first objective was to measure the unmet needs of older persons in the U. S. Virgin Islands, in the areas of transportation, in-home care, and sociorecreation. Its second objective was to determine which of five needs assessment methodologies is more costly, time consuming and valid.

Thirdly, this study intended to determine whether decision makers are influenced more by the findings of needs assessment or by the methodology utilized for the assessment. The final and major objective was to ascertain how the actual findings generated by needs assessment are used by decision makers.

The research question was: how are the linkages between needs assessment research and decision making established? To answer this question and meet the objectives of the study, the 
following five needs assessment methodologies were used:

population survey; (2) key informants survey; (3) community forum; (4) rates-under-treatment (RUT); and (5) social indicators analysis.

A typology of needs assessment highlighting the strengths and weaknesses of each of the methodologies was constructed. The typology can guide planners and decision makers in social services. A five-way comparative analysis examined the differences and similarities among the methodologies for the highest and lowest unmet need of the three variables measured by this study. There was also a comparison of the cost, time, and validity of the different techniques.

Finally, decision makers were surveyed for their opinions about the findings and methodologies of the five needs assessment studies.

In summary, seven major findings emerged:

1. Needs assessment is a purposeful, social research tool that is essential for planning programs for human service delivery. As a mechanism for assisting in the integration of services and identification of possible problem areas, especially at critical times, needs assessment serves as a guide to 
program design, development, implementation, and evaluation.

2. Decision makers, regardless of their backgrounds and positions, prefer population surveys because these surveys are the most credible and legitimate of the needs assessment methodologies, although they are also the most expensive and time consuming. The population survey, according to decision makers, serves as a check on what residents in a defined population want. Decision makers believe that a cohesive overview of the needs of the population could be formulated by going to the source of the problem area for input. The credibility of the survey data comes from the confidence placed in the survey that it reflects the views of the target population. It is also important that both elected and appointed decision makers share this view. This suggests a more generic finding as it applies to decision makers of all types. This merits further empirical testing. 
3. Different needs assessment techniques produce different results; therefore, it's more reasonable to use a multiple methods approach. Although this approach to assessing needs cannot be viewed as a panacea, it is looked at as a practical means of grasping what is worth knowing from a broad perspective. This approach is instrumental in creating a comprehensive understanding of the achievements of existing policies and of the types of policy changes are needed. Multiple methods cross validate findings and lend further credence to the study. Decision makers are, thus, more likely to use results that have been cross validated. This also merits further empirical testing.

4. Decision makers in the executive branch of government are influenced more by management factors than by legal and political factors as they make policy decisions. On the other hand, decision makers on the legislative side of government are influenced more by legal 
factors than by political and management factors. This finding is explained by the differences in the management cultures of the executive and legislative decision makers. The professional management values of the executive decision maker are oriented toward the abstract and non-partisan analysis of issues, whereas the culture of legislative decision makers is oriented toward meeting constituency's demands, especially through the enactment of laws, and through making partisan choices.

5. Decision makers overwhelmingly view themselves as predominantly democratic in their management style. However, in practice, when behavior is is examined, many decision makers are not democratic. Thus, decision makers perceive themselves as democratic but they may actually be autocratic. This deserves more empirical testing as well.

6. Needs assessment findings and their methodology influence decision makers almost equally. This 
suggests a more generic view of the utility of needs assessment which is a new finding in the 1iterature. More testing of this hypothesis is merited.

7. Acceptance of findings and methodology of needs
assessment is a critical factor for linking
needs assessment findings to policy decision making. Acceptance is influenced by several factors. These factors fall under the umbrella of three major categories:

* Congruency of findings with decision makers' goals

* Feasibility of the findings

* Credibility of the researcher

A model of acceptance illustrates the relationship between these factors and acceptance of the research findings and methodology. Future research will have to evaluate the relative importance of each of these factors.

The concepts presented in this study are central to decision making activities, specifically, in the context of public administration. These concepts are primarily concerned with the execution of needs assessment studies and the linking of their results to elite decision making. The study began with the 
premise that linking needs assessment research to public decision making is critical to the development of better public policy. That premise is based on the assumption that needs assessment is a helpful tool for generating usable data to make decisions.

Several critical implications for public administration and public policy research are discussed below.

IMPLICATIONS FOR PUBLIC ADMINISTRATION AND POLICY RESEARCH

* Given the importance of providing social services to the segments of the community in need of those services, researchers should identify those needs through the use of multiple needs assessment approaches that cross validate findings. This approach allows for the most comprehensive, balanced, and valuable identification of unmet needs.

* Good technique and findings are not enough! They are a necessary, but not sufficient for convertting research into action. Given the differences between the perspectives held by decision makers and researchers, decision makers should become involved with the research and the needs assessment process from the outset, and "buy in" early, 
in order to facilitate clarification of goals and implementation of the needs assessment findings.

* Given the dynamic, fluid, political environment of the public sector decision making arena, decision makers must be able to strike a balance between the scientific research, and the value system within which they perform. They must not lose sight of one of the major objectives of public decision making -- to improve the quality of the lives of human beings. Linking needs assessment research to decision making is one mechanism by which value commitments and partisan interests can be tempered. Needs assessment and its use thus allow a more rationale debate about choices without having to make your case on values alone.

This study suggests the need for further empirical testing of a number of hypotheses but central to further research in this area is the identification of a generic model of how needs assessment information is used by decision makers and the relative importance of congruence, feasibility, and credibility. 


\section{BIBLIOGRAPHY}

Agar, M.(1980). The professional stranger. New York: Academic Press.

Aging America - Trends and projections.(1991). U. S. Senate Special Committee on Aging. The American Association of Retired Persons, the Federal Council on the Aging, and the U. S. Administration on Aging.

A11, A. C.(1994). A literature review: Assessment and intervention in elder abuse. Journal of Gerontological Nursing, 20(7),25-31.

Allen, V. R. \& Miller, M. D. Miller.(1986). A model for assessing health needs of the rural elderly: Methodology and results. Journal of Allied Health, 15(3), 213-225.

Amand, S. \& Harris, C. J.(1994). Choosing a welfare indicator. The American Economic Review, 84(2),226-230.

Anderson, C. L., Jesswein, W. A., and Fleischman, W. (1990). Needs assessment based on household and key informant surveys. Evaluation Review, 14(2),182-191.

Anderson, R.(1968). A behavorial model of families' use of health services, Center for Health Administration Studies Research Series No. 25. Chicago: University of Chicago.

Angle, M.(1993). C Q Roundtable. Congressional Quarterly Weekly Report, p. 1326.

Associated Press. (1993, May 4). Seniors press for long-term care.

Averch, H. A.(1987). Applied social science, policy science, and the federal government. Knowledge: Creation, Diffusion, Utilization, 8(3),521-544.

Bachrach, K. M., and Zautra, A. (1980). Some uses of client and census records in community mental health planning. American Journal of Community Psychology, $8(3), 365-379$. 
Backer, T. E.(1991). Knowledge utilization - The third wave. Knowledge: Creation, Diffusion, Utilization, 12(3), 225-240.

Balacki, M. F. (1988). Assessing mental health needs in the rural community: A critique of assessment approaches. Issues in Mental Health Nursing. $9(3), 299-315$.

Barker, R. G., and Barker, L. S.(1961). The psychological ecology of old people in Midwest, Kansas and Torkdale, Yorkshire. Journal of Gerontology, 16(2), 144-149.

Bauer, R.(Ed.).(1966). Social indicators. Cambridge, Mass.: M.I.T. Press.

Baumheier, E., \& Hellar, G. A.(1974). Analysis and synthesis of needs assessment research in the field of human services, Denver, Colorado: Center for Social Research and Development, Denver Research Istitute, University of Denver.

Beaux, E. \& Callaghan, J. W. (1984). Estimating statewide health-risk behavior - A comparison of telephone and key informant survey approaches. Evaluation Review, 8(4),467-491.

Bell, R. A., Sundel, M., Aponte, J. F., Murrell, S. A., and Lin, E. (1983). Assessing health and human services needs - Concepts, methods and applications, Bernard Bloom (Ed.). Vol. III Community Psychology Series. New York: Human Services Press, Inc.

Bell, R. A., Warheit, G. J., \& Schwab, J. J. (1977). Needs assessment: A strategy for structuring change. In Coursey, R. D. (Ed.). Program evaluation for mental health: methods, strategies, participants. New York: Grude \& Stratton, Inc.

Benjamin, A. E.(1993). An historical perspective on home care policy. The Milbank Quarterly, 71(1),129-164.

Benton, B., Field, T., \& Millar, R.(1978). Social services federal legislation versus state implementation, Washington, D.C.:The Urban Institute, $990,34,34$. 
Berkman, M. B.(1993). Former state legislators in the U. S. House of Representatives: Institutional and policy mastery. Legislative Studies ouarterly. $18(1), 77-104$.

Binstock, R. H. \& George, L. K. (Eds.).(1990). Handbook of aging and the social services, San Diego, California.: Academic Press, Inc.

Booth, T.(1992). Social indicators and the Mondale initiative. Knowledge: Creation, Diffusion, Utilization, $13(4), 371-398$.

Bowers \& Associates. (1976). A guide to needs assessment in community education programs, Reston, VA.

Bowling, A., Farquahar, M. , Grundy, E., Formby, J. (1993). Changes in life satisfaction over a two and a half year period among very old elderly people in London. Social science and medicine, 36(5), 641-655.

Bradshaw, J.(1977). The concept of social need. In Gilbert, N. and Specht, H. (Eds.). Planning for social welfare: Issues, models and tasks, Englewood Cliffs, N.J.: Prentice Hall.

Branch, L. G.(1977). Understanding the health and social services needs of people over age 65, Center for Survey Research, A facility of the University of Massachusetts, and The Joint. Center for Urban Studies of M.I.T. and Harvard University.

Brewer, J.. \& Hunter, A. (1989). Multimethod research: A synthesis of styles, Newbury Park, CA.: SAGE Publications, Inc.

Bryson, J. M.(1989). Strategic planning for public and nonprofit organizations - A guide to strengthening and sustaining organizational achievement, San Francisco, California: Jossey-Bass Inc.

Butler, L. M. \& Butler, R. O.(1987). Needs assessment in international development - The context. In Johnson, D. E.; Meiller, L. R., Miller, L. C.; \& Summers, G. F. (Eds.). Needs ssessment - Theory and methods. Ames, Iowa: Iowa State University Press. 
Cabrera, C. (1993, June 1). Bilingualism an asset in this country. The Tampa Tribune, p.6.

Cagle, L. T.(1984). Using social indicators to assess mental health needs - Lessons from a statewide study. Evaluation Review, 8(3), 389-412.

Caleca, L. G. (1994, May 1). Too old to drive? The Indianapolis Star.

Campbel1, D. T. (1955). The informant in quantitative research. The American Journal of Sociology, $60(4), 339-343$.

Caputo, D. A.(1974). Politics and public policy in America: an introduction. U.S.A.: J. B.Lippincott Co.

Carroll, J.S. \& Johnson, E. J.(1990). Decision Research: A Field Guide, Newbury Park, CA.: Sage Publications.

Carsjo, K., Thorslund, M., \& Warneryd, B.(1994). The validity of survey data on utilization of health \& social services among the very old. Journal of Gerontology, 49(3) 5156-5164.

Center for Social Research \& Development.(1974). Analysis and synthesis of needs assessment research in the field of human services, Denver, Colorado: Denver Research Institute, University of Denver.

Chapin, R. K.(1984). Needs assessment of the elderly: Focus on utilization, A thesis for Doctor of Philosophy, University of Minnesota.

Chappe11, N. L.(1990). Aging and social care. In Binstock, Handbook of aging and the social services, San Diego, California.: Academic Press, Inc.

Chau, K. L. (1992) Needs assessment for group work with people of color: A conceptual formulation. Social work with groups, 15(2-3), 53-66.

Chelimsky, E. (1994). On the social science contribution to governmental decision-making. Science, 254 (October 11), 226-231. 
Ciarlo, J. A., Tweed, D. L., Shern, D. L., Kirpatrick, L. A., \& Sachs-Ericsson, N.(1992). Utilization of indirect methods to estimate need for mental health services. Evaluation and Program Planning, $15(1) 115-131$.

Cohen, B. M., and Fairbank, R. E.(1938). Statistical contributions from the mental hygiene study of the Eastern Health District of Baltimore. I. General Account of the 1933 Mental Hygiene Survey of the Eastern Health District. American Journal of Psychiatry, 94:1153-1161.

Cook, T. D., \& Campbe11, D. T. (1979). Ouasi-Experimentation: Design \& Analysis Issues for Field Settings, Chicago, I1.: Rand MCNally College Publishing Co.

Cornwe11, T. L., \& Speltz, N. F.(1991). Management of cultural and recreational services. In Bingham et al., Managing Local Government, Newbury Park, California: Sage Publications, p. 259-279.

Coulton, C. \& Frost, A. K.(1982). Use of social and health services by the elderly. Journal of Health and Social Behavior, 23(4),330-339.

Cox, E. O., \& Parsons, R. J.(1994) Empowerment-Oriented social work practice with the elderly, USA.: Wadsworth, Inc.

Craik, K. H., \& Appleyard, D.(1980). Streets of San Francisco: Brunswick's lens model applied to urban inference and assessment. Journal of Social Issues, $36,72-85$.

Cuzzi, L. F., Holden, G., Grob, G. G., Blazer, C. (1993). Decision making in social work. Social Work in Health Care, 18(2)1-22.

Daft, R. L.(1992). Organizational theory and design, St. Paul, Minnesota: West Publishing Company.

DeVillaer, M.(1990). Client-centered community needs assessment. Evaluation and Program Planning, 13 , 211-219. 
Dillon, W. R., \& Goldstein, M.(1984). Multivariate analysis - Methods and applications, USA: John Wiley \& Sons.

Dixon, C. \& Leah, B.(1984). Survey research in Underdeveloped Countries. Norwich, England: Geo Books.

Dluhy, M. J.(1981). Muddling through or thinking about the problem seriously: How to prepare policy documents. present information to decision makers, and maximize the impact of your advice. In M. J. Dluhy, E. Tropman, \& R. Lindet (Eds.), New strategic perspectives on social policy, (pp. 240-256). New York: Pergamon Press.

Dluhy, M. J.(1988). Improving the linkages between policy and research: The special case of long-term care. In M. J. Dluhy, J. Habib, M. B. Pelaez, \& M. Rothman (Eds.), Approaches to linking policy and research in aging: Israel and Florida: Report of a conference, (pp. 19-33). Miami, Fl.: Southeast Florida Center on Aging, Florida International University; and Jerusalem: JDC-Brookdale Institute of Gerontology and Adult Human Development.

Dluhy, M. J., \& Hunt, P.(1988). The use of needs assessments at the local level. In M. J. Dluhy, J. Habib, M. B. Pelaez, M. B. Rothman (Eds.). Approaches to linking policy and research in aging: Israel and Florida report of a conference, (pp. 91-94). Miami, F1.: Southeast Florida Center on Aging, FIU; \& Jerusalem: JDC-Brookdale Institute of Gerontology \& Adult Human Development.

Dunkle, R. E., \& Kart, C. S.(1990). Multipurpose senior centers. In A. Monk (Ed.), Handbook of gerontological services, (pp. 201-227), New York: Columbia University Press.

Donovan, R., Kurzman, P. A., Rotman, C.(1993). Improving the lives of home care workers: A partnership of social work and labor. Social Work, 38(5)579-585.

Driver, M. J., Brousseau, K. R., \& Hunsaker, P. L. (1990). The dynamic decisionmaker, New York: Harper and Row.

Ebener, P. A., \& Greenwood, P. W. (1993). Substance abuse problems and programs in Newark: A needs assessment for Newark's fighting back initiative, USA: Rand Corp. 
Eldar, R. (1992). The needs of elderly persons in natural disasters: Observations and recommendations.

Disasters, 16(4),355-358.

Erikson, E. H.(1968). Identity, youth \& crisis. New York: W. W. Norton.

Evashwich, C., Rowe, G., Diehr, P., Branch, L. 1984. Factors explaining the use of health care services by the elderly. Health Services Research, 19(3), 357-382.

Farris, R. E. L., and Dunham, H. W. 1939. Mental disorders in urban areas. Chicago: University of Chicago Press.

Fenig, S., Levav, I., Kohn, R., and Yelin, N.(1993). Telephone vs. Face-to-Face Interviewing in a community psychiatric survey. American Journal of Public Health, 83(6),896-898.

Ferraro, K. and Cobb, C.(1987). Participation in multipurpose senior centers. Journal of Applied Gerontology, 6(4),429-447.

Fink, A. and Kosecoff, J.(1985). How to use the key informant survey technique. How to Evaluate Education Programs. p.1-6.

Fiorina, M. P.(1994). Divided government in the American States: A byproduct of legislative professionalism? American Political Science Review, 88(2), 304-316.

Florida Department of Health and Rehabilitative Services. Office of Program Planning, Office of Evaluation. (1978). User's guide to needs assessment technologies. Department of Health \& Rehabilitative Services.

Florio, E. \& Demartini, J. R. (1993). The Use of Information by Policy Makers at the Local Community Level. Knowledge: Creation, Diffusion, Utilization, 15 (1), 106-123.

Fowler, F. J. Jr.(1990), Survey research methods. Newbury Park, California: Sage Publications. 
Freeman, H. E., Kiecolt, K. J., \& Allen, H. M. III.(1982). Community health centers: An initiative of enduring utility. Milbank Memorial Fund Quarterly/Health and Society, 60(2), 245-267.

Frenk, J.(1992). Balancing relevance and excellence: organizational responses to link research with decision making. Social Science Medicine, 35(11), 1397-1404.

Frey, J. H.(1989). Survey research by telephone, Newbury Park, California: Sage Publications

Friedman, M. A., \& Faraq, Z. E.(1991). Gaps in the dissemination/knowledge utilization base. Knowledge: Creation, Diffusion, Utilization, 12(3),266-288.

Gabris, G. T.(1992). Strategic planning in municipal government: A tool for expanding cooperative decision making between elected and appointed officials. Public Productivity \& Management Review, 16(1),77-93.

Genthon, Magdilen R.(1993). Needs Assessment for computer literacy for students and teachers in the public high school in Dominica, Master's Thesis, University of the Virgin Islands.

Gillespie, A. E., \& Sloan, K. S. (1990). Housing options and services for older adults: Choices and challenges, Santa Barbara, CA.; ABC-CLIO, Inc.

Gilmore, G. D., Campbel1, M. D., \& Becker, B. L. (1989). Needs assessment strategies for health education and health promotion. Indianapolis, Indiana: Benchmark Press, Inc.

Goddard, M. K.(1993). The importance of assessing the effectiveness of care: The case of hospices. Journal of Social Policy, 22(1), 1-17.

Goldsmith, H. F., Bell, R. A., Warheit, G.(1992). Indirect needs assessment for mental health services planning. Evaluation and Program Planning, 15(2), 111-113.

Gordon, G. J.(1982). Public administration in America, New York: St. Martin's Press.

Griffin, R. W.(1990). Management, USA: Houghton Mifflin Co. 
Gundry, K. G. and Heberlein, T. A. (1984). Do Public Meetings Represent the Public? Journal of the American Planning Association, 50(2), 175-182.

Harlow, K. S.(1990). Targeting resources to elders: The political dimensions of research definitions - Long term care briefs. Washington, D.C.: Administration on Aging.

Harlow, K. S. (1992). Research and the politics of decision making: Planning services for elders. The Journal of Applied Gerontology, 11(1),22-37.

Harlow, K. S. \& Turner, M. J.(1993). State units and convergence models: Needs assesment revisited. The Gerontologist, 33(2), 190-199.

Hart, J. (1994, May 5). Study: Parents, students like school choice but many towns are choosing not to participate. Boston Globe, p. 35.

Havighurst, R. J., and Albrecht, R.(1953). Older people, New York: Longmans, Green \& Co.

Hedlund, R. D.(1984). Organizational attributes of legislatures: Structure, rules, norms, resources. Legislative Studies Quarterly, 9:51-121.????

Henderson, H.(1994). Paths to sustainable development - The role of social indicators. Futures, 26(2), 125-137.

Hobbs, D.(1987). Strategies for needs assessments. In D. E. Johnson, L. R. Meiller, L. F. Milier, \& G. F. Summers. (Eds.) Needs Assessment - Theory and methods, Ames, Iowa: Iowa State University Press.

Hollingshead, A. B., \& Redlich, F. C.(1958). Social class and mental illness: A community study. New York: John Wiley \& Sons.

Holmstrom, D. (1993). New breed of lawmakers trained to run country, state, and local politicians are younger less genteel, more issue-oriented. Christian Science Monitor, Boston, (November 15), 4 . 
Horn, R. V.(1980). Social indicators: Meaning, methods, and applications. Technology and Society. $7(8), 419-460$.

Huebner, R. B.(1986). A Reappraisal of the Key Informant Technique in Community Mental Health Needs Assessment, A Dissertation for Doctor of Philosophy, Claremont, CA.: Claremont Graduate School.

Human Services Institute for Children and Families, Inc., Needs assessment in a Title $X X$ state social services planning system.

Humm-Delgado, D. and Delgado, M.(1986). Gaining community entree to assess service needs of Hispanics. Social Casework, 67(2),80-89.

Hyman, H. H.(1967). Studying expert informants by survey Methods: A cross-validation inquiry. Public Opinion Quarterly, 31,9-12.

Iutcovich, J. M. (1993). Assessing the needs of rural elderly. Evaluation \& Program Planning, 16(2)95-107.

Janis, I. L. (1989). Crucial decisions - Leadership in policymaking and crisis management. New York:

The Free Press.

Janis, I. L. \& Mann,L.(1992). Cognitive complexity in international decision making." In $P$. Suedfeld \& P. E. Tetlock (Eds.) Psychology and Social Policy. New York: Hemisphere Publishing.

Jennings, Joanne Griffin.(1981). Needs assessment \& the planning process: Three needs assessment methodologies demonstrated on the local level. DSW.: Columbia Univ.

Johnson, D. E. and Meilier, L. R.(1987). Community Level Surveys. In D. E. Johnson, L. R. Meiller, L. C. Miller, \& G. F. Summers (Eds.) Needs Assessment Theory and Methods. Ames, Iowa: Iowa state University Press.

Johnson, T. (1986). Critical issues in the definition of older mistreatment. In K. A. Pillemer \& R. S. Wolf (Eds.). Elder abuse: Conflict in the family, Dover, MA. : Auburn House. 
Jun, J. S. \& Storm, W. B.(1990). Social design in public problem solving. Public Administration Quarterly, (Spring) 14(1),19-30.

Kahn, A. J.(1969). Theory and practice of social planning, New York: Russell Sage Foundation.

Kaufman, R. (1987). A needs assessment primer. Training and Development Journal, 41(10)78-83.

Kaufman, S.(1991). Decision making and conflict management processes in local government. In Bingham, et al., Managing local government, Newbury Park, CA. Sage Publications, Inc.

Kast, F. E., \& Rosenzeig, J. E.. (1985). Organization and management: A systems and contingency approach, USA: McGraw-Hi11, Inc.

Keating, C., \& Finholm, V. (1993). The Hartford Courant, (February 19), B1.

Kepner, C. H., \& Tregoe, B. B. (1985). The rational manager. New York: McGraw-Hill.

Kilburg, R.(1987). Consumer survey as needs assessment method: A case study. Evaluation and Program Planning. 1(4), 285-292.

Kimme1, W. A.(1977). Needs assessment: A critical perspective. Washington, D.C.: U.S. DHEW. (December).

Knapp, E. S.(1993). Color us gray. State Government News. (June), 28-29.

Koontz, H., \& Weihrich, H.(1990). Essentials of management, USA: MCGraw-Hill Publishing Co.

Kooperman, L., Cooper, D. R., \& Clare, D. A. (1985).

A systems method for the identification of variable service needs of the elderly. Evaluation and Program Planning, 8(3), 231-237.

Korenbrot, C. C., Simpson, L., \& Phibbs, C. S. (1994). Prenatal care needs assessment comparing service use outcomes in Fresno, CA." Public Health Reports, 109 (1), 68-74. 
Kosberg, J. I.(1988). Preventing elder abuse: Identification of high risk factors prior to placement decisions.

The Gerontologist, 28(1),43-50.

Kosberg, J. I.(1990). Assistance to victims of crime and abuse. In A. Monk (Ed.). Handbook of Gerontological Services, pp. 450-473. New York: Columbia University Press.

Kowalewski, D., \& Peterson, S.(1993-1994). Everyday Lives of the elderly: A dimensional analysis, Sociological Practice, 11,83-97.

Krout, John A.(1989). Senior centers in America, New York: Greenwood Press.

Krout, J. A.(1994). Providing community-based services to rural elderly, USA: Sage Publications, Inc.

Laffrey, S., Meleis, A. I., Lipson, J., Solomon, M. , \& Omidian, P.(1989). Assessing Arab-American health care needs. Social Science and Medicine, 29(7),877-883.

Langner, T. S. and Michael, S. T. (1963). Life stress and mental health: The midtown Manhattan study, New York: The Free Press of Glencoe.

Lareau, L. S.(1983). Needs assessment of the elderly: Conclusions and methodologicalf approaches." The Gerontologist, 23(5),518-526.

Lavrakas, P. J.(1986). Telephone survey methods:" Sampling selection, and supervision, Newbury Park, CA.: Sage Publications.

Leighton, D. C., Harding, J.S., Macklin, D. B., Macmillan, A., \& Leighton, A. H. (1963). The character of danger, New York: Basic Books.

Leiser. J.,(1993). Pilot school programs pace themselves. The Tampa Tribune, (November 29), 1.

Leonard, L.(1993). Few would keep elderly home longer. The Columbus Dispatch, (May 23). 01C.

Lesemann, F. \& Martin, C.(1993). Home-based care, the the elderly, the family, and the welfare state: An international comparison. Canada: Univ. of Ottowa Press. 
Lester, J. F. \& Wilds, L. J. (1990). The utilization of public policy analysis - A conceptual framework. Evaluation and Program Planning, 13(1),313-319.

Leviton, L. C., \& Boruch, R. F.(1983). Contributions of evaluations to educational programs. Evaluation Review, $7(5), 563-599$.

Lipton, D. S.(1992). How to maximize utilization of Evaluation research by policymakers. Annals of the American Academy of Political \& Social Science, 521(May), 175-188.

Little, V. C.(1980). Assessing the needs of the elderly: State of the art. International Journal of Aging and Human Development, $11(1), 65-76$.

Lindblom, C. E.(1959). The science of muddling through. Public Administration Review, 19(Spring),79-88.

Logan, J. R. and Spitze, G. (1994). Informal support and use of formal services by older Americans. Journal of Gerontology, 49(1) S25-534.

Lowy, L. (1985). Social work with the aging - The challenge and promise of the later years, New York: Longman, Inc.

Lowy, L., \& Doolin, J. (1990). Multipurpose senior centers. In A. Monk (Ed.), Handbook of Gerontological Services, pp. 342-376. USA: Columbia University Press.

Lupia, A. \& McCubbins, M. D.(1994). Who controls? Information and the structure of legislative decision making. Legislative Studies Quarterly, 19(3), 361-384.

McClelland, D. C., \& Burnham, D. H. (1995). Power is the great motivator. Harvard Business Review, (Jan.-Feb.), $126-139$.

McKillip, J. (1987). Needs analysis - Tools for the human services and education. USA: Sage Publications.

McMullen, M. (1990). Staying on top in the 90 s. Journal of Public Relations, $46(4), 30-31$.

MacRae, D. Jr.(1985). Policy indicators - Links between social science and public debate, USA: The University of North Carolina Press. 
Maddock, J. M., Daley, D. \& Moss, H.(1988). Needs assessment techniques: A practical approach to needs assessment for chemical dependency programs. Journal of Substance Abuse Treatment, 5, 105-111.

Malzberg, B. (1944). Mental disease among American negroes:

A statistical analysis. In O. Klineberg, (Ed.).

Characteristics of the American Negro, New York: Harper.

March, J. G.(1994). A primer on decisionmaking: How decisions happen, New York: The Free Press.

Maroney, R. M.(1991). Social policy and social work Critical essays on the welfare state, New York: Aldine De Gruyter.

Martin, G. T. Jr. (1990). Social policy in the welfare state, Englewood Cliffs, NJ.: Prentice Hall, Inc.

Martin, L. (1983). The use of telephone surveys in human service needs assessment - An idea whose time has come. Journal of Sociology and Social Welfare. $10(3), 451-461$.

Megginson, L. C., Mosley, D. C., Pietri, P. H. Jr. (1991). Management - Concepts and Applications, USA: Harper Collins Publishers.

Minnesota State Planning Agency.(1977). Needs Assessment: A guide for human services agencies. St. Paul, Minn. Cited in United Way of America (1992).

Moen, E. (1978). The reluctance of elderly to access help. Social Relations, 23(3), 293-303.

Monk, A. \& Cox, C.(1991). Home care for the elderly, New York: Auburn House.

Moore, S.T.(1993). Goal-directed change in service utilization. Social Work, 38(2),221-226.

Morgan, B. S.(1984). Research tools for administrative decision making. In J. Rabin, S. Humes, \& B. S. Morgan, Managing administration, pp. 99-118. USA: Marcel Dekker, Inc. 
Morgan, E. E. Jr, \& Hiltner, J.(1992). Managing aging and human service agencies, New York: Springer Publishing Company.

Muha, L.(1994). Exercise called good for elderly. New York Newsday, August 24, p. A49.

Murrel1, S. A.(1983). Procedures for maximizing usage of need assessment data. In Bell, R. A. Sundel, Aponte, J. F., Murrell, S. A., \& Lin, E. (Eds.). Assessing health and human service needs - Concepts, methods, and applications, pp. 250-264. Vol. VIII, Community Psychology Series, Bloom, B. (Series Ed.), New York: Human Sciences Press, Inc.

Myers, G. C.(1990). Demography of aging. In Binstock, R. H., \& George, L. K. (Eds.). Handbook of aging and the social sciences, San Diego, CA.: Academic Press, Inc.

Nachmias, D., \& Nachmias, C., (1992). Research methods in the social sciences, New York: St. Martin's Press.

Nagel, S.(1991). Public policy - Goals, means, \& Methods, Lenham, MD.:University Press of America, Inc.

Nathan, R. P.(1993). Turning promises into performance The management challenge of Implementing Workfare, New York: Columbia University.

Neal, M. B., Pratt, C., \& Schafer, E.(1993). Aging Oregonians: Trends and Projections. Oregon.

Nelson, C., Roberts, J., Maederer, C. M., Wertheimer, B., Johnson, B.(1987). "The utilization of social science information by policymakers." The American Behavioral Scientist, $30(6), 567-77$.

Neuber, K., Atkins, W. T., Jacobson, J. A., \& Reuterman, N. A. (1980). Needs assessment - A model for community planning, Beverly Hills, CA.: Sage Publications.

Nickens, J. M., Purga, A. J. III, \& Noriega, P. P.(1980). Research methods for needs assessment, Washington, D. C.: University Press of America, Inc. 
Odegard, P. H. (1973). The alienation of political science. In M. P. Smith (Ed.). American politics and public policy, New York: Random House.

Olson, L. K. (1994). Public policy and privatization: Longterm care in the U. S. In L. K. OIson (Ed.). The graying of the world: Who will care for the frail elderly? pp. 25-58. New York: The Haworth Press.

Ormentrout, E. H., Horton, G., \& Latta, C. J.(1976). Techniques for needs assessment in social services planning, Atlanta, GA.: The Research Group, Inc.

Overhultz, G.(1990). How to have an information revolution without chaos. Marketing News, (January 8), 27.

Patton, M. Q. (1986). Utilization-focused evaluation, Beverly Hills, CA.: SAGE Publications.

Polansky, N. A. (1971). Research in social work. In The encyclopedia of social work, New York: National Association of Social Workers, $2,16$.

Quade, E. S.(1982). Analysis for public decisions, New York: Elsevier North Holland, Inc.

Quam, J. K., \& Whitford, G. S.(1992). Educational needs of nursing home social workers at baccalaureate level. Journal of Gerontological Social Work, 18(3-4), 143-156.

Quinn, J. B., and Mueller, J. A.(1991). Transferring research results to operations. Harvard Business Review, 69 (Jan.-Feb.) 39.

Rabiner, D. J.(1992). The relationship between program participation, use of formal in-home care, and satisfaction with care in an elderly population. The Gerontologist, 32(6),805-812.

Rasheed, S. Y.(1986). Serving the community mental health needs of African-Americans. A Dissertation. The Graduate School of Applied Professional Psychology of Rutgers, New Brunswick, NJ. 
Redford, L. J., \& Severns, A. B. (1994). Home health services in rural America. In J. A. Krout (Ed.), Providing community-based services to the rural elderly.

pp. 221-142. Thousand Oaks, CA.: SAGE Publications, Inc.

Reed, W. L.(1980). Access to services by the elderly: A community research model. Journal of Gerontological Social Work, 3(1),41-53.

Reuters. (1993). Millions of U. S. elderly worry about food. (November 15).

Robins, B. J.(1982). Local response to planning mandates -The prevalence and utilization of needs assessment by human service agencies. Evaluation and Program Planning, $5(3), 199-208$.

Ross, J. W.(1993). Decision making and social work: Another look. Health and Social Work, 18(1),3-6.

Rossi, P. H. \& Freeman, H. E. (1989). Evaluation: A systematic approach, Newbury Park, CA.: Sage Publications, Inc.

Rossi, R. J. \& Gilmartin, K. J.(1980). The handbook of of social indicators: Sources, characteristics and analysis, New York: Garland STPM Press.

Royse, D. \& Drude, K. (1982). Mental health needs assessment: Beward of false promises. Community Mental Health Journal, 18(2),97-107.

Ryan, V. D. (1987) Use of action research. In Johnson, D. E., Meiller, L. R., Miller, L. C., and Summers, G. F. (Eds.). Needs assessment - Theory and methods, Ames, Iowa: Iowa State University Press.

Sallis, J., \& Henggeler, S. W.(1980). Needs assessment: A critical review. Administration in mental health, 7 (3), 200-209.

Sauer, B., \& Biggar, J. C.(1964). Retirement plans: Concepts and attitudes of farm operations in three eastern South Dakota Counties, (USDA Bulletin \#515), Washington, D.C.: U. S. Government Printing Office. 
Schauer, P. M. \& Weaver, P.(1994). Rural elder transportation. in Krout, Providing community-based services to the rural elderly. USA: Sage Publications, Inc.

Schmid, H., Bar-Gal, D., and Y. Hasenfeld, (1991). Executive behavior in community service organizations. Journal of Social Service Research, 15(1/2),23-29.

Schulte, P. J.; Brockway, J. M., \& Murell, S. A. (1978). Kentucky elderly needs assessment survey, Louisville KY: University of Louisville.

Seidler, J.(1974). On using informants: A technique for collecting quantitative data and controlling measurement error in organizational analysis. American Sociological Review, 39(6),816-831.

Shafir, E., Simonson, I., \& Tversky, A. (1993). Reason-based choice. Cognition, 49(1-2),11-36.

Sharratt, J.(1989). The impact of the information explosion on management innovation. Industrial Management \& Data Systems, 3,22-25.

Sheehan, M. W.(1992). Successful administration of senior housing: Working with elderly residents, Newbury Park, CA.: SAGE Publications, Inc.

Shortell, S., Morrison, E., \& Friedman, B.(1990). Managing change in turbulent times. San Francisco: Jossey-Bass Publishers.

Shurman, M.(1994). What to expect in the state new goals, guidelines, \& programs. The Record, New Jersey, November 16 .

Siedler, J.(1974). On using informants: A technique for collecting quantitative data and controlling measurement error in organizational analysis. American Sociological Review, 39(6),816-831.

Siegel, L. M. . Attkisson, C., \& Cohn, A. H. (1977). Mental health needs assessment: Strategies and techniques. In Hargreaves, W. A., Attkisson, C. C., and Sorensen, J. E. (Eds.). Resource materials for community mental program evaluation, (pp. 46-65), Washington, D.C.: National Institute of Mental Health. 
Siegel,L. M. Attkisson, C. C., and Carson, L. G. (1987). Need identification and program planning in the community context. In Cox, F. M., Erlich, J. L. Rothman, J., \& Tropman, J. E. (Eds.), Strategies of community organization, Itasca, I11.: F. E. Peacock Publishers, Inc.

Silverstone, B. (1984). Informal social support systems for the frail elderly. In Institute of Medicine/National Research Council (Ed.). America's Aging: Health in an older society. Washington, D.C.: National Academy Press.

Simon, H.(1976). Administrative behavior, New York: The Free Press.

Snider, E. L. (1982). Social indicators, health policy, and the elderly. Social indicators research. 11,405-419.

Snow, D. L., Gersick, K. E., Leslie, L., Lyons, L.., Lyons, M. Russe11, D. Adkins, E., \& Kozak, A.(1987). A key informant needs assessment of an adult population: application to consultation and prevention programs. Journal of Community Psychology, 15(2), 161-175.

Soderstrom, E. J.(1981) Social impact assessment Experimental methods and approaches. New York: Praeger Publishers.

Sonnichsen, R. C.(1989). Methodology: A bridge or barrier between evaluators and managers? Evaluation and Program Planning, 12(1), 287-290.

Squire, Peveri11.(1992). Legislative professionalization and membership diversity in state legislatures. Legislative Studies Quarterly, 17(1)69-79.

Sterngold, A., Warland, R. H., Herrmann, R. O.(1994). Do surveys overstate public concerns? Public Opinion Quarterly, 58(2), 255-263.

Stewart, R.(1979). The nature of needs assessment in community mental health. Community Mental Health Journal, 15(4)287-295. 
Stoller, E. P. \& Pollow, R. (1994). Factors affecting frequency of health enhancing behaviors by the elderly. Public Health Reports, 109,3.

Sung, K-T.(1992). Identification and prioritization of needs of families by multiple groups: Residents, key informants and agency directors. Social Indicators Research, 26,137-158.

Tanur, J. M. (1994). The trustworthiness of survey research. The Chronicle of Higher Education, XL(38) B1-B2.

Taves, M. J., and Hansen, G. D. (1963). Seventeen hundred elderly citizens. In Rose, A. M. (Ed.), Aging in Minnesota, Minneapolis: University of Minnesota Press.

Taylor, B. J., \& Devine, T.(1993). Assessing needs and planning care in social work, Brookfield, VT: Ashgate Publishing Co.

Taylor, F. A.(1990). The numerate social worker. Journal of Social Work Education, 26(1), 25-35.

Thorson, J. A., \& Powel1, F. C.(1992). Rural and urban elderly construe health differently. The Journal of Psychology, 126(3)251-260.

Truesdale, P. and Lobb, J.(1979). Key informant mailout questionnaire for identifying mental health needs in northcentral Montana. In Landsberg, G., Neigher, W. D., Hammer, R. J., Windle, C., \& Woy, J. R. (Eds.)

Evaluation in practice: A source book of program evaluation studies from mental health care systems in the United States. Rockville, MA.: U. S. Department of Health and Human Services.

United Way of America.(1982). Needs assessment - The state of the Art. Alexandria: Privately Published.

USDHEW Office of Aging.(1964). A rural county cares for its aging (Case Study \# 17). Washington, D.C.: Government Printing office.

Van Fleet, D. D., \& Yuk1, G. A. (1986). A century of leadership research. In D. A. Wren \& J. A. Pearce (Eds.), Papers dedicated to the development of modern management, Academy of Management. 
Verdier, J.(1984). Advising Congressional decision makers: Guidelines for economists. Journal of Policy Analysis and Management, 3(1),421-438.

Vosburgh, M. G.(1990). Needs assessment and strategic planning - A study of the Girls Scouts. Evaluation and Program Planning. 13(1), 165-173.

Vourlekis, B. S., Green, R. R., Gelfand, D. E., Zlotnik, J. L.(1992). Searching for the doable in nursing home social work practice. Social Work in Health Care, $17(3), 45-70$.

Wade, J. L.(1989). Felt needs and anticipatory needs: Reformulation of a basic, community development principle. Journal of Community Development Society, 20(1), 116-123.

Warheit, G. J., Bell, R. A., and Schwab, J. J. (1977). Needs assessment approaches: Concepts and methods, DHEW Publication No. 77-472, Washington, D.C.: U. S. Government Printing office.

Warheit, G. J., Buhl, J. M., and Bell, R. A. (1978). A critique of social indicators analysis and key informants surveys as needs assessment methods. Evaluation and Program Planning, 1(3), 239-247.

Warheit, G. J.., Holzer, C. E. III, \& Robins, L. (1979). Social indicators and mental health planning: An empirical case study. Community Mental Health Journal, $15(2), 94-103$.

Warheit, G. J., Vega, W. A., and Buhl-Auth, J., (1983). Mental health needs assessment approaches: A case for applied epidemiology. Prevention in Human Services $2(4), 9-33$

Watson, D. J., Juster, R. J., and Johnson, G. W. (1991). Institutionalized use of citizen surveys in the budgetary and policy making processes: A small city case study. Public Administration Review, 51(3), 232-239.

Webb, D. B.(1984). A comparison of the needs of the elderly and delivery of services as perceived by directors of and participants in senior centers and 
nutrition sites. (Dissertation for Doctor of Philosophy, North Texas State University.

Weinbach, R. W.(1990). The social workers as manager theory and practice, USA: Addison-Wesley Publishing Co., Inc.

Weiss, C. H.(1983). Ideology, interests, and information. In Callahan, D. \& Bruce. Ethics, the social sciences, and policy analysis., New York: Plenum.

Weiss, C. H.(1987). U.S. Congressional Committee as problematic users of analysis. In M. Bulmer (Ed.). Social Science Research and Government, Cambridge, MA:Cambridge University Press.

Weiss, C. H. \& Bucuvalas, M. J.(1980). Truth tests and utility tests: Decision-makers' frames of references for social science research. American Sociological Review, 45 (Apri1), 302-313.

Wentland, E. J., \& Smith, K. W. (1993). Survey responses: An evaluation of their validity. San Diego, CA:Academic Press, Inc.

Wilderom, C. P. M., Nijkamp, P., \& Vollering, A. M. C., (1992). Services for the elderly in Europe: A crossnational survey. Journal of Aging \& Social Policy. $4(1-2), 149-175$.

Windley, P. G.(1983). Community services in small rural towns: Patterns of use by older residents. The Gerontologist, 23(2), 180-184.

wingens, M.(1990). Toward a general utilization theory. Knowledge: Creation, Diffusion, Utilization, 12(1),27-42.

Wittmer, D.(1992). Ethical sensitivity and managerial decisionmaking: An experiment. Journal of Public Administration Research and Theory, 2(4),443-462.

Wolinsky, F. D., \& Johnson, R. J.(1991). The use of health services by older adults. Journal of Gerontology: Social Sciences, $46(6)$, S345-357.

Wren, D. A.(1994). The evolution of management thought. USA: John Wiley \& Sons, Inc. 
Yetton, P., \& Crawford, M.(1992). Reassessment of articipative decision-making: A case of too much participation. In F. Heller (Ed.), Decision-making and leadership, USA: Cambridge University Press.

Young, F. W. \& Young, R. C.(1961). Key informant reliability in rural Mexican villages. Human Organization, $20(3), 141-148$.

Young, J. J.(1986). How can resources be allocated to the elderly according to the greatest social need? A Dissertation for Doctor of Philosophy at Claremont Graduate School, Claremont.

Zautra, A., Bachrach, K., \& Hess, R.,(1983). Strategies for Needs Assessment in Preventon, New York: The Haworth Press.

Zedlewski, S. R., Barnes, R. O., Burt, M. K., McBride, T. D.. \& Meyer, J. A. (1989). The need of the elderly in the 21 st Century, Washington, D.C., : The Urban Institute.

Zemke, R. \& Kramlinger, T. 1982. Figuring Things out. Reading, MA.: Addison Wesley. 
APPENDIXES 
APPENDIX A

LIST OF KEY INFORMANTS 


\section{KEY INFORMANTS}

No.

Title

Organization

\section{LEGISLATIVE}

1. Chair, Legislative Committee on Government Operations

2. Chair, Legislative Committee on Housing, Parks, \& Recreation

3. Chair, Legislative Committee on Youth \& Human Services

4. Chair, Legislative Committee on Health

Legislature of V. I.

Legislature of V. I.

Legislature of V. I.

Legislature of V. I.

\section{EXECUT IVE}

5. Assistant Commissioner (St

6. Administrator, Division of

C.) Dept. of Human Services Senior Citizens Affairs

7. Asst. Administrator, Homes \& Nutrition

8. Asst. Administrator, SocioRecreation Services

9. Asst. Director, Elderly Social Services

10. Acting Director, Home Health Services

11. Director of Public Transportation Services

12. Director of Operations, Public Transportation Services

13. Director, Senior Citizens Center

14. State Director, Adult Education Art Appreciation Classes for the Elderly

15. Director of Mgm.\& Tenant Services

\section{PRIVATE/NON-PROFIT/COMMUNITY}

16. Executive Director

17. Executive Director

18. Manager

Dial-A-Ride, St. T.
Dial-A-Ride, St. C.
Catholic Social
Services, St. C

(Cont'd) 
Key Informants (Cont'd)

No.

Title

Organization

19. Manager

20. Executive Director

21. Director

22. President

23. Community Coordinator

24. Project Director

25. Director of Nursing
Catholic Social Services, St. T. Chamber of Commerce V.I. Association for Independent Living, St. Thomas

AARP, St. Thomas

AARP, St. Croix Rotary Multi-Purpose Center, St. T. Seaview Nursing and Rehabilitation Center, St. Thomas 
APPENDIX B

AGENCIES CONTACTED FOR

RATES-UNDER-TREATMENT STUDY 


\section{AGENCIES CONTACTED \\ FOR RATES-UNDER-TREATMENT STUDY}

TRANSPORTATION SERVICES

1. DEPARTMENT OF HUMAN SERVICES

Senior Citizens Affairs

Senior Citizens Transportation Services (SCAT)

2. DEPARTMENT OF PUBLIC WORKS

Public Transportation

1. Mannassah Bus Lines (St. Thomas)

2. Abramson Bus Service (St. Croix)

3. NON-PROFIT ORGANIZATIONS

Dial-A-Ride

1. St. Thomas

2. St. Croix

IN-HOME CARE SERVICES

1. DEPARTMENT OF HUMAN SERVICES

Senior Citizens Affairs

1. Homes for the Aged

2. In-Home Services

3. Home Delivered Meals

2. DEPARTMENT OF HEALTH

Home Health Services

SOCIO-RECREATION SERVICES

1. DEPARTMENT OF HUMAN SERVICES

Senior Citizens Affairs

2. NON-PROFIT/PRIVATE ORGANIZATIONS

V. I. Association for Independent Living

Senior Citizens Centers

SEAVIEW Nursing \& Rehabilitation Center

3. HOUSING AUTHORITY

4. DEPARTMENT OF EDUCATION 
APPENDIX C

RATES-UNDER-TREATMENT

DATA COLLECTION FORM 


\section{RATES-UNDER-TREATMENT DATA COLLECTION FORM}

1. Agency name

2. Type of Agency:

1 Public 2 Private 3 Non-Profit 4 Community

3. Type of service provided:

1 Transportation 2 In-Home Care 3 Socio/Recreation

4. Place of residence:

Address

5. Social Security \# or other unique identifier:

6. Sex: 1 Male 2 Female

7. Race: 1 White 2 Black 3 Other

8. Date of birth:

Month Day Year

9. Last year of schooling completed:

10. Most recent occupation of client:

(give title and exact duties)

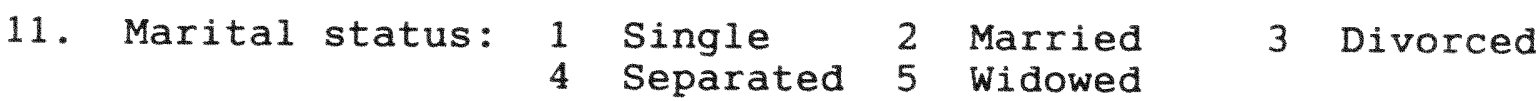

12. Estimated total family income: \$

13. Amount of persons in household

14. Type of dwelling:

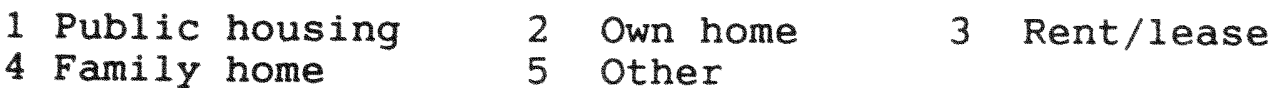

15. Length of residency

16. Length of time receiving service 
APPENDIX D

LIST OF DECISION MAKERS 


\section{DECISION MAKERS}

No.

Title

Organization

\section{LEGISLATIVE}

1. President of the Legislature

2. Chair, Legislative Committee on Finance

3. Chair, Legislative Committee on Youth \& Human Services

4. Chair, Legislative Committee on Government Operations

5. Exec. Dir. of the Legislature

6. Legislative Legal Counsel

7. Legislative Consultant

8. Former Pres. of the Legislature

Legislature of the V. I.

Legislature of the V. I.

Legislature of the V. I.

Legislature of the V. I.

Legislature of the V. I.

Legislature of the V. I.

Legislature of the V. I.

Legislature of the V. I.

\section{EXECUT IVE}

9. Commissioner

10. Asst. Commissioner (St.T.-St.J.)

11. Asst. Commissioner (St. C.)

12. Spec. Asst. to the Commissioner

13. Adm., Senior Citizens Affairs

14. Adm., Voc. \& Rehab. Services

15. Asst. Adm., Homes \& Nutrition

16. Asst. Adm., Socio-Recreation

17. Dir. of Homemaker Services

18. Dir., Senior Community Service Employment Program

19. Territorial Coordinator, Youth Development Programs

20. Adm. Assistant, Multipurpose

Center, St. John

21. Commissioner

22. Commissioner

23. Attorney General of the V. I.

24. Executive Director

25. Manager, Home Ownership Program

26. Administrator

Dept. of Human Services

Dept. of Human Services

Dept. of Human Services

Dept. of Human Services

Dept. of Human Services

Dept. of Human Services

Dept. of Human Services

Dept. of Human Services

Dept. of Human Services

Dept. of Human Services

Dept. of Human Services

Dept. of Human Services

Dept. of Housing, Parks, \& Recreation

Dept. of Licensing \&

Consumer Affairs

Dept. of Justice

V. I. Housing Finance Authority

$V$. I. Housing Finance Authority

Government Employees

Retirement System

(Cont'd) 
Decision Makers (Cont'd)

No. Title

Organization

27. Director

28. Assistant to the Governor

29. Executive Assistant/Attorney

30. Exec. Asst. to the President for Administration

31. Chair, Div. of Bus. Adm.

32. Adm., Home Health Agency

33. Nurse-in-Charge, Home Health Agency

34. State Dir. of Adm. \& Tech.

35. State Dir. of Special Education

36. Assistant Associate Director

37. Dir., Office of Transportation

38. Director of Operations

39. Assistant to the Commissioner

40. General Manager

\section{NON-PROFIT ORGANIZATIONS}

41. Executive Director

42. Executive Director

43. Director
Law Enforcement Planning Commission

Office of the Governor Office of the Governor

University of the V. I. University of the V. I. Department of Health

Department of Health Department of Education Department of Education Office of Mgm. \& Budget Dept. of Public Works Dept. of Public Works Dept. of Public Works V. I. Public TV System

Dial-A-Ride, St. Thomas Dial-A-Ride, St. Croix V. I. Association for Independent Living 
APPENDIX E

POPULATION SURVEY QUESTIONNAIRE 


\section{U.S.V.I. OLDER PERSONS POPULATION NEEDS ASSESSMENT QUESTIONNA IRE}

The questions I'm going to ask you relate to your needs in the areas of transportation, in-home services, and sociorecreation. First, we are interested in how you get around when you leave your home/apartment.

1. Do you have a car?
A. Yes
B. No
z. Don't know/no opinion/no response

2. Could you tell me how many cars or trucks are used separately by you or anyone else living in your home or apartment?
A. None available
D. Three or more
$B$. One
Z. Don't know/no opinion/
no response

Let me read you a list of places that most people go and you tell me how you get there. We are only interested in your principal form of transportaton in each area.

\begin{tabular}{|c|c|c|c|c|c|c|}
\hline $\begin{array}{l}\text { A. } \\
\text { do } \\
\text { not } \\
\text { go }\end{array}$ & $\begin{array}{r}B . \\
\operatorname{tax} i\end{array}$ & $\begin{array}{l}\text { C. } \\
\text { Human } \\
\text { Ser- } \\
\text { vices }\end{array}$ & $\begin{array}{l}\mathrm{D} . \\
\text { bus }\end{array}$ & $\begin{array}{r}E . \\
\text { walk }\end{array}$ & $\begin{array}{l}\text { F. } \\
\text { drive } \\
\text { self }\end{array}$ & $\begin{array}{l}\text { G. } \\
\text { someone } \\
\text { else } \\
\text { drives }\end{array}$ \\
\hline
\end{tabular}

3. Shopping

4. Doctor's office

5. Dentist's office

6. Bank

7. Church

8. Friends'/ relatives' homes 
9. Entertainment

10. Job

11. Senior center

12. Club activities

13. Do you have trouble getting to places you need to go?
A. Yes
B. No (skip to 15)
$Z$. Don't know/no opinion/no response

14. What is the main reason you have trouble getting to these places? (Probe for most important. Code only one answer. (Read list if necessary).
A. Don't drive
B. No car available
C. My physical condition prevents me from driving
D. Public transportation not available
E. Public transportation is too far away
F. Cabs are too expensive
G. Cabs are not available
H. Due to a disability, I cannot use public transportation
$z$. Don't know/no opinion/no response

15. Are you familiar with the Senior Citizens Activities Transportation Program (SCAT) provided by the Department of Human Services?
A. Yes
B. No (skip to 18)
$Z$. Don't know/no opinion/no response

16. Have you used SCAT within the last year?
A. Yes
B. No (skip to 18)
$Z$. Don't know/no opinion/no response

17. How satisfied are you with this transportation? Are you (read responses): 

A. Very satisfied
B. Somewhat satisfied
C. Somewhat dissatisfied
D. Very dissatisfied
Z. $\mathrm{DK} / \mathrm{NO} / \mathrm{NR}$

18. How satisfied are you overall, that your transportation need is being met?
A. Very satisfied
B. Somewhat satisfied
C. Somewhat dissatisfied
D. Very dissatisfied
Z. $\mathrm{DK} / \mathrm{NO} / \mathrm{NR}$

Now, I would like to ask you some questions about your living activities, things that we all need to do as a part of our daily lives.

I would like to know if you can do these activities WITHOUT ANY HELP AT ALL, if you need SOME HELP to do them, or if you CAN'T DO THEM AT ALL. (Humor people who are still healthy. We are trying to determine difficulties for the others).

A. B. C. Z. Without with Completely DK/ $\begin{aligned} & \text { help some unable } \text { NO/ } \\ & \text { help to do NR }\end{aligned}$

19. Drive a car?

20. Get to places out of walking distance?

21. Go shopping for groceries or clothes?

22. Prepare your own meals?

23. Do your own housework?

24. Take your own medicine?

25. Manage your own money or pay bills?

26. Eat without assistance?

27. Dress and undress yourself?

28. Take care of your own appearance? (i.e. combing hair or shaving) 
29. Walk without assistance?

30. Get in and out of bed?

31. Take a bath or shower?

32. Walk up and down stairs?

33. Are you CURRENTLY RECEIVING any kind of help because of a health problem, disability or long term illness?

A. Yes

B. No (skip to 49)

Z. Don't know/no opinion/no response

What KIND OF HELP are you receiving? (Check as many as apply. Read if necessary).

34. Preparation of food

35. Shopping

36. Bathing

37. Help with toilet

38. Light chores

39. Heavy chores

40. Dressing and grooming

41. Nursing care

42. Companionship

WHO is providing the help (Read list if necessary).

A.

Yes
A.

Yes

B.

No
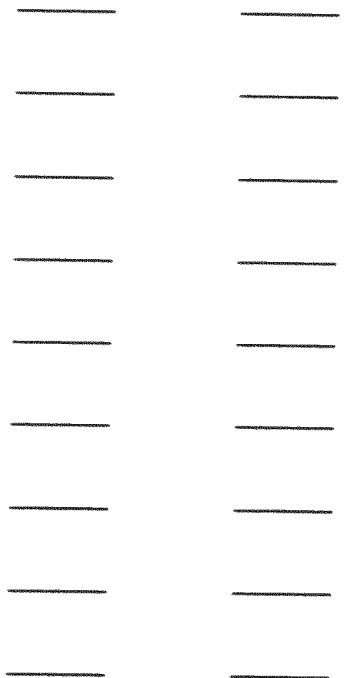
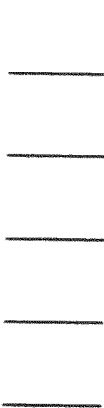

$\mathrm{Z}$.

$\mathrm{DK} / \mathrm{NO} / \mathrm{NR}$ 
45. Friend or neighbor

46. Community agency (i.e. social worker from DHS, visiting nurse, etc.)

47. Private source (pay)

48. Volunteer

49. If you were to become sick but stay at home, who would be the most likely person to help you during your illness? (Read list, but only one answer).
A. One of my children
B. My spouse
F. Private source (pay)
C. A relative
D. A friend or neighbor
E. Community agency
G. Volunteer
H. No one
Z. $\mathrm{DK} / \mathrm{NO} / \mathrm{NR}$

50. Are you familiar with the Homemaker Services Program provided by the Department of Human Services?
A. Yes
B. No (skip to 53)
$Z$. Don't know/no opinion/no response

51. Have you used Homemaker Services within the last year?
A. Yes
B. No (skip to 53)
Z. Don't know/no opinion/no response

52. How satisfied are you with these services?
A. Very satisfied
B. Somewhat satisfied
C. Somewhat dissatisfied
D. Very dissatisfied
Z. DN/NO/NR

53. How satisfied are you overall, that your need for in-home services is being met?
A. Very satisfied
B. Somewhat satisfied
C. Somewhat dissatisfied
D. Very dissatisfied
Z. DN/NO/NR

Now, I want to ask you a few questions about HOW YOU SPEND 
54. About how often do you visit with any of your neighbors, either in their homes or in your own? Would you say?
A. At least once a week
B. At least once a month
C. Less than once a month
D. Never
Z. DK/NO/NR

55. How often do you get together with FRIENDS AND RELATIVES -- I mean, things like going out together or visiting in each other's homes? Would you say:
A. At least once a week
B. At least once a month
C. Less than once a month
D. Never
Z. DK/NR/NO

56. How often do you ATTEND CHURCH OR RELIGIOUS SERVICES? Would you say:
A. At least once a week
B. At least once a month
C. Less than once a month
D. Never
Z. DK/NR/NO

57. Do you belong to any CLUBS or ORGANIZATIONS such as church groups, senior citizens' groups, fraternal groups, or the like?
A. Yes
B. No
Z. $D K / N O / N R$

58. In a typical week, how many times do you TALK ON THE TELEPHONE WITH FAMILY MEMBERS, FRIENDS, OR NEIGHBORS? Would you say:
A. At least once a day
D. Never
$B$. At least once a week
C. Less than once a week
Z. $\mathrm{DK} / \mathrm{NO} / \mathrm{NR}$

59. How often do you get out of your house (home or apartment)? (Pause) Would you say:
A. Every day
B. Twice or 3 times a week
C. Once a week
D. Almost never (less than once a week)
E. Never (if homebound)
Z. DK/NO/NR

60. Are you familiar with senior citizens centers which provide social and recreational activities for older persons in the community? 

A. Yes
B. No (skip to 63)
Z. Don't know/no opinion/no response

61. Have you participated in activities in any of these centers within the last year?
A. Yes
B. No (skip to 63)
$z$. Don't know/no opinion/no response

62. How satisfied are you with activities provided at these centers?
A. Very satisfied
B. Somewhat satisfied
C. Somewhat dissatisfied
D. Very dissatisfied
Z. $D K / N O / N R$

63. How satisfied are you, overall, that your need for recreation activities is being met?
A. Very satisfied
B. Somewhat satisfied
C. Somewhat dissatisfied
D. Very dissatisfied
Z. DK/NO/NR

Now that I've asked you questions about TRANSPORTATION SERVICES, IN-HOME CARE, AND SOCIO-RECREATIONAL SERVICES, how would you rank them as YOUR UNMET needs? (Rank the one considered the HIGHEST UNMET NEED as 1 , and the LOWEST UNMET NEED as 3.

64. Transportation

65. In-home care

66. Socio-recretion services

Just a few more questions and we are done!

67. How many years have you lived in the U.S. Virgin Islands?
A. Less than a year
B. 1 - 5 years
C. 6 - 10 years
D. 11 - 20 years
E. 21 - 30 years
F. Over 30 years
Z. DK/NO/NR

68. How long have you lived at your present address?
A. Less than a year
B. 1 - 5 years
E. 21 - 30 years
$F$. Over 30 years 

C. $6-10$ years
D. 11 - 20 years
Z. DK/NO/NR

69. Are you married, separated, divorced, widowed, or have you never been married?
A. Married (including living with someone as a couple)
B. Separated
C. Divorced
D. Widowed
E. Never married
Z. $\mathrm{DK} / \mathrm{NO} / \mathrm{NR}$

70. Do you have any living children?

(Interviewer: include adopted and stepchildren)
A. Yes
B. No
Z. Don't know/no opinion/no response

71. Would you mind telling me approximately when you were born?
A. Between 1929 and $1933(60-64)$
B. Between 1924 and $1928(65-69)$
C. Between 1919 and $1923(70-74)$
D. Between 1914 and $1918(75-79)$
E. Between 1909 and $1913(80-84)$
F. Between 1904 and 1908 (85-89)
G. Before 1904 ( 90 plus)
$z$. Don't know/no opinion/no response

72. And, what is your race or cultural background? (Begin reading)
A. Black, non-Hispanic
E. Native American
B. White, non-Hispanic
F. Jewish
C. Oriental
D. Hispanic
G. Other
Z. DK/NO/NR

73. Sex of respondent (ask only if it is not obvious)
A. Male
B. Female

74. In which of the following range does your annual HOUSEHOLD income fall (yours and husband or wife income)?
A. $\$ 20,000$ or more
B. $\$ 10,000-\$ 20,000$
C. $\$ 5,000-\$ 10,000$
D. Under $\$ 5,000$
Z. DK/NO/NR 
WHERE DOES YOUR INCOME (money) come from (yours and husband or wife). (Interviewer: Circle ALL applicable respónses).

75. Earnings from employment (wages, salaries or from business)

76. Social Security (including Social Security Disability)

77. Veterans Administration benefits such as G.I. Bil1 \& Disability

78. Disability payments not covered by Social security or Veterans Administration

79. Retirement pension from job

80. Regular assistance from employed children

81. Welfare payments

82. Other

WHO ELSE lives in your home with you? (Check all that apply).

A. B. Z.

Yes No DK/NO/NR

83. Live alone

84. Live with spouse

85. Live with children

86. Live with parents

87. Live with brothers \& sisters

88. Live with grandchildren, great-grandchildren

89. Live with other relatives

90. Live with friends

91. Live with other adults 
92. What is the total number of people in your household?
A. One
B. Two
E. Five
C. Three
F. Six or more
D. Four
$\mathrm{Z}$. $\mathrm{DK} / \mathrm{NO} / \mathrm{NR}$

93. The final two questions now. As an individual, what do you think is the MOST SERIOUS PROBLEM facing you at this time?

94. If the community were to offer more social services for people 60 years of age and older, which one would you recommend? JUST GIVE ME YOUR TOP CHOICE!

THANK YOU VERY, VERY MUCH. 


\section{APPENDIX F}

KEY INFORMANTS QUESTIONNAIRE 


\section{KEY INFORMANTS INTERVIEW \\ QUESTIONNA IRE}

1. Date

2. Name of informant

3. Sex: Male (1)

4. Age: Under 25 years (1) $25-34$ years $(2)$ $35-44$ years $(3)$ Female (2)

$25-34$ years (2)
$-35-44$ years (3)

Female $(2)$
$45-54$ years $(4)$
$45-64$ years $(5)$
5 Over 64 years $(6)$

5. Race: White (1) Black (2) other (3)

6. Marital status:

Single (1) Married (2)
Separated (4) Widowed (5)
Divorced

7. Educational background:

High shool graduate (1)
Attended college (2)
College graduate ( 3 )
Attended graduate school (4)
Graduate degree (specify)

8. What district does your organization represent?

St. Thomas-St. John only (1)

St. Croix only (2)

Both districts (3)

9. What is the name of your organization?

10. What type of organization is it?

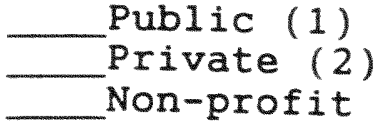
Non-profit
Community (4) Other (specify)

11. If public, which branch of government? Executive (1) Legislative(2) Judiciary 
12. What is your title/position within the organization?

13. How long have you worked for the organization?

Under 1 year (1)
$\quad 1-5$ years (2)
$6-10$ years (3)

$11-15$ years $(4)$

16 years or more (5)

14. In which of the following levels of management in the organization does your position fall?

Upper level (1)

Middle level (2) Lower level

15. Is your organization a provider of services to persons 60 years of age or older (henceforth referred to as "older persons")?

Yes (1)

No (2)

16. If yes, in which specific area(s)?

17. If no, what is your organization's interest in older persons?

This study's focus is on the transportation, in-home care, and socio-recreational needs of older persons in your community. The following set of questions will address those needs. Please indicate your responses by district (St. Thomas/St. John and/or St. Croix).

18a. In your opinion, what are the top three (3) reasons why older persons need transportation?

St. Thomas/St. John

St. Croix

1.

2.

3.

1.

2 .

3. 

18b. Do you believe that their transportation need is being
met?

St. Thomas/St. John: Yes (1) $\mathrm{NO} / \mathrm{NR} / \mathrm{DK}$

St. Croix:

Yes (1) (2) NO/NR/DK

18c. How satisfied, in your opinion, are older people that their transportation need is being met?

St. Thomas/St. John:

Very satisfied (1) Somewhat satisfied (2) Somewhat dissatisfied (3)
Very dissatisfied NO/NR/DK (5)

St. Croix:

Very satisfied (1)

Somewhat satisfied (2) Somewhat dissatisfied (3)
Very dissatisfied (4) NO/NR/DK (5)

19. What would you recommend as an IMMEDIATE remedy for improving transportation for older people?

St. Thomas/St. John:

St. Croix:

20. What would you recommend as a LONG RANGE remedy for improving transportation for older people?

St. Thomas/St. John: 
St. Croix:

21a. In your opinion, what are the top three (3) reasons why older persons need in-home care services?

St. Thomas/St. John

1 .

2 .

3.

St. Croix

21b. Do you believe that their in-home care need is being met?

St. Thomas/St. John: __ Yes (1)

1.

2.

3.

St. Croix:

Yes (1)

No (2) NO/NR/DK (3)

Yes (1)

No (2)

$\mathrm{NO} / \mathrm{NR} / \mathrm{DK}$

21c. How satisfied, in your opinion, are older people that their in-home care need is being met?

St. Thomas/St. John:

Very satisfied (1)

Somewhat satisfied (2)

Somewhat dissatisfied (3)
Very dissatisfied (4) NO/NR/DK (5)

St. Croix:

Very satisfied (1) Somewhat satisfied (2) Somewhat dissatisfied (3)
Very dissatisfied (4) NO/NR/DK (5)

22. What would you recommend as an IMMEDIATE remedy for improving in-home care services for older people?

St. Thomas/St. John:

St. Croix: 
23. What would you recommend as a LONG RANGE remedy for improving in-home care services for older people?

St. Thomas/St. John:

St. Croix:

24a. In your opinion, what are the top three (3) reasons why older persons need socio-recreation activities?

St. Thomas/St. John

St. Croix

1.

2 .

3.

1 .

2 .

3.

24b. Do you believe that their socio-recreation needs are being met?

St. Thomas/St. John

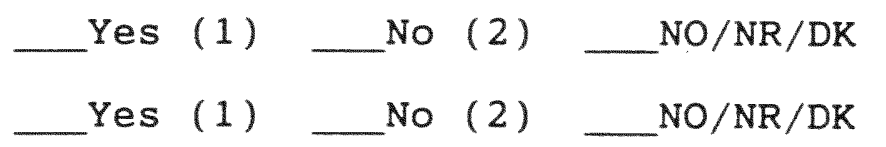

St. Croix

Yes (1)

No (2)

24c. How satisfied, in your opinion, are older people that their socio-recreation needs are being met?

St. Thomas/St. John:

Very satisfied (1)

Somewhat satisfied (2)

Somewhat dissatisfied (3)
Very dissatisfied (4) NO/NR/DK (5)

St. Croix:

Very satisfied (1)

Somewhat satisfied (2) Somewhat dissatisfied (3)
Very dissatisfied NO/NR/DK (5) 
25. What would you recommend as an IMMEDIATE remedy for improving socio-recreation activities for older people?

St. Thomas/St. John:

St. Croix:

26. What would you recommend as a LONG RANGE remedy for improving socio-recreation activities for older people?

St. Thomas/St. John:

St. Croix:

27. Now that I've asked you questions about transportation, in-home care services, and socio-recreation activities, how would you rank them as unmet needs of older persons in the Territory? Rank the one considered the HIGHEST UNMET NEED as 1 , and the LOWEST UNMET NEED as 3.

St. Thomas/St. John:

Transportation

In-home care services

Socio-recreation activities

st. Croix:

Transportation

In-home care services

socio-recreation activities 
THE FINAL TWO QUESTIONS NOW.

28. In your opinion, what is the MOST SERIOUS PROBLEM facing older persons in the Territory at this time?

St. Thomas/St. John:

St. Croix:

29. If the Territory were to offer more social services for older persons, age 60 and over, which ONE would you recommend? Give your TOP choice.

St. Thomas/St. John:

St. Croix: 
APPENDIX G

COMMUNITY FORUM QUESTIONNAIRE 


\section{COMMUNITY FORUM QUESTIONNA IRE}

SEX : Male (1)

Female (2)

AGE :

$\begin{array}{r}\text { Under } 25 \text { years (1) } \\ 25-34 \text { years (2) } \\ 35-44 \text { years (3) } \\ \hline 45-54 \text { years }(4)\end{array}$

55-64 years 65-74 years Over 74 years (7)

RACE:

White (1)

Black (2) Other (3)

HOW EFFECTIVE, DO YOU THINK, IS THE PROVISION OF THE FOLLOWING SERVICES TO THE ELDERLY OF THE COMMUNITY? (ON A SCALE OF 1-5)

NOT AT ALL

EFFECTIVE
VERY

EFFECTIVE

OVERALL SERVICE DELIVERY

1

12

12

12

IN-HOME CARE SERVICES

TRANSPORTATION SERVICES

SOCIO/RECREATIONAL SERVICES

WHAT'S YOUR INTEREST IN ATTENDING THIS MEETING?

1. OVERALL CONCERN FOR SERVICES FOR THE ELDERLY

2. SPECIFIC CONCERN FOR TRANSPORTATION SERVICES

3. SPECIFIC CONCERN FOR IN-HOME CARE SERVICES

4. SPECIFIC CONCERN FOR SOCIO/RECREATIONAL SERVICES

5. OTHER CONCERNS 
HOW WOULD YOU RANK THE FOLLOWING AS UNMET NEEDS OF OLDER PERSONS IN THE TERRITORY? RANK THE ONE CONSIDERED HIGHEST UNMET AS 1; LOWEST UNMET AS 2 . TRANSPORTATION NEED IN-HOME CARE NEED SOCIO-RECREATION NEED

IN YOUR OPINION, WHAT IS THE MOST SERIOUS PROBLEM FACING OLDER PERSONS IN YOUR COMMUNITY AT THIS TIME?

IF THE DEPARTMENT OF HUMAN SERVICES WERE TO OFFER MORE SOCIAL SERVICES FOR PEOPLE 60 YEARS OF AGE AND OLDER, WHICH ONE WOULD YOU RECOMMEND? GIVE YOUR TOP CHOICE.

HOW SATISFIED ARE YOU WITH TONIGHT'S TOWN MEETING? CHOOSE ONE (1) ONLY ON A SCALE OF 1 - 5). 
APPENDIX H

DECISION MARERS QUESTIONNAIRE 


\section{DECISION MAKERS \\ QUEST IONNA IRE}

1. Name

2. Sex:

Male (1)

Female (2)

3. Age:

Under 25 years (1)

$25-34$ years (2)

$45-54$ years $(4)$

$35-44$ years $(3)$ $55-64$ years $(5)$

Over 64 years (6)

4. Race:

White (1)

Black (2)

Other (3)

5. Marital Status:

Single (1) Married (2) Divorced (3)
Separated (4) Widowed (5)

6. Educational background:

High school graduate (1) Attended college (2) College graduate ( 3 ) Attended graduate school (4) Graduate degree (specify)

7. What district does your organization represent?

St. Thomas/St. John only (1)

St. Croix only (2)

Both districts (3)

8. What is the name of your organization?

9a. What type of organization is it?

Public (1) Private (2) Non-Profit (3)
Community (4) Other (specify)

$9 \mathrm{~b}$. If public, which branch of government?

Executive (1)

Legislative (2)

Judiciary 
10. What is your title/position within the organization?

11. How long have you been associated with the organization?

Under 1 year (1)
-5 years (2)
$-6-10$ years (3)

12. In which of the following levels of management in the organization does your position fall?

Upper level(1) Middle level(2) Lower level(3)

13. Which management style best describes your style?

Autocratic (1)

Democratic (2)

NO/NR/DK (4)

Laissez-faire (3)

14. Is the elderly population in the Territory a significant constituency?

Yes (1)

No (2)

NO/NR/DK (3)

15a. Does the elderly constituency effectively lobby for social services, such as TRANSPORTATION, IN-HOME CARE and SOCIO-RECREATION services?

Yes (1) N_N No (3) NO N N N N

15b. If yes, how effective is its lobbying efforts? (Circle one)

Not effective at a11

Extremely

effective

$\begin{array}{lllll}1 & 2 & 3 & 5\end{array}$

15c. If not, how can the lobbying effort become more effective? (Please explain) 
16a. Does the Territory have a legal mandate to provide social services, such as TRANSPORTATION, IN-HOME

CARE, and SOCIO-RECREATION services to the elderly?

Yes (1)

No (2)

$\mathrm{NO} / \mathrm{NR} / \mathrm{DK}$

$16 \mathrm{~b}$. If yes, does this legal mandate adequately meet the demand by the elderly for these services?

Yes (1)

No (2)

NO/NR/DK

16c. If no, should the Territory have a legal mandate to provide these services to the elderly?

Yes (1)

No (2)

NO/NR/DK

17a. Does the Territory have enough programs to meet the elderly's need for social services, such as TRANSPORTATION, IN-HOME CARE, and SOCIO-RECREATION services?

Yes (1)

No (2)

NO/NR/DK (3)

$17 \mathrm{~b}$. If yes, are these programs adequately structured to meet the needs of the elderly in the Territory? Yes (1) No (2) NO/NR/DK (3)

Needs assesments are very often used to determine what type of services an agency should provide. The following questions will address that topic:

18a. Does the use of needs assessments influence the way that you make a policy decision?

Yes (1)

No (2)

NO/NR/DK (3)

18b. If no, why not? (Please explain) 
18c. If yes, what influence do the following methods of needs assessments have on the way that you make a policy decision?

$$
\begin{array}{ccc}
\text { No influence } & \text { Some } & \text { Very } \\
\text { at all } & \text { influence } & \text { influential }
\end{array}
$$

\begin{abstract}
POPULATION SURVEYS
(Surveys done on

the population of study)
\end{abstract}

\title{
PUBLIC FORUMS \\ (Meetings held to \\ get the public's \\ opinion of what \\ the needs are).
}

KEY INFORMANTS
SURVEYS
(Getting the
opinion from
experts in the
community about
the needs in the
area of study).

RATES UNDER

TREATMENT

(Using records of

services being

used to determine

the needs)

SOCIAL INDICATORS

(Using Census data

and other such

information to

determine needs)

18d. Five needs assessments, using the five different methods noted above, were conducted on the elderly population of the Virgin Islands. The attached is a typology of the findings. Which of these findings do you accept as the one most representative of the needs of the Territory's elderly? 
KEY INFORMANT (2)

COMMUNITY FORUM (3)
Treatment) (4) SOCIAL INDICATORS (5)

18e. Why? (Please Explain)

18f. How much influence does the COST of doing a needs assessment have on your decision to perform a needs assessment?

Not at all

Influential

Very

Influential

$\begin{array}{lllll}1 & 2 & 3 & 4 & 5\end{array}$

$18 \mathrm{~g}$. How much influence does the amount of TIME needed to successfully complete a needs assessment have on your decision to perform a needs assessment?

Not at all

Influential

1

3

4

Very

Influential

19a. Is the METHOD of conducting needs assessment a significant factor when you make a policy decision?

Yes (1)

No (2)

NO/NR/DK (3)

19b. If yes, Why? (Please Explain)

19c. If no, why not? (Please explain) 
20a. Are the FINDINGS of needs assessments a significant factor when you make a policy decision?

Yes (1)

No $(2)$

NO/NR/DK

20b. If yes, why? (Please explain)

20c. If no, why not? (Please explain)

21. When making a policy decision, I am more influenced by:

Results than Methodology (1)

Methodology than Results (2)

Both Results and Methodology equally (3)

None (4)

NO/NR/DK (5)

22. Which of the following has the MOST INFLUENCE on the way

that you make a policy decision? (Choose one only)

POLITICAL FACTORS (1)

LEGAL FACTORS (2)

MANAGEMENT FACTORS (3)

(PLEASE EXPLAIN WHY)

23. What other factor(s), if any, influence how you make a policy? (Please explain). 
VITA

January 30, 1939

1968

1984

1987

1995

$1981-1984$

$1984-1988$

1991-1994
Born, St. Thomas

U. S. Virgin Islands

A.A., Business/Liberal Arts Collegiate Institute New York City, New York

B.A., Business Administration University of the Virgin Islands St. Thomas, U. S. Virgin Islands

M.A., Public Administration University of the Virgin Islands St. Thomas, U. S. Virgin Islands

Ph.D. in Public Administration Florida International University Miami, Florida

Executive Director, Commission on Ethics \& Conflict of Interest St. Thomas, U. S. Virgin Islands

Deputy Director, V. I. Housing Finance Authority

St. Thomas, U. S. Virgin Islands

Deputy Commissioner, Program Development \& Evaluation Department of Human Services St. Thomas, U. S. Virgin Islands 